Dieses Dokument ist eine Zweitveröffentlichung (Postprint) /

This is a self-archiving document (accepted version):

Panpan Zhang, Faxing Wang, Sheng Yang, Gang Wang, Minghao Yu, Xinliang Feng

Flexible in-plane micro-supercapacitors: Progresses and challenges in fabrication and applications

Erstveröffentlichung in / First published in:

Energy Storage Materials. 2020, 28, S. 160 - 187. ScienceDirect. ISSN 2405-8297.

DOI: https://doi.org/10.1016/j.ensm.2020.02.029

Diese Version ist verfügbar / This version is available on:

https://nbn-resolving.org/urn:nbn:de:bsz:14-qucosa2-744311 


\title{
Flexible in-plane micro-supercapacitors: progresses and challenges in fabrication and applications
}

Keywords: flexible in-plane micro-supercapacitors, microfabrication technologies, smart responses, self-powered integrated systems

\begin{abstract}
The great popularity of portable, wearable, and implantable smart electronics has intensively boosted the development of flexible miniaturized power supplies. Owing to the fast charge/discharge capability, high power delivery, long cycling lifetime, easy fabrication and integration, flexible in-plane micro-supercapacitors (FPMSCs) are of significance as the micropower sources for the next-generation flexible on-chip electronics. In this review, we provide a comprehensive overview about FPMSCs and discuss the recent advances in their fabrication and applications. Particular emphasis is put on the emergent device fabrication technologies of FPMSCs, including deposition techniques, coating strategies, etching methods, and printing technologies. Moreover, we highlight the unique applications of FPMSCs in constructing smart responses and self-powered integrated systems in terms of multifunctional operation modes. Finally, the remaining challenges regarding flexibility, performance improvement, smart response, and microdevice integration of FPMSCs are discussed, which will stimulate further research in this thriving field.
\end{abstract}




\section{Introduction}

Flexible electronics are attracting extensive attention due to their potential applications in human activity monitoring and personal health management, including implantable medical devices, intelligent electronic skins, foldable displays, and conformal human-machine interfaces [1-5]. One of the main development tendencies in flexible electronics is miniature, convenience, lightweight, integration, and intelligence. Such flexible electronics have boosted the emerging research field of miniaturized flexible energy storage devices, especially those with in-plane architecture [4, 6-11]. The in-plane design can not only improve the space utilization, but also benefit the easy integration with on-chip electronics. To date, according to different charge storage characteristics, the available microscale in-plane energy storage units are divided into micro-batteries (MBs) and micro-supercapacitors (MSCs) [9, 12]. Their total areal size can be in the millimeter or even the centimeter scale with a distance between two adjacent electrodes down to the micrometer scale. Contrary to MBs with low areal power density $\left(<5 \mathrm{~mW} \mathrm{~cm}^{-2}\right)$ and limited lifetime ( $<1000$ cycles) [13-15], MSCs can be fully charged or discharged in seconds, providing ultrahigh areal power density $\left(>10 \mathrm{~mW} \mathrm{~cm}^{-2}\right)$ and long cycle lifetime ( $\geq 10000$ cycles) [16-20]. MSCs can be briefly categorized into three main kinds based on device dimensions, namely fiber-shaped MSCs, in-plane MSCs, and threedimensional (3D) MSCs. Fiber-shaped MSCs are particularly promising power sources for fiber and textile electronics due to their small diameter, lightweight, flexibility, and weavability. They have parallel, twisted, or coaxial structures by employing fiber-shape electrodes, which are not compatible with the planar structure of on-chip electronics. Extending the length and diameter of fiber-shaped MSCs is often accompanied by the performance deterioration due to the increased electrical and ionic transport resistance. In contrast, in-plane MSCs are fabricated with standard microelectromechanical systems, facilitating their integration with other on-chip components for constructing on-chip electronic systems. The planar interdigital electrode 
architecture with small gap between microelectrodes decreases ion diffusion distance, which enables in-plane MSCs with superior rate capability. In addition, 3D MSCs with internal 3D architectures deliver much higher areal performance than in-plane MSCs due to the large areal loading mass of active materials on planar interdigital current collectors. However, complicated fabrication processes are generally required for the microelectrode in 3D MSCs, and the use of thick microelectrodes leads to the sacrifice of flexibility.

As favorable power sources for various flexible on-chip electronics including flexible sensors, artificial electronic skin, and roll-up displays, flexible in-plane MSCs (FPMSCs) have gained increasing attention due to their high output power, ultra-long cycling stability, high flexibility, and great conformability. The mechanical properties of electrodes, electrolytes, substrates, and current collectors play a key role in determining the flexibility of MSCs. To satisfy the requirement of electricity storage for flexible microelectronics, advanced electrode materials as the key component should be developed for high-performance FPMSCs with high energy and power densities. Up to now, a number of active materials ranging from zero-dimensional graphene quantum dots, one-dimensional carbon nanotubes, to two-dimensional graphene and metal carbides and nitrides (MXenes) have been explored for pursuing high electrochemical capacitance $[21,22]$. The structural engineering strategies of electrode materials, such as phase transformation, interlayer intercalation, surface modification, material hybridization, and hierarchical structuration have been developed to maximize their outstanding advantages and break their performance limits [23]. So far, electrode materials with large specific surface area, high electrical conductivity, reversible redox-active site, easy preparation, up-scalability, and low cost are still highly desirable for practical applications. One special merit for FPMSCs is the design of microelectrode fingers with interdigital configuration. It is beneficial for rapid ion transport of the electrolyte with good accessibility to the microelectrodes during the charge storage. The realization of such high-resolution design of microelectrodes relies on the 
advanced microfabrication technologies such as photolithography, deposition, laser etching, and inkjet printing. However, current microfabrication technologies applied in most FPMSCs are not fully compatible with the fabrication technologies of other electronic components. Thus, the device fabrication of FPMSCs should be further optimized for the whole electronic systems.

Aiming at operating flexible microelectronics with self-powered and maintenance-free modes, FPMSCs are usually integrated with energy harvesting units in practical utilizations. The self-powered systems can harvest solar, thermal, or mechanical energy from the environment or human movement, convert those energies into electricity, and subsequently store them in FPMSCs. These self-powered systems allow to deploy over a large area, assess into large networks, and autonomously transmit data in connection with computer systems [2426]. In addition, the rapid development of high-performance smart devices has stimulated the demand for multifunctional integration with combined features of electrochromism, thermal response, stretchability, self-healing, etc [8, 27, 28]. Furthermore, practical applications of flexible microelectronics require the micropower sources to be flexible, bendable, twistable, compressible, washable, biodegradable, biocompatible, etc. The introduction of smart functions into FPMSCs not only saves spaces, but also enhances user experiences for flexible microelectronics. Currently, most of the reported FPMSCs and other electronic devices are operated independently, leading to a low space-utilization efficiency and huge energy consumption due to the external connection systems. Integrating FPMSCs with these electronic devices onto a single flexible substrate can potentially increase the package density and reduce the complexity of the overall device design by avoiding the use of complicated circuits.

Despite significant progresses have been achieved in electrode materials, device fabrication, and integrated systems for FPMSCs $[12,18-21,23,25,29-35]$, a comprehensive review covering all aspects from design principles, material selections, microfabrication techniques, smart responses to self-powered integrated systems has not yet been described so far. In this 
review article, we provide a critical overview on the latest progresses and challenges in the fabrication and applications of FPMSCs, as illustrated in Fig. 1. The first part is dedicated to provide a definition of important device characteristics and performance metrics of FPMSCs. The recent progresses in the fabrication of FPMSCs are further summarized by evaluating the microfabrication techniques and corresponding electrochemical properties. Afterwards, we particularly focus on the latest advances in fabricating smart responsive FPMSCs through the rational design of functional electrodes, electrolytes, and substrates. The applications of FPMSCs toward smart responsive self-powered integrated systems are further discussed. At last, we conclude by highlighting the key technological challenges with respect to the criteria of this field and providing future directions for the development of FPMSCs.

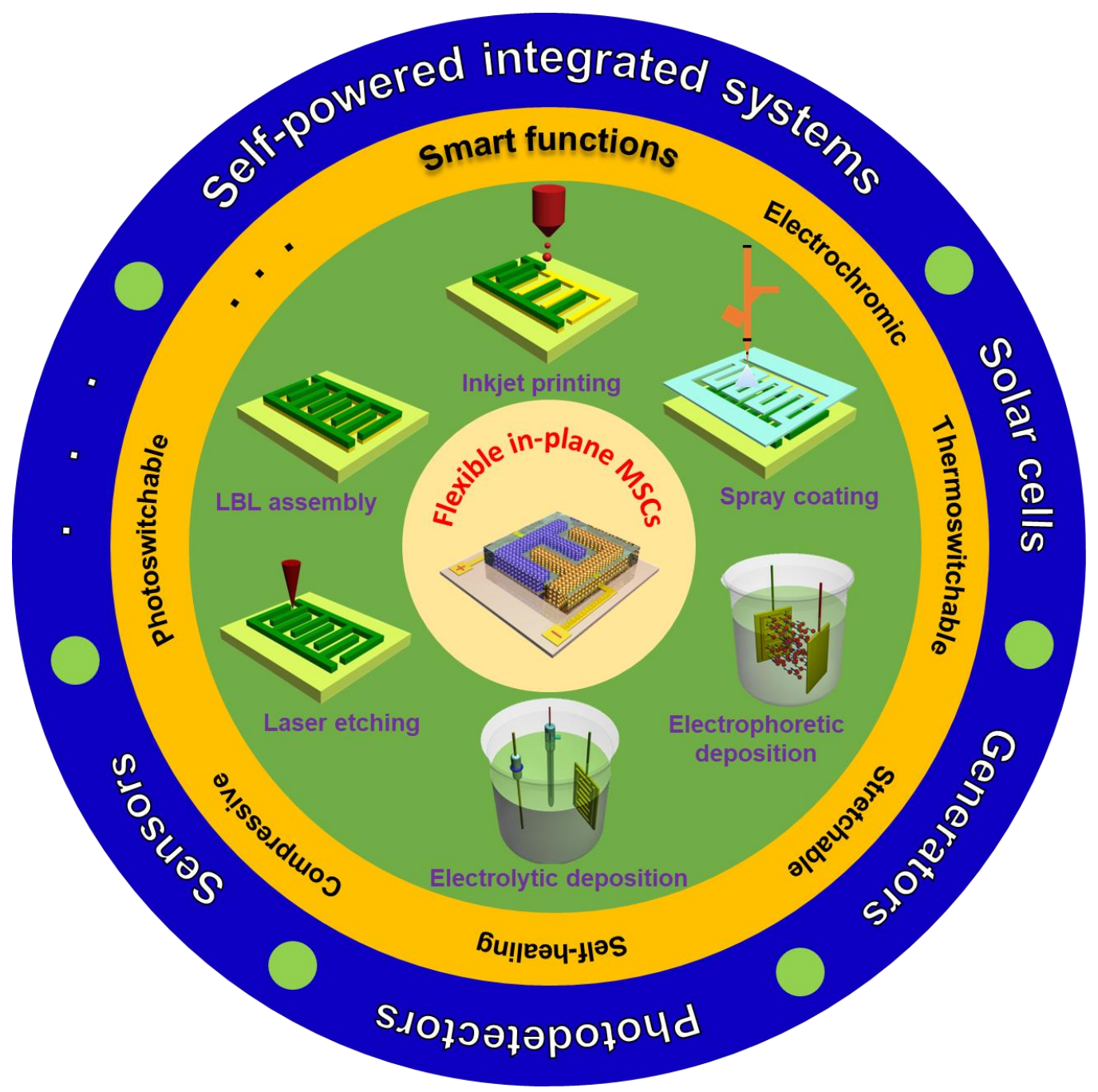


Fig. 1. Schematic of the review content including microfabrication technologies, smart functions, and self-powered integrated devices \& systems.

\section{Design principle and performance evaluation of FPMSCs}

FPMSCs are generally composed of electrode materials, electrolyte, and current collectors on various flexible substrates, which is beneficial to the integration with other planar on-chip electronic components. To search for the suitable electrodes to construct FPMSCs, a threeelectrode electrochemical system is generally used to assess the electrochemical properties (including stable potential range and specific capacitance) of active materials. Typically, a three-electrode cell is composed of a counter electrode, a reference electrode, and a working electrode made of active materials. Ideal active materials are expected to have large specific capacitance, high rate capability, long cycling lifetime, and good chemical/mechanical stabilities. Compared to a three-electrode configuration, a two-electrode cell characterization provides the practical device performance of active materials [36-39].

\subsection{Structural components}

\subsubsection{Electrode materials}

Electrode materials used in conventional supercapacitors (SCs) and FPMSCs are the same. Based on the charge storage mechanisms, they are classified as electric double-layer capacitor (EDLC) type and pseudocapacitive electrode [35, 40-47]. In EDLC-type electrode, electrostatic charges accumulate at the electrode/electrolyte interface through physically ion adsorption to form electric double layers. Therefore, EDLC-type electrodes can achieve rapid charge/discharge rate up to $100 \mathrm{~V} \mathrm{~s}^{-1}$ and run millions of cycles without obvious capacitance decay. Thanks to the advantages of low cost, non-toxic, large-scale production, and high chemical stability, porous carbon materials with high specific surface areas and good electric 
conductivities are the most common EDLC-type electrodes. The high specific surface area is beneficial to store large amounts of charges on the surface of electrode materials, while the good electronic conductivity enables the fast transport of electrons. Up to now, many nanostructured carbon materials, such as activated carbon (AC), carbon nanotube (CNT), onion-like carbon (OLC), carbide-derived carbon (CDC), and graphene, have been used as electrode materials in FPMSCs [48-61].

Despite the high power density and excellent cycling stability, the reported areal capacitances of EDLC-type FPMSCs are still too low. The researchers also pay attention to the pseudocapacitive materials, such as metal oxides, hydroxides, and carbides, as well as conducting polymers [62]. The charge storage of pseudocapacitive electrodes relies on the reversible Faradaic surface reactions, providing high energy density. Currently, numerous appealing candidates with attractive natural abundance have been reported, such as $\mathrm{MnO}_{2}$ [6365], $\mathrm{V}_{2} \mathrm{O}_{5}[66], \mathrm{Fe}_{2} \mathrm{O}_{3}[67,68]$, and $\mathrm{Nb}_{2} \mathrm{O}_{5}[69,70]$. Compared to EDLCs, pseudocapacitors can significantly increase both specific capacitance and energy density, but at the expense of power density and cycle life.

Hybrid concept was also employed to design electrode materials, in which EDLC-type materials function as the conductive backbone for pseudocapacitive materials to boost their electrochemical performance. Attributed to the synergistic effect, the resultant hybrid materials are promising to push the performance of FPMSCs to a higher level in a limited footprint area. In addition, compared with symmetric MSCs using either pure EDLC-type/pseudocapacitive materials or hybrid materials, asymmetric MSCs (AMSCs) show superior overall performance. Specifically, pseudocapacitive materials as one electrode serve as the energy source, whereas EDLC materials as the other electrode store charge on the surface and supply high-level power.

\subsubsection{Electrolytes}


Liquid electrolytes used in FPMSCs are divided into three categories: aqueous, organic, or ionic liquids. The stable operating potential window and ionic conductivity are two key parameters for electrolytes. Acid- (e.g., $\mathrm{H}_{2} \mathrm{SO}_{4}, \mathrm{H}_{3} \mathrm{PO}_{4}$ ), alkali- (e.g., $\left.\mathrm{KOH}, \mathrm{LiOH}\right)$, and neutral-based (e.g., $\left.\mathrm{LiCl}, \mathrm{Na}_{2} \mathrm{SO}_{4}, \mathrm{Li}_{2} \mathrm{SO}_{4}\right)$ aqueous electrolytes have higher conductivity $\left(10^{1}-10^{2} \mathrm{mS} \mathrm{cm} \mathrm{cm}^{-1}\right)$ than organic electrolytes $\left(10^{0}-10^{1} \mathrm{mS} \mathrm{cm}^{-1}\right)$ [71]. However, due to the limitation of water electrolysis, the thermodynamic potential window of aqueous electrolyte is limited to be $1.23 \mathrm{~V}$. Electrolytes composed of salts dissolved in organic solvents (e.g., propylene carbonate (PC), acetonitrile (ACN), dimethyl sulfone (DMSO), and adiponitrile (ADN)) show much wider electrochemically stable windows (up to $3.5 \mathrm{~V}$ ) than aqueous ones [72]. Quaternary ammonium salts, such as tetraethylammonium tetrafluoroborate $\left(\mathrm{TEA}^{+} \mathrm{BF}_{4}^{-}\right)$are widely used in organic electrolytes. However, the specific capacitance of electrode materials evaluated in organic electrolytes is lower than that in aqueous ones. In addition, salts in the liquid state, known as ionic liquid, are an emerging electrolyte [73]. These room-temperature molten salts (e.g., hexafluorophosphate, tetrafluoroborate, and bistriflimide salts) possess a low vapor pressure, superb electrochemical stability, and large operating voltage (up to $3.7 \mathrm{~V}$ ). However, owing to the high viscosity and low conductivity, the output power of the ionic liquids-based devices remains limited.

In general, the commonly used liquid electrolytes in conventional SCs cannot be directly utilized in on-chip MSCs, as the liquid electrolytes would lead to electrolyte leakage hazard and packaging difficulty of the on-chip electronic systems. Alternatively, extensive attentions have been paid to quasi-solid gel polymer electrolytes (GPEs), which own excellent flexibility and elasticity, particularly suitable for wearable electronics [74]. GPEs are composed of host polymer, solvent, and electrolytic salt. These components are blended by solution or melting processes, such as casting method [71, 75, 76], in-situ polymerization [77, 78], and phase inversion method $[74,79,80]$. Typically, the host polymers used in GPEs can be poly(vinyl alcohol) (PVA) [81-83], poly(ethylene oxide) (PEO) [84, 85], sodium carboxymethyl cellulose 
(CMC) [86, 87], agarose [88], gelatin [89], poly(acrylonitrile) (PAN) [90], poly(methyl methacrylate) (PMMA) [91, 92], poly(vinylidene fluoride-co-hexafluoropropylene) (PVDFHFP) [93, 94], and triblock copolymers $[95,96]$. These polymers are dissolved in water or organic solvents. However, these GPEs suffer from some drawbacks, such as solvent evaporation and conductivity decrease, resulting in the performance decay of FPMSCs.

Ionogel, as a specific class of solid-state electrolytes, has fair ionic conductivity and excellent stability. It is made up of a mixture of ionic liquids and fumed silica matrix. Gel-type electrolytes and solid-state electrolytes are highly recommended to be employed in MSCs, as they can not only prevent the possible internal shorting and external electrolyte leakage issues, but also help to reduce the thickness of MSC devices by avoiding the use of separators. Although FPMSCs assembled with GPEs achieve good ion migration rate, sufficient mechanical strength, and outstanding flexibility, encapsulation is needed for solvent antievaporation with stable electrochemical performance and security reason. Until now, FPMSCs have been sealed with hot-melted thermal plastics (e.g., ethylene-vinyl acetate copolymer (EVA), polyvinyl chloride (PVC), polyurethane (PU), parafilm, and Ecoflex) [88, 97-102], adhesive tapes (e.g., Kapton, Scotch) [87, 103], or silicone elastomers (e.g., polydimethylsiloxane (PDMS), silicone sealant, silicone rubber) [96, 104-106].

\subsubsection{Flexible substrates}

The rigid substrates (silicon wafer, glass and quartz) have been widely used in MSCs because of the excellent compatibility with silicon microfabrication techniques [107-109]. Along with the increasing interest in flexible and wearable electronics, the development of these electronics critically demands high-performance power sources with superior flexibility and durability. Until now, the flexible substrates used in FPMSCs are divided into three classes: polymer (plastic, rubber, and elastomer) [110, 111], paper (glassine, glossy, photocopy, and printing) $[112,113]$, and textile cloth (garments) $[114,115]$. These substrates are able to bear different 
mechanical deformations, such as curing, rolling, folding and compressing. Notably, the electrochemical performance of FPMSCs can be influenced by the adhesion affinity between current collectors, electrode materials, as well as the substrates [116]. The selection of suitable substrate is of significant importance in fabricating FPMSCs.

\subsection{Performance metrics}

In comparison with conventional supercapacitors, FPMSCs are much thinner, smaller, and lighter. With in-plane configuration, the electrolyte ions can rapidly transport in the narrow interspace between interdigital microelectrodes to supply a high rate capability due to the short ion diffusion distance. The separator is not required in such microdevices, which is beneficial to the fabrication of isolated microelectrodes and integration with other microelectronics on the same plane. In general, the weight of active materials used for FPMSCs is negligible. A key consideration of miniaturized energy storage units is the footprint area of the microdevice. Therefore, the capacitance, energy and power densities based on the area, instead of active mass, are important performance metrics for evaluating FPMSCs.

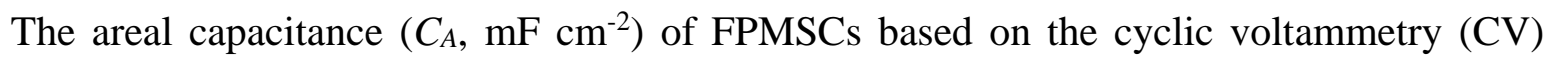
curves can be calculated according to the equation (1), where $S$ is the total surface area of the device, $v$ is the scan rate $\left(\mathrm{V} \mathrm{s}^{-1}\right), V_{\mathrm{f}}$ and $V_{\mathrm{i}}$ are the integration potential limits of $\mathrm{CV}$ curves and $I(V)$ is the voltammetric current (in amperes). $\int_{V_{i}}^{V_{f}}|I(V)| d V$ is the integrated area from $\mathrm{CV}$ curves. The areal capacitance $\left(C_{A}, \mathrm{mF} \mathrm{cm}^{-2}\right)$ can be also calculated from the galvanostatic charge-discharge (GCD) curves by the equation (2), where $I / S$ is the current density $\left(\mathrm{mA} \mathrm{cm}^{-2}\right)$ and $t$ is the discharge time (s). $v$ is the voltage range $(\mathrm{V})$. In addition, on the basis of the calculated areal capacitance, the volumetric capacitance $\left(C_{V}, \mathrm{~F} \mathrm{~m}^{-3}\right)$ is determined by the equation (3), where $\mathrm{d}$ is the thickness of active materials $(\mathrm{cm})$.

$$
C_{A}=\frac{1}{2 \times S \times v \times\left(V_{\mathrm{f}}-V_{i}\right)} \int_{V_{i}}^{V_{\mathrm{f}}}|I(V)| d V
$$




$$
\begin{aligned}
& C_{A}=\frac{I}{S} \times \frac{t}{v} \\
& C_{V}=\frac{C_{A}}{d}
\end{aligned}
$$

Energy and power densities are two key parameters to evaluate the electrochemical performance of FPMSCs. The areal ones are the most important performance metrics for FPMSCs with thin thickness. When the electrode is thicker $(>10 \mu \mathrm{m})$, the volumetric performance of FPMSCs becomes important as well. The areal energy densities $\left(E_{A}, \mathrm{Wh} \mathrm{cm}^{-2}\right)$ and power densities $\left(P_{A}, \mathrm{~W} \mathrm{~cm}^{-2}\right)$ are calculated from equations (4) and (5), while the volumetric energy densities $\left(E_{V}, \mathrm{Wh} \mathrm{cm}^{-3}\right)$ and power densities $\left(P_{V}, \mathrm{~W} \mathrm{~cm}^{-3}\right)$ are calculated based on equations (6) and (7), where $\Delta V$ is the discharge voltage range and $\Delta t$ is the discharge time (s).

$$
\begin{gathered}
E_{A}=\frac{1}{2} \times C_{A} \times \frac{(\Delta V)^{2}}{3,600} \\
P_{A}=\frac{E_{A}}{\Delta t} \times 3,600 \\
E_{V}=\frac{1}{2} \times C_{V} \times \frac{(\Delta V)^{2}}{3,600} \\
P_{V}=\frac{E_{V}}{\Delta t} \times 3,600
\end{gathered}
$$

Flexibility is another important parameter for FPMSCs, especially when FPMSCs are used in wearable electronics. So far, test standard has not been well established for the assessment of the flexibility of FPMSCs. Recently, Li et al. [117] suggested a systematic test methodology to evaluate the properties of flexible energy storage devices. As shown in Fig. 2a, three key geometric parameters: the bending angle $(\theta)$, the bending radius of curvature $(\mathrm{R})$, and the length of the device (L), should all be provided to claim a capacitance retention with bending test. Moreover, with regard to the comfortability of flexible devices, the softness can be evaluated by a commercially available leather and fabric softness tester (Fig. 2b). 

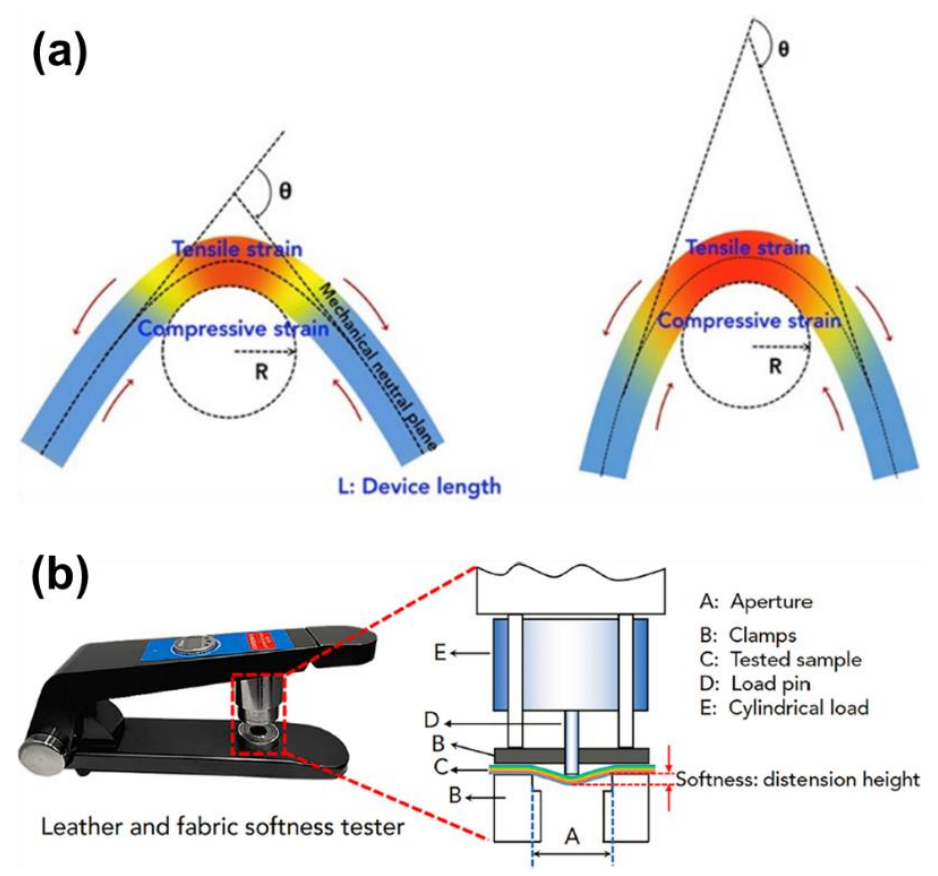

Fig. 2. (a) Schematics of the bending states of flexible and wearable energy storage devices according to the three key parameters (L, $\theta$, and R). (b) Photograph of the softness tester and schematic illustration for measuring softness. Reproduced with permission from Ref. [117]. Copyright 2019, Elsevier Ltd.

\section{Device fabrication of FPMSCs}

Throughout the development histories of electronic evaluation and MSCs (Fig. 3), various electrode materials, MSC devices, and related flexible electronics have been explored. Obviously, not only selecting appropriate electrode materials but also designing suitable device configurations determine the performance of FPMSCs with high rate capability. This section summarizes the main microfabrication technologies (e.g., deposition techniques, coating strategies, etching methods, and printing technologies) used for fabricating thin films or microelectrode finger arrays in FPMSCs. The advantages and disadvantages of the technologies mentioned above are detailed in Table $\mathbf{1 .}$ 


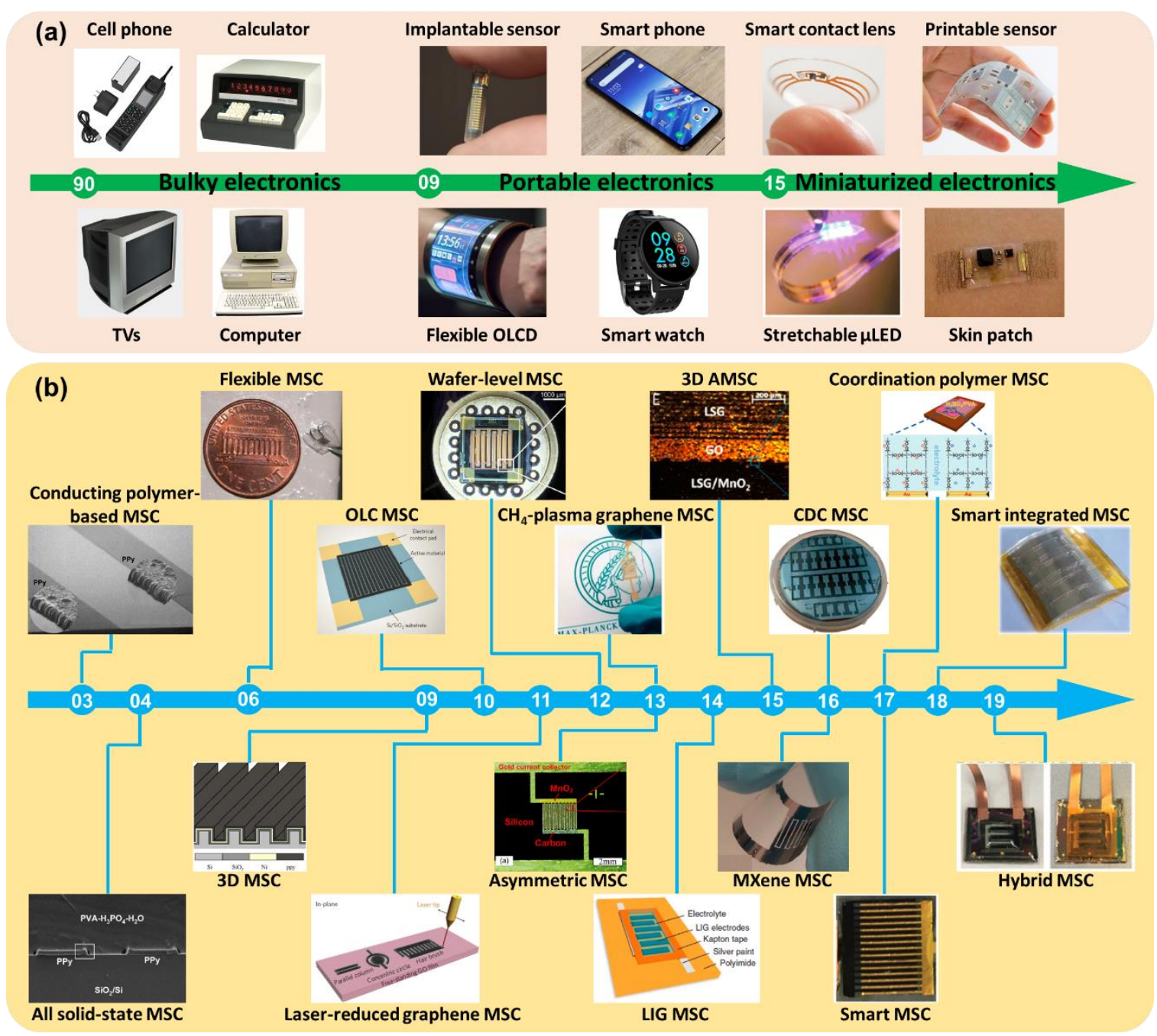

Fig. 3. Brief timeline of the development histories of (a) electronic evaluation and (b) MSCs. “Conducting polymer-based MSC". Reproduced with permission from Ref. [118]. Copyright 2003, Elsevier Ltd. "All solid-state MSC”. Reproduced with permission from Ref. [90]. Copyright 2004, Elsevier Ltd. "Flexible MSC". Reproduced with permission from Ref. [119]. Copyright 2006, Elsevier Ltd. “3D MSC”. Reproduced with permission from Ref. [120]. Copyright 2009, Elsevier Ltd. "OLC MSC". Reproduced with permission from Ref. [56]. Copyright 2010, Nature Publishing Group. “Laser-reduced graphene MSC”. Reproduced with permission from Ref. [121]. Copyright 2011, Nature Publishing Group. "Wafer-level MSC". Reproduced with permission from Ref. [122]. Copyright 2012, Springer. "CH4-plasma graphene MSC". Reproduced with permission from Ref. [123]. Copyright 2013, Nature Publishing Group. "Asymmetric MSC". Reproduced with permission from Ref. [124]. 
Copyright 2013, Elsevier Ltd. "LIG MSC". Reproduced with permission from Ref. [125]. Copyright 2014, Nature Publishing Group. “3D AMSC”. Reproduced with permission from Ref. [126]. Copyright 2015, National Academy of Sciences. "CDC MSC”. Reproduced with permission from Ref. [53]. Copyright 2016, the American Association for the Advancement of Science. “MXene MSC”. Reproduced with permission from Ref. [127]. Copyright 2016, Royal Society of Chemistry. "Smart MSC”. Reproduced with permission from Ref. [128]. Copyright 2017, Wiley-VCH. "Coordination polymer MSC". Reproduced with permission from Ref. [129]. Copyright 2017, Wiley-VCH. "Smart integrated MSC". Reproduced with permission from Ref. [130]. Copyright 2018, Wiley-VCH. "Hybrid MSC". Reproduced with permission from Ref. [131]. Copyright 2019, Wiley-VCH.

Table 1. Comparisons of different microfabrication technologies for FPMSCs.

\begin{tabular}{|c|c|c|}
\hline Technologies & Advantages & Disadvantages \\
\hline $\begin{array}{l}\text { Electrophoretic } \\
\text { deposition }\end{array}$ & $\begin{array}{l}\text { Simple equipment, low-cost, controllable } \\
\text { thickness }\end{array}$ & $\begin{array}{l}\text { Limited to the charged } \\
\text { nanoparticles/nanotubes/nanosheets }\end{array}$ \\
\hline Electrolytic deposition & $\begin{array}{l}\text { Fast fabrication, low-cost, eco-friendly, } \\
\text { scalable }\end{array}$ & $\begin{array}{l}\text { Uncontrollable growth in a lateral } \\
\text { direction }\end{array}$ \\
\hline Spray coating & Simple procedure, scalable, universal & Low homogeneity of the film \\
\hline Layer-by-layer assembly & Material-saving, facile, robust & Complex preparation procedure \\
\hline Vacuum filtration & $\begin{array}{l}\text { Low-cost, convenient, controllable thickness } \\
\text { and construction }\end{array}$ & $\begin{array}{l}\text { Limited to electrode materials with } \\
1 \mathrm{D} \text { or } 2 \mathrm{D} \text { morphologies }\end{array}$ \\
\hline Laser scribing & Fast fabrication, scalable, eco-friendly & Expensive equipment \\
\hline Plasma etching & One-step, simple, efficient & Limited to carbon materials \\
\hline Inkjet printing & $\begin{array}{l}\text { Precise control, scalable, efficient, low-cost, } \\
\text { commercially available }\end{array}$ & $\begin{array}{l}\text { Need of high-quality inks, relatively } \\
\text { low-resolution electrode patterns }\end{array}$ \\
\hline Screen printing & Fast fabrication, low-cost, scalable & Low-resolution electrode patterns \\
\hline Extrusion printing & Material-saving, scalable & Need of high-concentration inks \\
\hline $3 \mathrm{D}$ printing & $\begin{array}{l}\text { Scalable, time and energy saving, controllable } \\
\text { thickness }\end{array}$ & Low-resolution electrode patterns \\
\hline
\end{tabular}

\subsection{Deposition techniques}

As the earliest fabrication techniques used in MSCs, mature deposition methods have been extensively reported, including chemical vapor deposition (CVD), electrolytic and electrophoretic depositions. Microelectrodes can be directly obtained by depositing active materials on substrate, avoiding the use of binder additives. CVD is particularly suitable for the 
growth of electrode materials based on chemical reactions. Although a series of microelectrodes have been fabricated by CVD method [55, 58, 59, 70, 132-141], the deposition process involves the ultrahigh temperature treatment, for which the flexible plastic substrates cannot withstand.

Additionally, electrophoretic and electrolytic depositions are another common techniques for depositing various electrode materials, such as activated carbon [48, 56, 124], CNTs [142], graphene [143, 144], graphene quantum dots [145, 146], and carbon onions [57, 147], as well as transition metal oxides [148-152] and conducting polymers [119, 153-158]. These methods are cost-effective and scalable with a simple fabrication equipment. In electrolytic deposition, charged nanoparticles/nanotubes/nanosheets diffuse, migrate, and deposit on the pre-patterned current collectors under the force of an electric field. In 2013, Niu et al. [143] fabricated flexible, compact, and ultrathin rGO-based FPMSCs by combining electrophoretic deposition together with photolithography lift-off method (Fig. $4 \mathbf{a}$ and b). The areal and volumetric capacitances of the fabricated FPMSCs were $462 \mu \mathrm{F} \mathrm{cm}$ and $359 \mathrm{~F} \mathrm{~cm}^{-3}$, respectively. The calculated volumetric energy density was $31.9 \mathrm{mWh} \mathrm{cm}^{-3}$. Unlike electrophoretic method, electrolytic deposition is used for the growth of electrode material through the redox reactions in a solution containing precursors under an electric field. In 2019, conducting polymer (polyaniline (PANI)) hydrogels with 3D interconnected frameworks were electrochemically polymerized onto the interdigital gold current collectors (Fig. 4c) [158]. Due to the high electrical conductivity (0.43 $\mathrm{S} \mathrm{cm}^{-1}$ ) and improved ion/electron transports, the areal capacitance of the fabricated FPMSCs with PVA/ $\mathrm{H}_{2} \mathrm{SO}_{4}$ gel electrolyte could reach $135.9 \mathrm{mF} \mathrm{cm}^{-2}$ at a current density of $0.5 \mathrm{~mA} \mathrm{~cm}-$ ${ }^{2}$ and maintain $76 \%$ of its initial capacitance after 10000 cycles (Fig. 4d and e). Apart from conducting polymers, metal oxide based microelectrodes can be also fabricated by electrolytic deposition. In 2016, a FPMSC on a PET substrate was manufactured by employing electrodeposited $\mathrm{MnO}_{2}$ as the positive electrode, electrodeposited PPy as the negative electrode, and nanoporous gold as the interdigital current collector (Fig. 4f and g). Notably, the resultant FPMSCs delivered an areal capacitance of $1.27 \mathrm{mF} \mathrm{cm}^{-2}$ at $0.28 \mathrm{~mA} \mathrm{~cm}{ }^{-2}$ and a maximum 
power density of $440.4 \mathrm{~W} \mathrm{~cm}^{-3}$ (Fig. 4h). Although these deposition methods are simple and time-saving, the fabrication of FPMSC arrays in series requires special consideration. Moreover, the growth of active materials in a lateral direction tends to bridge the gap between two adjacent microelectrodes, causing an electrical short circuit. Therefore, the concentration of the electrodeposition solution and the time of electrodeposition need to be carefully controlled.

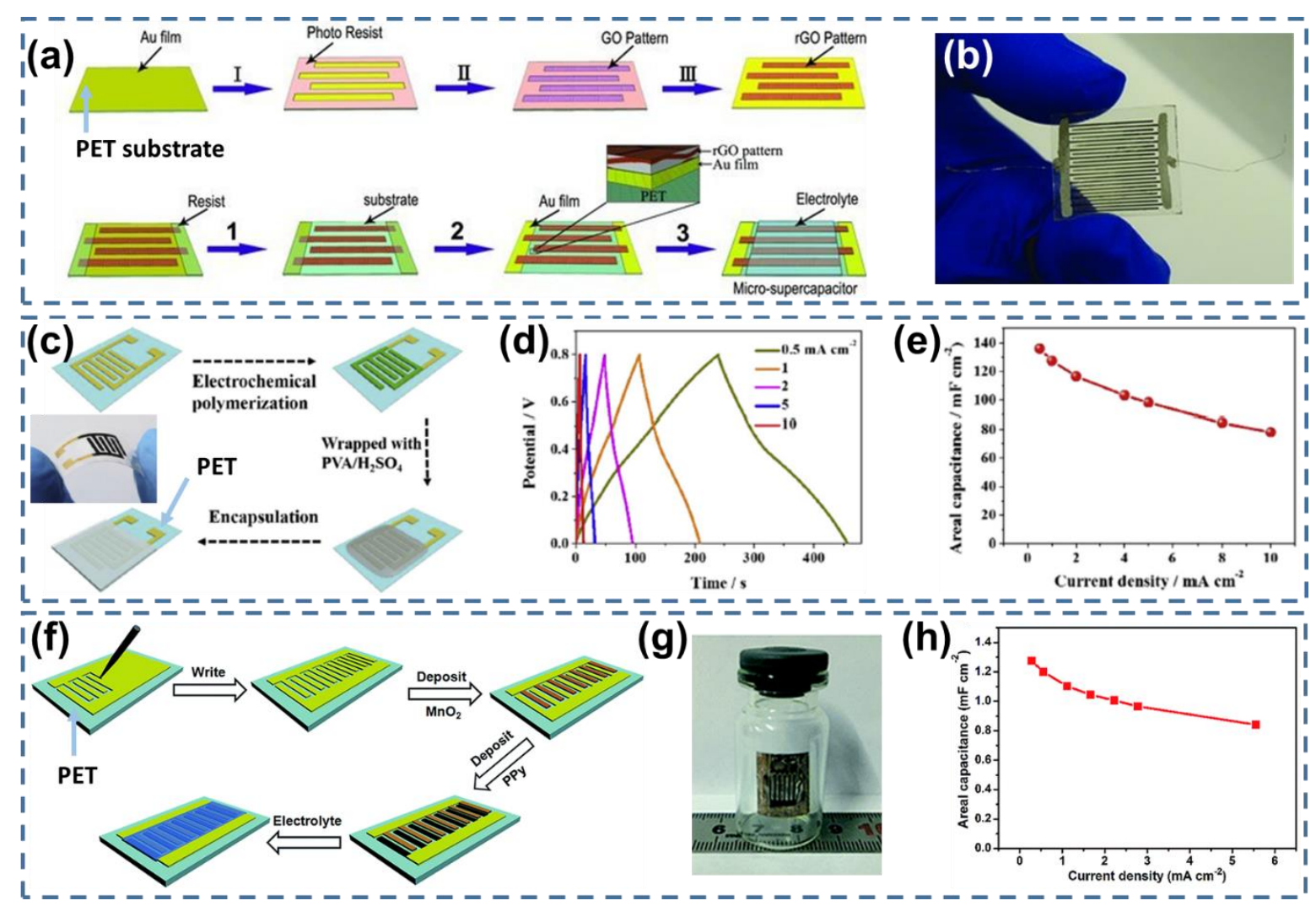

Fig. 4. Electrolytic and electrophoretic depositions of microelectrodes for FPMSCs. (a) Schematic of the fabrication process of rGO-based FPMSCs by combining photolithography with electrophoresis. (b) Photograph of a FPMSC on PET substrate. Reproduced with permission from Ref. [143]. Copyright 2013, Wiley-VCH. (c) Schematic of the fabrication process of FPMSCs with PANI. (d) GCD curves of the FPMSC. (e) Areal capacitance calculated from GCD curves. Reproduced with permission from Ref. [158]. Copyright 2019, Elsevier Ltd. (f) Schematic illustration for the fabrication processes of the FPMSC. (g) Photograph of a fabricated FPMSC attached to the curved wall of a vial $(\mathrm{r}=10 \mathrm{~mm})$. (h) Areal 
capacitance variation with current density. Reproduced with permission from Ref. [159]. Copyright 2016, Royal Society of Chemistry.

\subsection{Coating strategies}

Coating strategies, such as spray coating, layer-by-layer (LBL) assembly, and vacuum filtration, are widely employed for the highly reproducible fabrication of thin-film electrodes with large area and high structural uniformity $[68,98,123,160-162]$. These strategies involve coating a homogeneous dispersion onto a horizontal substrate, evaporating the solvent, and leaving a solid film with highly controllable film thickness. Inorganic, organic, and inorganic/organic hybrid solutions have been used for the fabrication of thin-film electrodes. After obtaining thinfilm electrodes, the interdigital fingers of the current collector are deposited onto the film by photolithography or spray-coating with a shadow mask. The uncovered area can be etched away by oxygen plasma and chemical reagents. Finally, the solid-state gel electrolyte is dropped on the electrodes to obtain the FPMSC.

Spray coating has been extensively used for microelectrode fabrication or film coating [84, $96,97,104,127,161,163-175]$. It can be applied to various substrates with an air brush or spray gun. The key point in this method is the capability of the ink to generate droplets without jamming the nozzle during spraying. The parameters of spray coating, such as distance between the nozzle and the substrate, substrate temperature, and deposition time strongly influence the homogeneity and mass loading of active materials in the fabricated devices. In 2017, planar graphene-based linear tandem FPMSCs with asymmetric configurations were fabricated by a spray-coating method with the assistance of customized patterned mask on a flexible nylon membrane, as illustrated in Fig. 5a and b. The excellent properties of high output voltage, tailorable capacitance, and outstanding flexibility were demonstrated with electrochemically exfoliated graphene (EG)//MnO 2 nanosheets/PH1000-based linear tandem FPMSC arrays [167]. Only $6 \%$ loss of initial capacitance and no structural instability or delamination of the electrode 
film were observed under a high bend state. Likewise, Jiang et al. [174] fabricated MXene FPMSCs using a photolithographic lift-off process followed by spray-coating of MXene dispersions (Fig. 5c). As a proof of scalable fabrication, Fig. 5d displays 100 devices on a flexible PET substrate. The CV curves of 10 MXene FPMSCs connected in series presented nearly rectangular shape up to a scan rate of $300 \mathrm{~V} \mathrm{~s}^{-1}$ with $6 \mathrm{~V}$, showing great potential in highvoltage-needed applications (Fig. 5e).

\section{(a)}

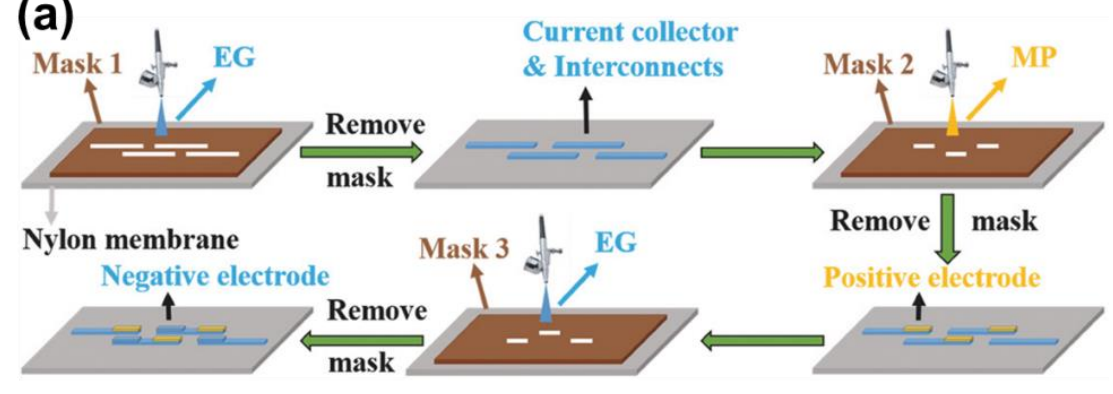

(c)

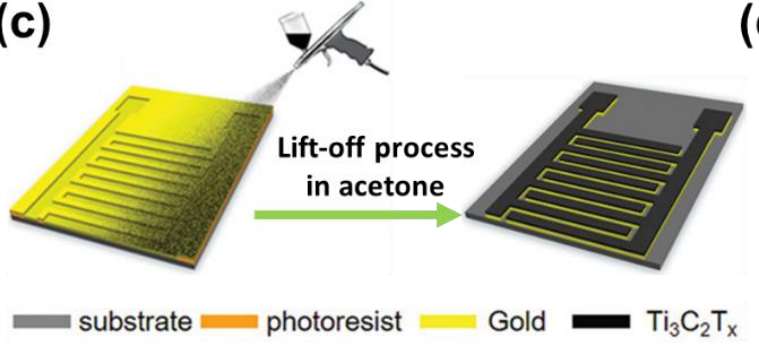

(b)

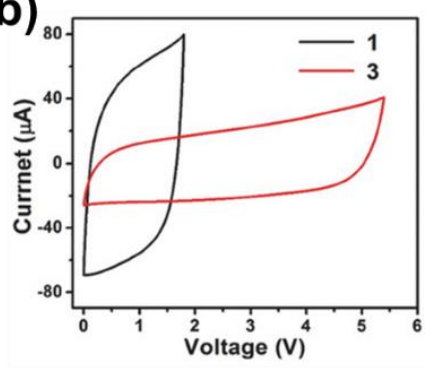

(e)

(d)
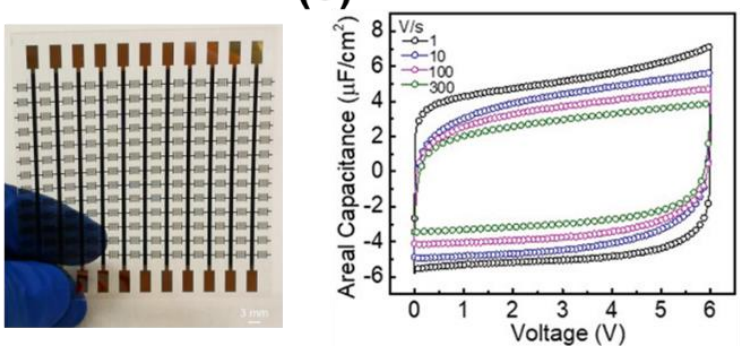

Fig. 5. (a) Schematic of the fabrication and self-integration of asymmetric EG//MnO 2 nanosheets/PH1000 linear tandem FPMSCs serially connected three units. (b) CV curves obtained at a scan rate of $100 \mathrm{mV} \mathrm{s}{ }^{-1}$ of three asymmetric $\mathrm{EG} / / \mathrm{MnO}_{2}$ nanosheets/PH1000 linear tandem FPMSCs. Reprinted with permission from Ref. [167]. Copyright 2017, Wiley-VCH. (c) Schematic of the fabrication process of MXene FPMSCs. (d) Photograph showing the scalable production of the MXene FPMSCs on a PET substrate. (e) CV curves of 10 MXene FPMSCs connected in series from 1 to $300 \mathrm{~V} \mathrm{~s}^{-1}$. Reprinted with permission from Ref. [174]. Copyright 2019, Wiley-VCH.

The LBL assembly is also an attractive method to fabricate thin films for MSCs, because of the simple, cost-effective, and large-scale deposition of active materials into films $[85,129$, 
176-183]. The thin film is formed by depositing alternating layers of oppositely charged materials. In particular, it is easy to control the thickness at the micro-/nanometer scale. Recently, our group presented a novel LBL approach for fabricating high energy-density FPMSCs based on Prussian-blue nano-thin films with vacancies modified by pyridine (Fig. 6) [183]. Among diverse electrode materials for MSCs, coordination polymer frameworks are emerging due to the designable porous structure and tunable functionality [184]. A series of pyridine-modified Prussian-blue nano-thin films can be directly in-situ grown on the interdigital gold current collectors with rationally controlled nanoscale thickness by different cycles. The pyridine-modified vacancy within Prussian-blue networks improved the film-forming property, hydrophilicity, and electrochemical activity of the thin films. The resultant FPMSCs exhibited a remarkable areal capacitance of up to $4.69 \mathrm{mF} \mathrm{cm}^{-2}$ and a volumetric capacitance of $347 \mathrm{~F}$

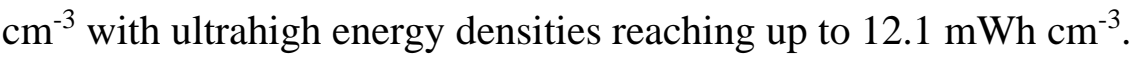

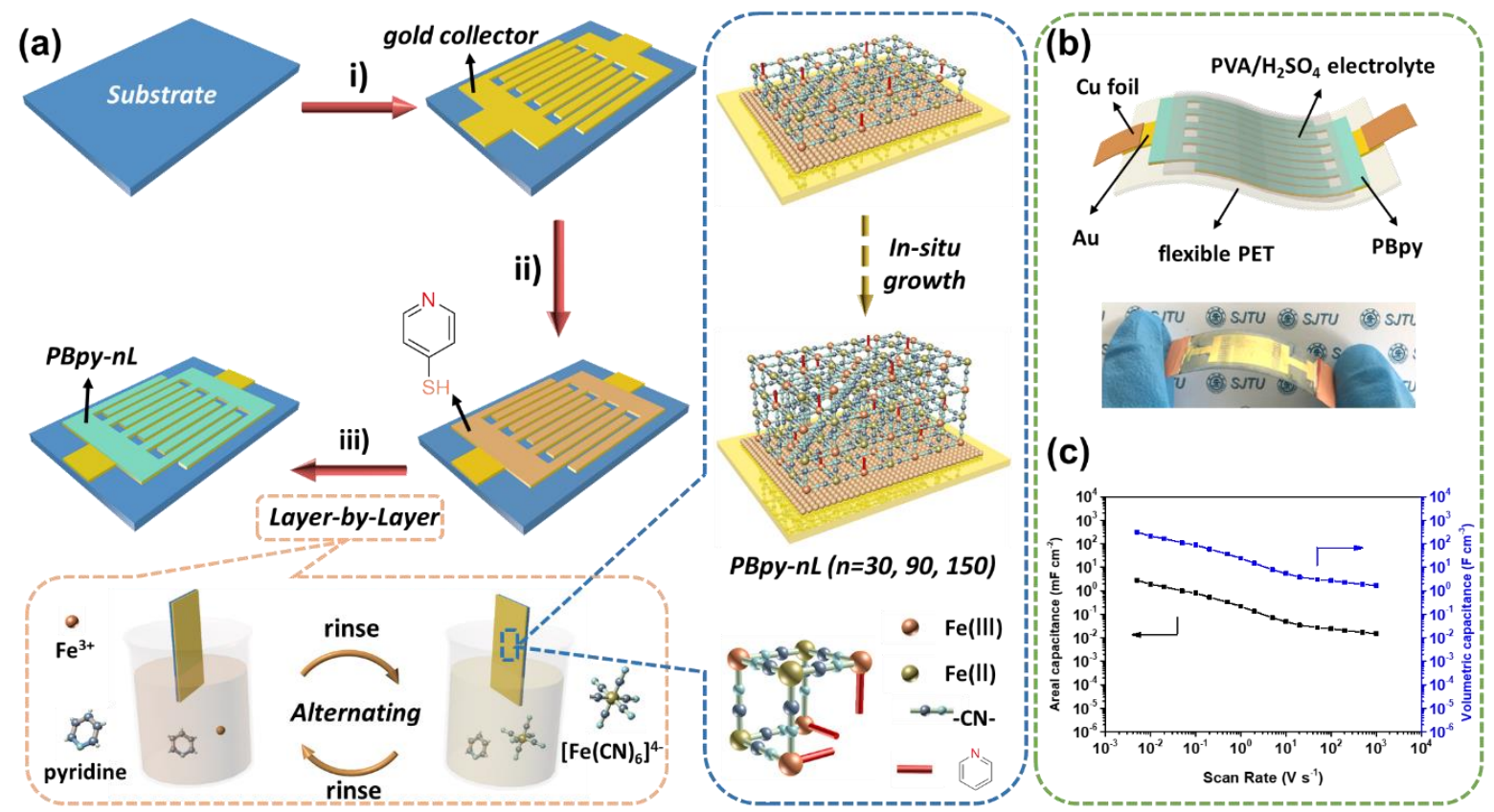

Fig. 6. LBL method for fabricating FPMSCs based on 2D conjugated coordination polymer as microelectrodes. (a) Illustration of in-situ growth of pyridine-modified Prussian-blue nano-thin films as electrode materials for FPMSCs. (b) Schematic and photograph of the fabricated FPMSC on PET substrate. (c) Areal and volumetric capacitances calculated from CV curves. Reprinted with permission from Ref. [183]. Copyright 2019, Elsevier Ltd. 
Vacuum filtration is one of the most commonly used film fabrication methods by separating a solid product from a liquid [103, 128, 185-206]. A stacked dense film is permeable to ions, resulting in the fabricated electrodes that have high energy density. Furthermore, due to the diversity of homogeneous dispersions, it is facile to form uniform films comprising various hybrid materials. For a single electrode material, it is still difficult to simultaneously achieve high capacitance, fast frequency response and large power delivery, as well as long cycling stability. From the perspective of material selection, the hybridization of EDLC-type and pseudocapacitive materials is a reliable strategy for achieving both high energy and power densities. In 2017, Xiao et al. [103] fabricated an hybrid film composed of phosphorene nanosheets and EG nanosheets (PG) by one-step mask-assisted vacuum filtration. Then, the resulted hybrid film was used directly as a binder- and additive-free interdigital electrode for FPMSCs (Fig. 7a-c). The reported PG-MSC device delivered an energy density of $11.6 \mathrm{mWh}$ $\mathrm{cm}^{-3}$. Another efficient approach is to fabricate hybrid electrodes by alternately stacking EDLCtype materials and pseudocapacitive materials. In this structure design, the continuous layer of EDLC materials provides a rapid electron transport pathway in the electrode film, and the alternative layer of pseudocapacitive materials provides high Faradaic capacitance. As a typical example, alternately stacked PANI-graphene (PANI-G) and EG hybrid films were prepared for FPMSCs [190]. The optimal proportion of the alternately stacked structure was two PANI-G layers and three EG layers (denoted as P2G3). P2G3-based FPMSCs delivered ultrahigh areal and volumetric capacitances of $210 \mathrm{mF} \mathrm{cm}^{-2}$ and $436 \mathrm{~F} \mathrm{~cm}^{-3}$ at $10 \mathrm{mV} \mathrm{s}^{-1}$, respectively. Such remarkable performance is attributed to the unique alternately stacked structure with a strong coupling effect between 2D pseudocapacitive PANI-G and capacitive EG nanosheets with accessible ion-transporting channels, an elastic spatial confinement effect, and a rapid electron transport pathway. Recently, AMSCs have attracted much attentions due to the high capacitances and wide operating voltage windows [65, 97, 173, 192, 199, 207-214]. For 
instance, in 2019, Qin et al. [192] fabricated ultrathin mesoporous $\mathrm{MnO}_{2}$ nanosheets as positive electrode, porous VN nanosheets as negative electrode, and EG as conductive agent and metalfree current collectors by mask-assisted vacuum filtration in assembled all-solid-state flexible AMSCs on the nylon membrane (Fig. 7d). The resultant AMSCs operated stably up to $2 \mathrm{~V}$ and presented volumetric capacitances of 38.8 and $32.7 \mathrm{~F} \mathrm{~cm}^{-3}$ at $1 \mathrm{mV} \mathrm{s}^{-1}$ in $\mathrm{SiO}_{2}$-lithium bis(trifluoromethanesulfonyl)imide (LiTFSI) gel electrolyte and 5M LiTFSI liquid electrolyte, respectively (Fig. 7e). Moreover, 98\% of initial capacitance was retained at a highly bending angle of $180^{\circ}$, demonstrative of outstanding structural stability and mechanical flexibility.
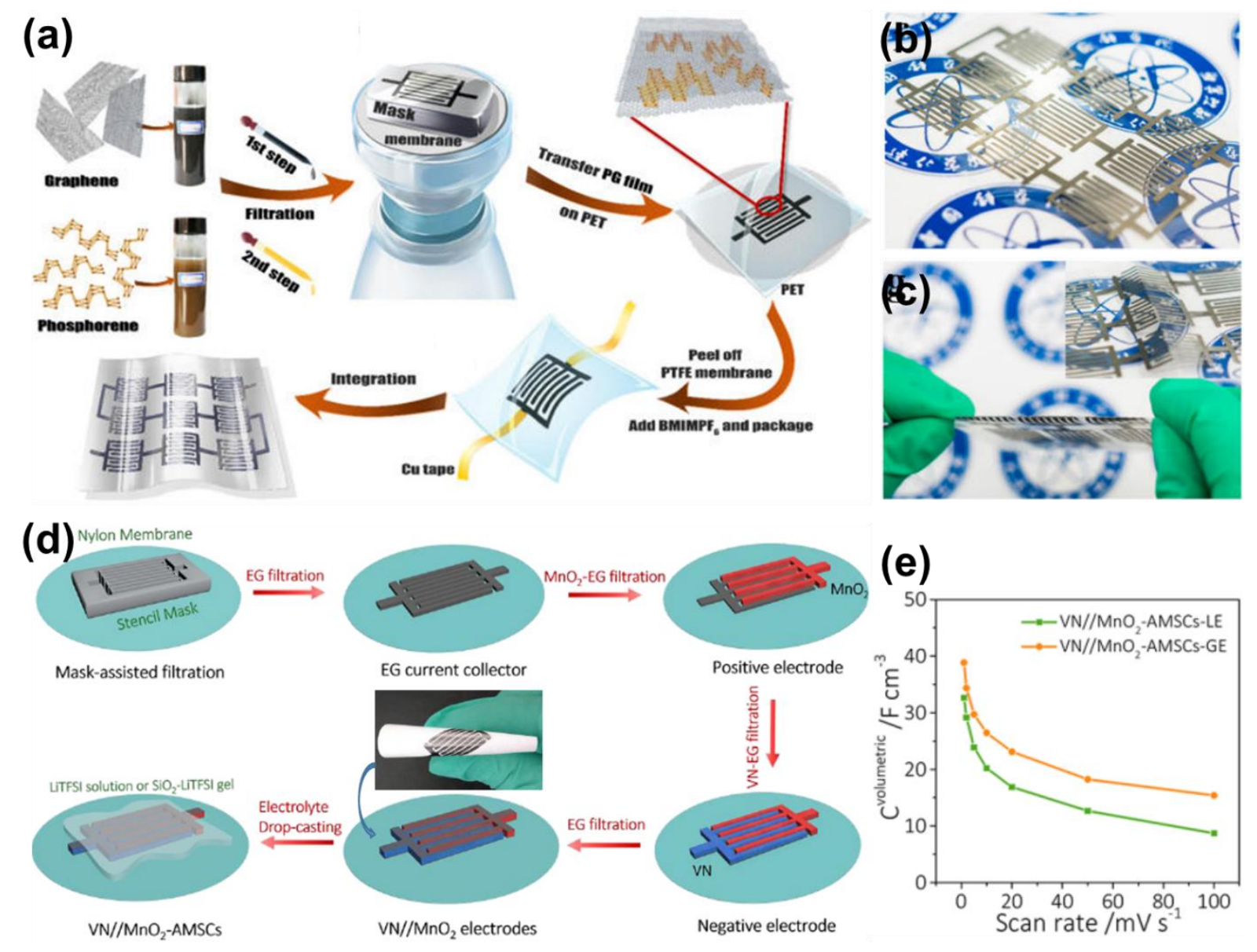

Fig. 7. Mask-assisted vacuum filtration for the fabrication of FPMSCs. (a) Schematic of the fabrication process of PG-MSCs. (b) Photograph of 9 serially connected PG-MSCs. (c) Flexibility and stability demonstration of PG interdigital electrodes at a highly folded state. Reprinted with permission from Ref. [103]. Copyright 2017, American Chemical Society. (d) Schematic of the fabrication process of $\mathrm{VN} / / \mathrm{MnO}_{2}$-AMSCs. (e) Volumetric capacitance 
calculated from $\mathrm{CV}$ curves of $\mathrm{VN} / / \mathrm{MnO}_{2}-\mathrm{AMSC}$ in $\mathrm{SiO}_{2}$-LiTFSI gel electrolyte and $5 \mathrm{M}$ LiTFSI liquid electrolyte, respectively. Reprinted with permission from Ref. [192]. Copyright 2019, Elsevier Ltd.

\subsection{Etching methods}

Etching methods (laser etching, plasma etching, gas etching, etc.) have been employed to engrave with high-resolution patterns for developing on-chip MSCs [215-217]. Laser-scribing technique has several advantages for fabricating MSCs due to its simple, scalable, clean, and time-saving process [100, 218-228]. The laser parameters such as wavelength, scanning speed, pulses per inch, power, pulse duration, and pulse frequency can be controlled easily and precisely for the reproducible fabrication of high-quality devices. As shown in Fig. 8a, Gao et al. [121] used laser irradiation to reduce and pattern hydrated GO films for the scalable FPMSCs in 2011. Later in 2013, El-Kady et al. applied a standard LightScribe DVD optical drive for the direct laser reduction of GO to graphene (LSG) [224, 229-232]. The LSG-based FPMSCs exhibited a power density of $200 \mathrm{~W} \mathrm{~cm}^{-3}$, a frequency response of $19 \mathrm{~ms}$, and exceptional electrochemical stability under different bending/twisting conditions (Fig. 8b). Developing scalable and straightforward synthesis approaches for graphene-based nanomaterials remains a technologically important goal in achieving commercialized MSCs [93, 221, 233-236]. In 2014, Lin et al. [125] reported one scalable approach for producing and patterning porous graphene films by pulsed laser irradiation with commercial flexible polyimide (PI) film (Fig. 8c). The laser-induced graphene (LIG) FPMSCs exhibited a specific capacitance of $4 \mathrm{mF} \mathrm{cm}^{-2}$ and a power density of approximately $9 \mathrm{~mW} \mathrm{~cm} \mathrm{~cm}^{-2}$. 

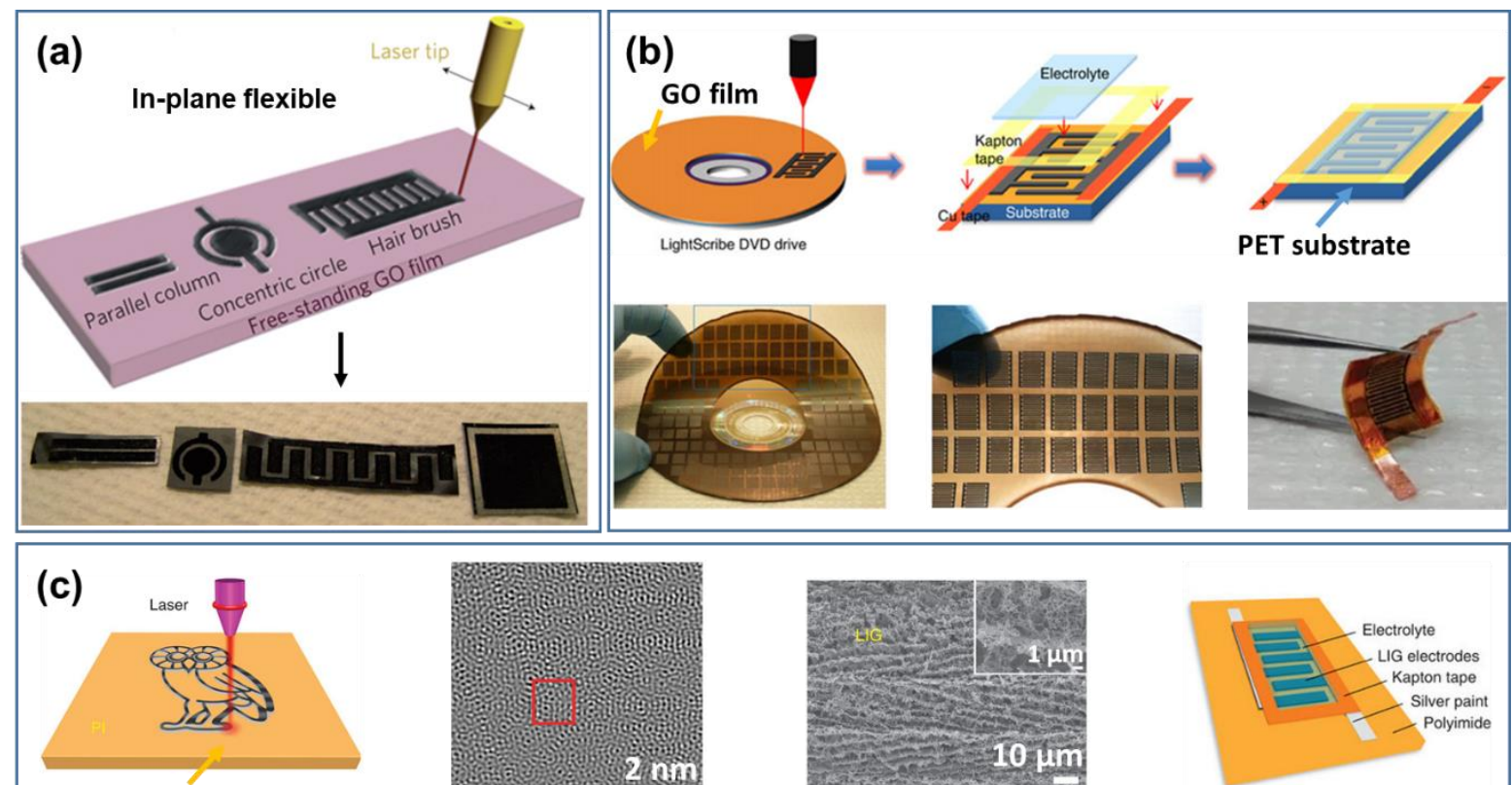

PI substrate
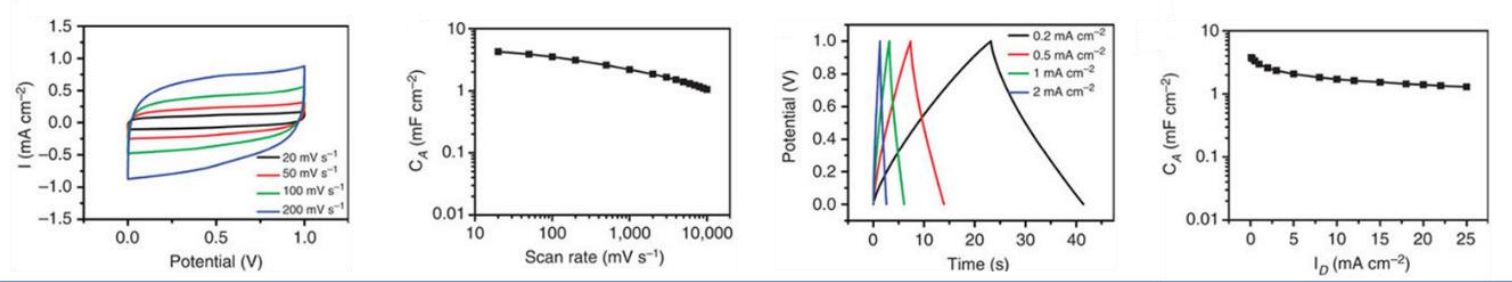

Fig. 8. FPMSCs produced with etching methods. (a) Schematics of $\mathrm{CO}_{2}$ laser-patterning of freestanding hydrated GO films to fabricate rGO-GO-rGO devices with in-plane geometries. The black contrast to rGO and the light contrast to unmodified hydrated GO. The bottom row shows photographs of patterned films. Reprinted with permission from Ref. [121]. Copyright 2011, Nature Publishing Group. (b) Schematics of the fabrication process for an LSG FPMSC and more than 100 micro-devices produced on a single run. Reprinted with permission from Ref. [224]. Copyright 2013, Nature Publishing Group. (c) Schematics and characterizations of LIGbased FPMSCs with porous graphene networks. Reprinted with permission from Ref. [125]. Copyright 2014, Nature Publishing Group.

The above-mentioned pure graphene (LSG or LIG)-based FPMSCs still suffer from the limited potential window and capacitance. In recent years, extensive attentions have been paid to developing hybrid materials and asymmetric devices to enhance the electrochemical performance [237-240]. For instance, by using a laser-scribing technique and an 
electrodeposition method (Fig. 9a), El-Kady et al. [126] demonstrated a flexible AMSC based on LSG-MnO 2 as the positive electrode and LSG as the negative electrode on the PI film. A charge balance between two electrodes was performed by precisely controlling the deposition time of $\mathrm{MnO}_{2}$ nanosheets at the positive electrode and the thickness of the graphene film at the negative electrode. The flexible AMSCs exhibited high rate capability (capacity retention of $96 \%$ ) with scan rates of up to $10 \mathrm{~V} \mathrm{~s}^{-1}$, a wide potential window of $2 \mathrm{~V}$ in aqueous $\mathrm{Na}_{2} \mathrm{SO}_{4}$ electrolyte, and a high volumetric energy density of $42 \mathrm{~mW} \mathrm{~h} \mathrm{~cm}^{-3}$ (Fig. 9b).

Notably, as the most promising member of AMSCs, the hybrid MSC comprises two different electrodes: a battery-type Faradaic electrode (anode) and a capacitor-type electrode (cathode) [131, 241-244]. This design offers a unique advantage of wide operational voltage window and thereby significantly enhances the energy density. In 2017, Jiang et al. [243] developed a facile and scalable process for fabricating 3D ultra-thick hybrid MSCs by direct-laser cutting technique (Fig. 9c). The patterned 3D nickel foam as the current collector offers maximum electroactive material loading with optimal electrochemical performance in a given footprint area. Employing pseudocapacitive $\mathrm{NiCo}_{2} \mathrm{~S}_{4}$ as a positive electrode and EDLC-type carbon nanofiber $(\mathrm{CNF})$ as a negative electrode, the operating potential window reached $1.6 \mathrm{~V}$, as demonstrated in Fig. 9d. Furthermore, the $\mathrm{NiCo}_{2} \mathrm{~S}_{4} / / \mathrm{CNF}$ hybrid MSC possesses the broad redox peaks ascribed to both EDLC-type and Faradaic charge storage. As presented in Fig. 9e, the device delivered an areal capacity of $240 \mu \mathrm{A} \mathrm{h} \mathrm{cm} \mathrm{h}^{-2}$ at $5 \mathrm{~mA} \mathrm{~cm}^{-2}$ and retained $190 \mu \mathrm{A} \mathrm{h}$ $\mathrm{cm}^{-2}$ at $15 \mathrm{~mA} \mathrm{~cm}^{-2}$, indicating good rate performance (79\%). As shown in Fig. 9f, the discharge capacity maintained $89 \%$ of the initial value over 10000 cycles at a high current density of 40 $\mathrm{mA} \mathrm{cm} \mathrm{cm}^{-2}$ in $1 \mathrm{M} \mathrm{KOH}$ electrolyte. Finally, an excellent energy density up to $200 \mu \mathrm{Wh} \mathrm{cm} \mathrm{cm}^{-2}$ can be delivered at a power density of $4.4 \mathrm{~mW} \mathrm{~cm}^{-2}$ (Fig. 9g). Although substantial efforts have been devoted to the design and fabrication of hybrid MSCs, the development of FPMSCs with high energy and power densities as well as long cycling stability remains challenging. Limited by the operating voltage of the aqueous electrolyte, nonaqueous solvent-based gel electrolytes 
have emerged as a research focus, which own large voltage window (3-5 V), high ionic conductivity, safety, and mechanical stability. Hybrid MSCs with nonaqueous solvent-based gel electrolyte hold great potential as the next-generation high-performance miniaturized energy storage devices.

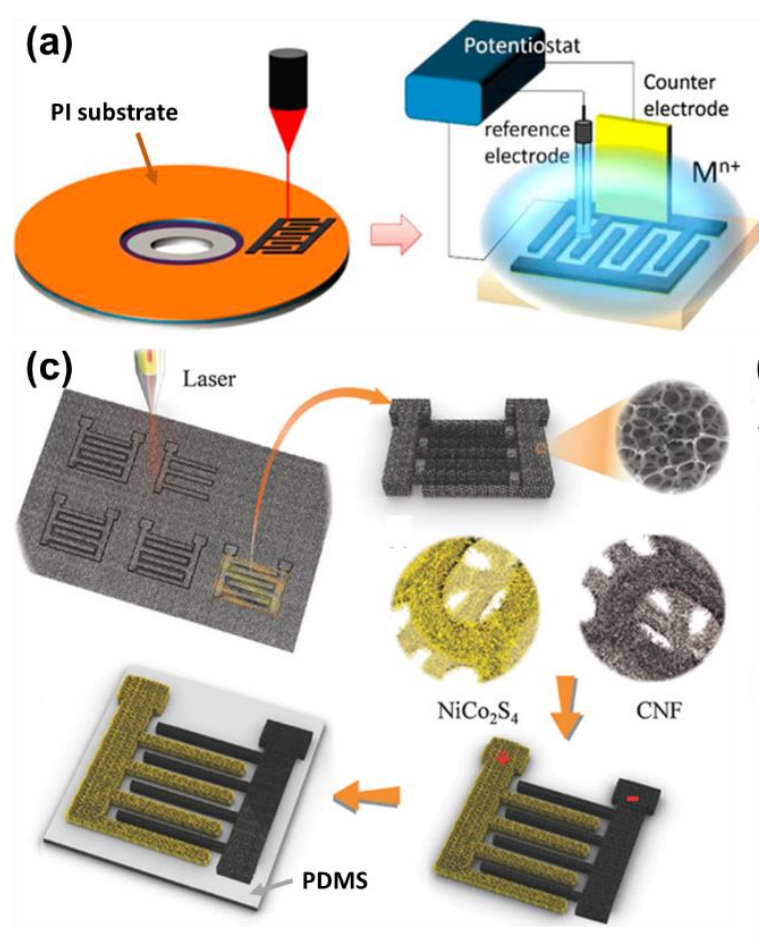

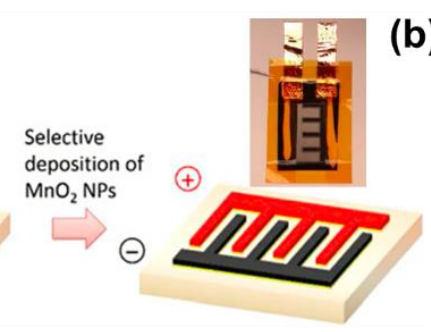

(d) $\quad$ Potential (v)

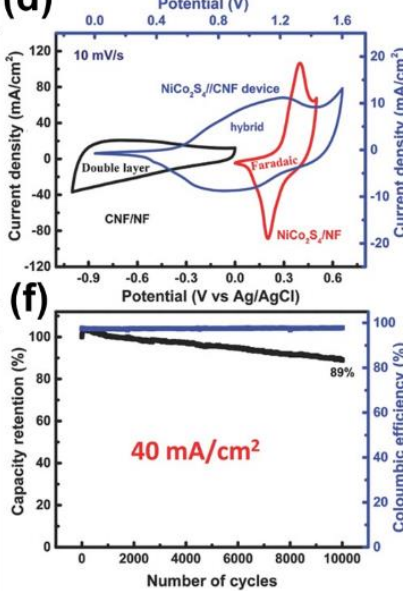

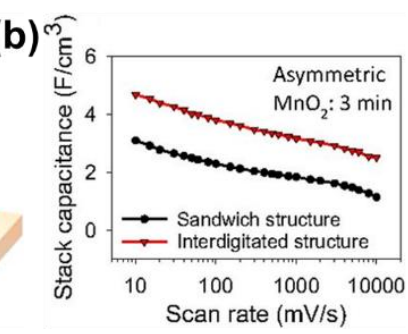

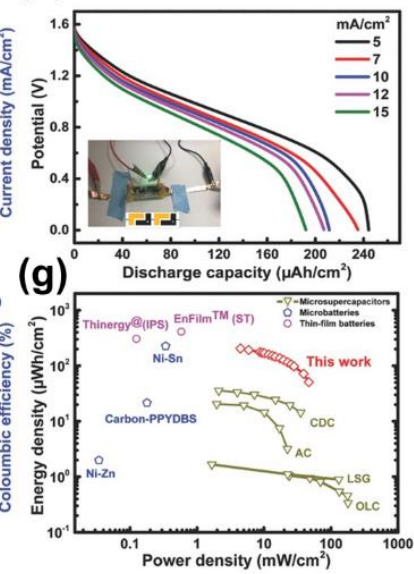

Fig. 9. Asymmetric and hybrid FPMSCs with high operating voltage by laser scribing and electrodeposition. (a) Schematic of the fabrication process for an asymmetric FPMSC based on LSG-MnO 2 as the positive electrode and LSG as the negative electrode. (b) Comparison of the volumetric capacitance of the asymmetric supercapacitor between the sandwich structure and the planar interdigitated structure with $\mathrm{MnO}_{2}$ deposition (3 min). Reprinted with permission from Ref. [126]. Copyright 2015, National Academy of Sciences. (c) Schematic illustrating fabrication of the hybrid devices. (d) $\mathrm{CV}$ curves of $\mathrm{NiCo}_{2} \mathrm{~S}_{4} / \mathrm{NF}, \mathrm{CNF} / \mathrm{NF}$ electrodes, and $\mathrm{NiCo}_{2} \mathrm{~S}_{4} / / \mathrm{CNF}$ device at a scan rate of $10 \mathrm{mV} \mathrm{s}^{-1}$. (e) Galvanostatic discharge curves at different current densities of the $\mathrm{NiCo}_{2} \mathrm{~S}_{4} / / \mathrm{CNF}$ hybrid MSC, inset shows that two series connected devices were able to light a LED. (f) Cycling stability and Coulombic efficiency of the hybrid device over 10000 cycles. (g) Ragone plot shows the areal energy and power densities of 
commercial thin-film batteries, state-of-the-art MBs, and MSCs compared to the $\mathrm{NiCo}_{2} \mathrm{~S}_{4} / / \mathrm{CNF}$ hybrid MSC. Reprinted with permission from Ref. [243]. Copyright 2017, Wiley-VCH.

Plasma etching is another promising etching technique, which is commonly used as an assistive tool in the fabrication of interdigital microelectrode arrays [245]. The designed current collector arrays are deposited on the thin film of electrode materials by combining photolithography with the home/lab-made mask and sputtering/evaporation. Then, uncovered parts of the thin film are removed by plasma-etching and left with the electrode finger arrays. For example, our group fabricated graphene or graphene-based hybrid films and then deposited $\mathrm{Au}$ current collector arrays on their surface (Fig. 10). Afterwards, interdigital microelectrode arrays were fabricated by using $\mathrm{O}_{2}$-plasma to etch the thin film that is un-covered by the current collectors $[123,178,202,246]$. Although plasma etching is a practical technique, the scope of suitable materials is limited to carbon materials, which restricts the wide applications of plasma etching. Furthermore, it is time-consuming to fabricate symmetric MSCs with a thick film of electrode materials.

(a)
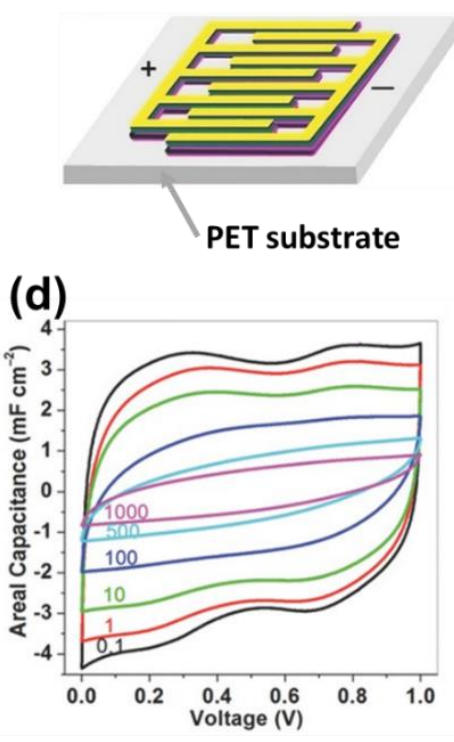

(b)

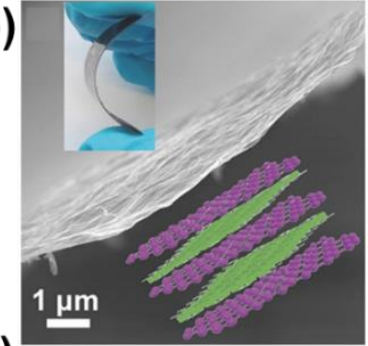

(e)

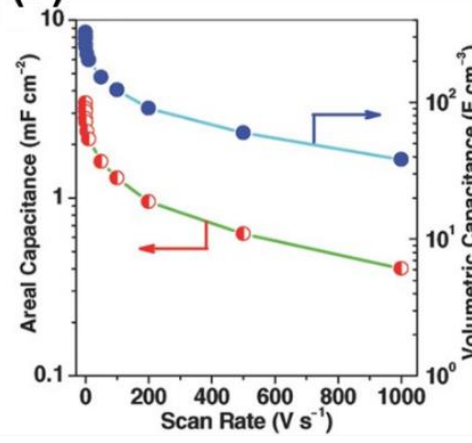

(c)

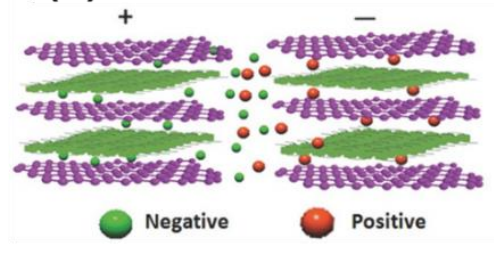

(f)

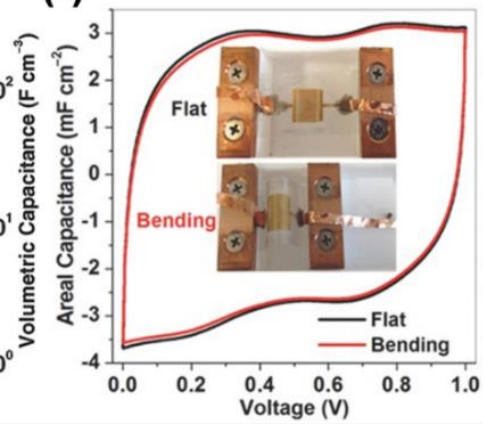

Fig. 10. FPMSCs based on stacked-layer 2D thiophene nanosheets and graphene heterostructure film as microelectrodes. (a) Schematic of the planar FPMSCs in top view. (b) 
SEM image of the freestanding thiophene/graphene heterostructure film (Top-left inset is the as-prepared film on PET substrate and the bottom-right one is the scheme of the heterostructure film). (c) In-plane geometry of thiophene/graphene-FPMSCs in a charging state. (d) CV curves of thiophene/graphene-FPMSCs at varied scan rates. (e) Areal and volumetric capacitances of thiophene/graphene-FPMSCs as a function of scan rate. (f) CV curves of thiophene/grapheneFPMSCs at $1 \mathrm{~V} \mathrm{~s}^{-1}$ under flat and bending state. The inset shows the photographs of thiophene/graphene-FPMSCs under flat and bending states. Reproduced with permission from Ref. [202]. Copyright 2017, Wiley-VCH.

\subsection{Printing technologies}

Printing technologies (inkjet printing, screen printing, extrusion printing, gravure printing, 3D printing, etc.) are promising for fabricating interdigital microelectrode arrays by direct ink writing $[32,247-250]$. These technologies are material- and time-saving, inexpensive, and upscalable. Specifically, commercially available inkjet printers offer precise control of nanostructures (width, thickness, distance, and porosity) through the ejection of ink droplets from nozzles to various substrates [164, 210, 251-261]. In 2016, using a commercial desktop inkjet printer, Choi et al. [252] demonstrated a new class of solid-state FPMSCs, which were directly fabricated on conventional A4 paper (Fig. 11a). First, cellulose nanofibril (CNF)mediated nanoporous mats were inkjet-printed on the surface of paper as a primer layer to enable high-resolution images. Then, interwelded $\mathrm{AgNW}$ networks were introduced to improve the electrical conductivity of the resultant electrodes. FPMSCs were assembled with AC/CNTs as the electrode material and an ionic liquid/ultraviolet-cured triacrylate polymer-based solidstate electrolyte. Finally, the device was sealed with a polypropylene-based adhesive film. To assess the flexibility of the printed FPMSCs, repeated bending deformation (bending radius = $2.5 \mathrm{~mm}$ ) was performed along with CV tests. As displayed in Fig. 11b, the FPMSCs retained their structural integrity without capacitance decay after 1000 bending cycles. Interestingly, the 
FPMSCs with various geometries can be also fabricated through the inkjet printing process. The letter-shaped and symbol-like FPMSCs (marked by a red box in Fig. 11c and d) were inkjet-printed and then seamlessly connected with the inkjet-printed electrical circuit, eventually powering a LED lamp. Notably, upon being placed on a hot plate (set at $150{ }^{\circ} \mathrm{C}$ ) for $0.5 \mathrm{~h}$, the inkjet-printed FPMSC could light up the LED lamp without any volumetric swelling (inset of Fig. 11d), suggesting the high thermal stability of the device.

Similarly, our group prepared graphene-based ink $\left(0.8 \mathrm{mg} \mathrm{mL}^{-1}\right)$ and printed FPMSCs on paper and ultrathin PET substrates with commercial inkjet printer [164]. Later in 2017, our group achieved scalable production of graphene-based FPMSCs on various substrates by employing a full-inkjet-printing technique [262]. High-concentration electrochemically exfoliated graphene (EG) inks were formulated to efficiently print thick EG films. Due to the high electrical conductivity, the printed EG served as both the electrodes and current collectors. More importantly, poly(4-styrenesulfonic acid) (PSSH) ink acting as a solid-state electrolyte was directly printed on the surface of EG interdigital electrode. The PSSH inks remained chemically stable for a long period even without packaging (Fig. 11e). As displayed in Fig. 11f, the EG-based FPMSCs fabricated by full-inkjet-printing technique exhibited an areal capacitance of $\sim 0.7 \mathrm{mF} \mathrm{cm}^{-2}$. The simplicity of the whole fabrication process makes FPMSCs potentially easy and efficient to integrate the array in arbitrary connections at any scale. Notably, large-scale FPMSC arrays consisting of more than 100 devices were manufactured on a rigid $\mathrm{Si} / \mathrm{SiO}_{2}$ wafer and a flexible Kapton substrate (Fig. 11g). The CV curves showed that the FPMSC arrays could reach over $10 \mathrm{~V}$ and deliver approximately two times higher power density than the individual device (Fig. 11h). Thus, the relatively mature printing technology and commercially available printers make inkjet printing promising for up-scalable FPMSCs with potential industrial scale. As an important component of printers, a good ink for printable FPMSCs should possess proper fluidic properties, especially viscosity and surface tension [263- 
265]. Therefore, it is highly desirable to formulate printable inks with suitable fluidic properties at high concentrations and without flake aggregation and toxicity.
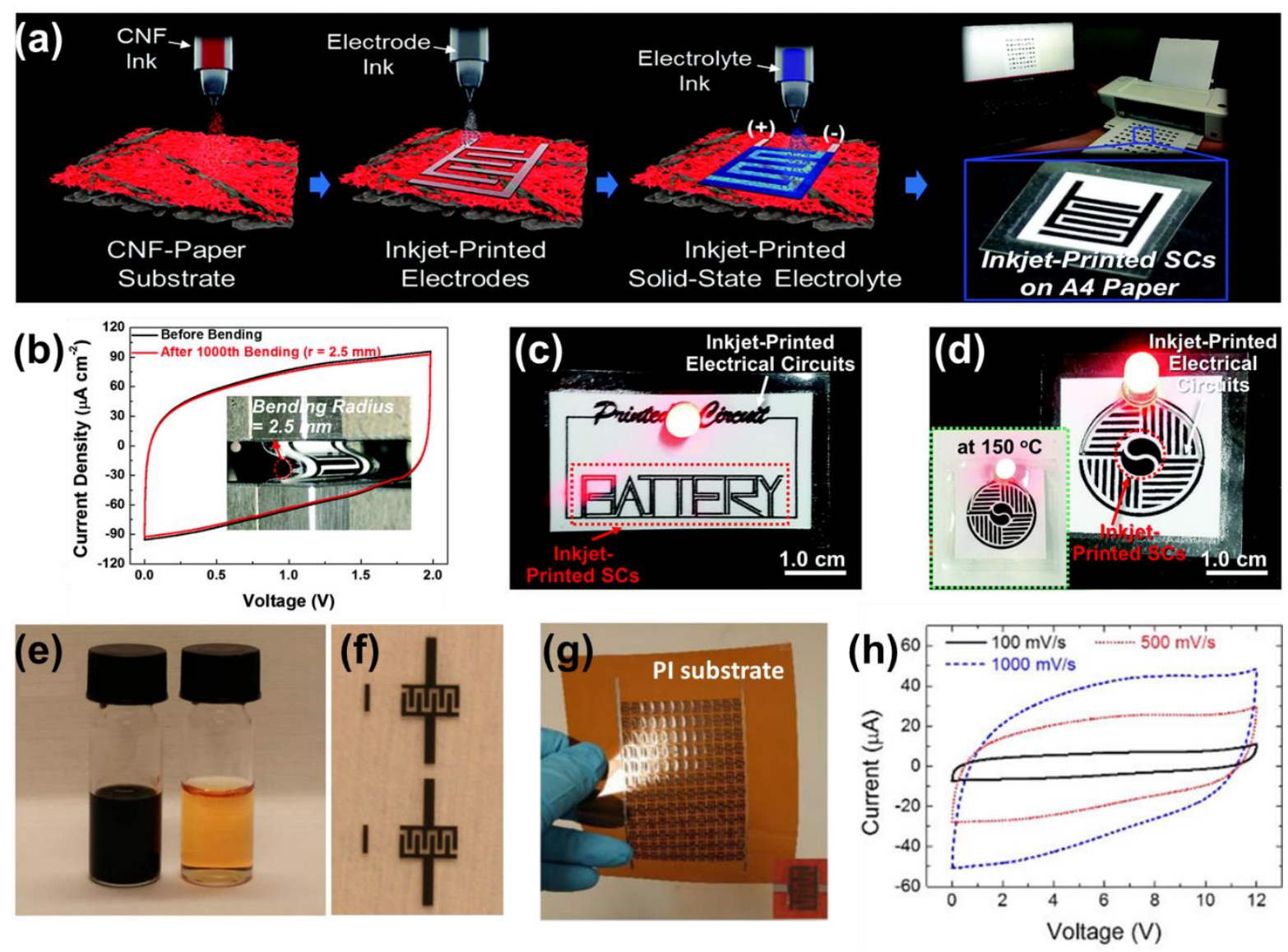

Fig. 11. All-inkjet-printed FPMSCs. (a) Schematic of the stepwise fabrication procedure of the inkjet-printed FPMSCs, and a photograph of the used desktop inkjet printer. (b) CV curves at a scan rate of $1 \mathrm{mV} \mathrm{s}^{-1}$ after repeated 1000 bending cycles (bending radius $=2.5 \mathrm{~mm}$ ). The inset shows the deformed state of the inkjet-printed FPMSC. (c) Photograph of the inkjet-printed, letter ("BATTERY")-shaped FPMSC (marked by a red box) that was seamlessly connected with the inkjet-printed electrical circuits and a LED lamp. (d) Photograph of the inkjet-printed, traditional Korean “Taegeuk” symbol-like FPMSC (marked by a red circle) that was seamlessly connected with the inkjet-printed electrical circuits and a LED lamp. The inset is a photograph of the FPMSC after being placed on a hot plate $\left(150{ }^{\circ} \mathrm{C}\right)$ for $0.5 \mathrm{~h}$. Reproduced with permission from Ref. [252]. Copyright 2016, Royal Society of Chemistry. (e) Photographs of EG ink (black) and PSSH ink (orange) for printing the electrodes and electrolyte, respectively. (f) 
Photograph of two fully printed MSCs on a glass slide substrate. (g) Photograph of a 12 in series $\times 12$ in parallel FPMSC array on Kapton. (h) CV curves of the FPMSC array at various scan rates with reaching $12 \mathrm{~V}$ (The data was measured one month after the fabrication). Reproduced with permission from Ref. [262]. Copyright 2017, American Chemical Society.

Screen printing is a mature printing technique that uses a woven mesh to obtain a desired shape, which is simple, rapid, and cost-effective for scalable production [102, 114, 260, 266271]. During the screen-printing process, inks containing various nanomaterials can be pressed through the opening of the mesh to form the designed pattern on various flexible substrates, such as plastic, cloth and paper. Most recently, Shi et al. [271] prepared a highly stable and conductive ink by mixing high-quality graphene, conducting carbon black and poly(vinyl chloride-co-vinyl acetate) binder in dimethyl mixed dibasic acid ester solvent. The resulted ink showed outstanding shear-thinning behavior, enabling the extrusion of the ink through screen meshes under shear force and its quick solidification. As illustrated in Fig. 12a, the fabrication of screen-printed graphene-based integrated MSCs (denoted as SPG-IMSCs) is highly scalable with excellent flexibility, diverse sizes, and complex planar geometries. In order to highlight the excellent modularization of the printed SPG-IMSCs, the large-scale FPMSC arrays on flexible PET substrate with connected units in series and parallel were constructed as the demonstrations shown in Fig. 12b and c. Remarkably, Fig. 12d indicates that the modular SPGIMSCs can stably output an ultra-high voltage of $104 \mathrm{~V}$. However, the use of additional organic binders or additives in the ink decreases the electrochemical performance. Very recently, Li et al. [268] formulated binder-free hydrous $\mathrm{RuO}_{2}$-decorated MXene and $\mathrm{AgNW}$ hybrid inks for fully-printed FPMSCs (Fig. 12e). The screen-printing ink with high elasticity exhibited a solidlike behavior, beneficial for solidification of the inks during the screen-printing process. Based on the GCD curves, the volumetric capacitance of the fabricated FPMSC on paper was determined to be $267.9 \mathrm{~F} \mathrm{~cm}^{-3}$ at a current density of $0.1 \mathrm{~mA} \mathrm{~cm}^{-2}$ (Fig. 12f). 
As the derivative of screen printing, gravure printing is emerging due to its low production cost, high output, controllable size, and ability to use various potential inks [255, 272-274]. Various stamps with desired configurations can be easily designed and fabricated. Then, the prepared ink is brushed onto the surface of the stamp, and firmly pressed onto the substrates. Finally, the gel electrolyte is casted and dried naturally at room temperature to form solid-state gravure-printed MSCs. For example, Zhang et al. [273] stamped all-MXene FPMSCs with desired configurations (Fig. 12g). By optimizing the finger numbers as well as the finger gaps, the areal capacitance of the printed FPMSCs can reach $57 \mathrm{mF} \mathrm{cm}^{-2}$ at $5 \mathrm{mV} \mathrm{s}^{-1}$, as shown in Fig. 12h. Furthermore, Fig. 12i demonstrates the scalable production of the MXene-based FPMSCs in minutes by using either pad or cylindrical stamps. However, gravure printing suffers from the difficulty to realize the high-resolution finger gap, leading to the easy short circuit.

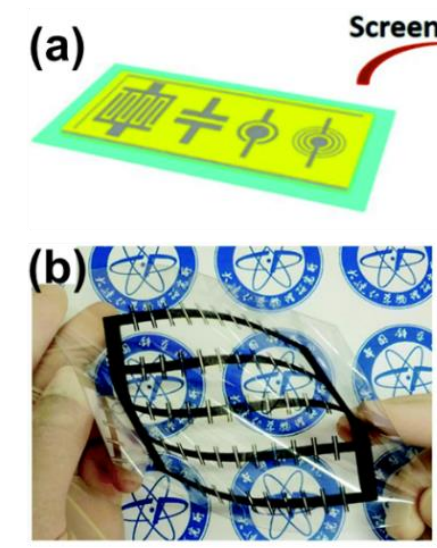

(e)
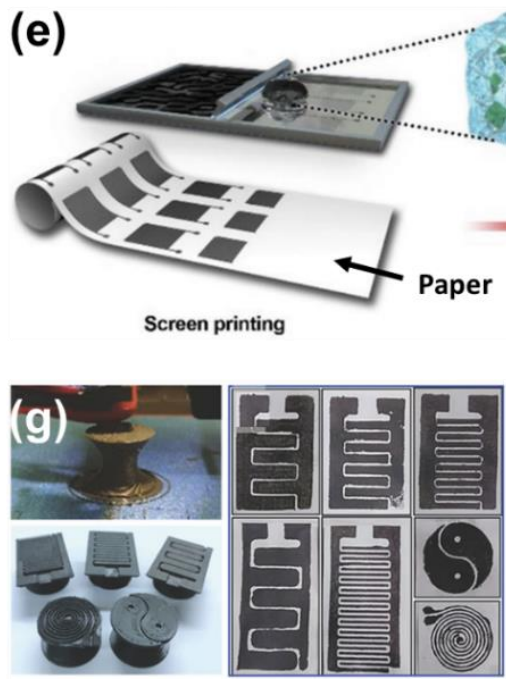
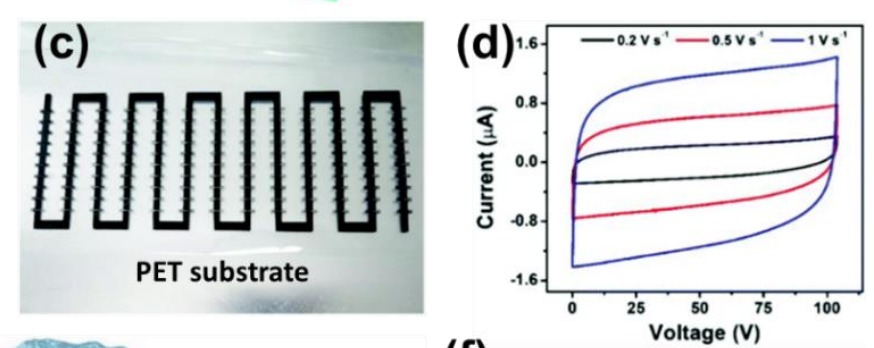

(f)
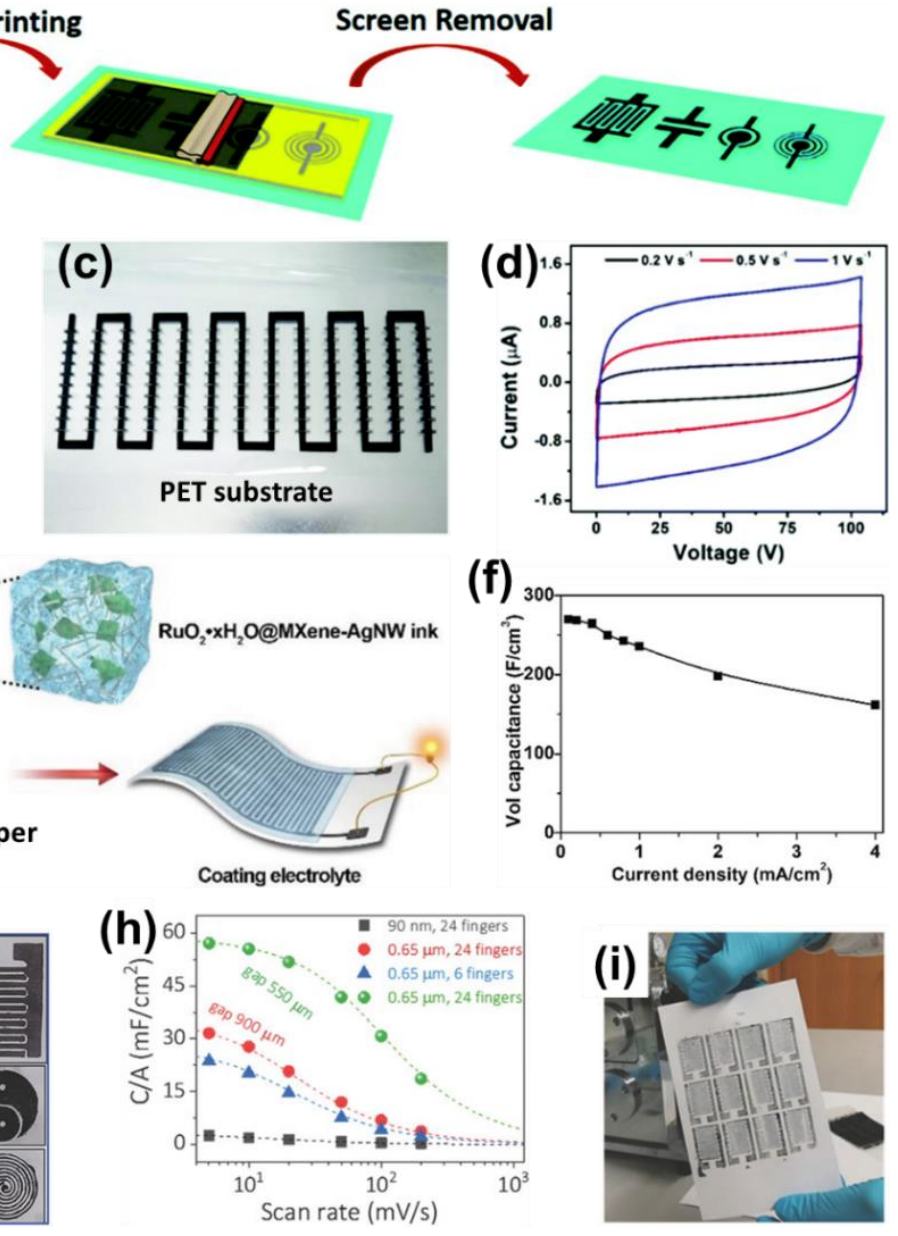

Fig. 12. FPMSCs via screen printing and gravure printing. (a) Schematic of the fabrication process of SPG-IMSCs with diverse planar geometries. (b) Photograph of SPG-IMSCs (10S $\times$ 
5P). (c) Photograph of a tandem SPG-IMSC consisting of 130 serially-connected units. (d) CV curves of the tandem SPG-IMSC measured at scan rates from 0.2 to $1 \mathrm{~V} \mathrm{~s}^{-1}$. Reproduced with permission from Ref. [271]. Copyright 2019, Royal Society of Chemistry. (e) Schematic of the fabrication process for screen-printed FPMSC. (f) Volumetric capacitance obtained at different current densities. Reproduced with permission from Ref. [268]. Copyright 2019, Wiley-VCH. (g) Photographs of 3D printer in operation, the as-printed stamps, and as-stamped MXene FPMSCs with various architectures. (h) Areal capacitances of MXene FPMSCs with various configurations. (i) Scalable production of MXene FPMSCs by rolling. Reproduced with permission from Ref. [273]. Copyright 2018, Wiley-VCH.

As another type of printing technologies, extrusion printing is conducted by extruding active material ink through a nozzle, which is featured with simplicity, high speed, and up-scalability for fabricating MSCs with patterned geometries [247, 275, 276]. It requires inks with good stability, high viscosity, and homogeneous dispersion of active materials. In 2018, Liu et al. [275] demonstrated extrusion-printed symmetric FPMSCs based on aqueous-based GO/PANIPEDOT:PSS (GO/PA-PE) inks with suitable rheological properties (Fig. 13a). The interdigital electrode thickness can be controlled by repetitive layer-by-layer printing. As shown in Fig. 13b, the areal capacitance of the printed FPMSC increased from 17.5 to $153.6 \mathrm{mF} \mathrm{cm}^{-2}$ along with the increase of the printed layers from 2 to 20 , indicating the good ion accessibility of the printed electrodes. Furthermore, flexible AMSCs were also made with GO/PA-PE cathodes and rGO-PEDOT:PSS anodes by using two print-heads (Fig. 13c). Later, Zhang et al. [276] reported additive-free MXene aqueous ink with a high concentration of $\sim 36 \mathrm{mg} \mathrm{mL}^{-1}$ and a high viscosity of $\sim 0.71 \mathrm{~Pa} \cdot \mathrm{s}$ (Fig. 13d). All-MXene FPMSCs were extrusion-printed on paper substrates using a 3D printer. Fig. 13e exhibited the pseudo-capacitive and high rate behavior of the device (line gap $\sim 89 \mu \mathrm{m}$, finger number $<\mathrm{N}>=3$ ) in $\mathrm{PVA} / \mathrm{H}_{2} \mathrm{SO}_{4}$ gel electrolyte. Generally, increasing the number of interdigital fingers $(<\mathrm{N}\rangle)$ results in an enhancement of 
areal capacitance. For instance, the normalized areal capacitance improved from 3.5 to $43 \mathrm{mF}$ $\mathrm{cm}^{-2}$ upon printing the MXene ink from $\langle\mathrm{N}\rangle=1$ to 5 (Fig. 13f).

(a)

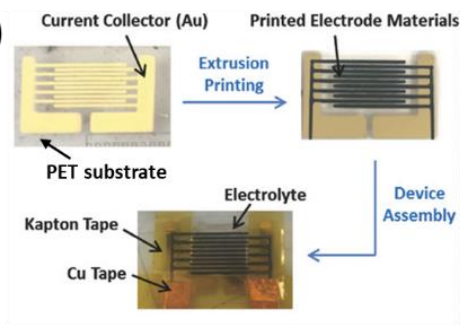

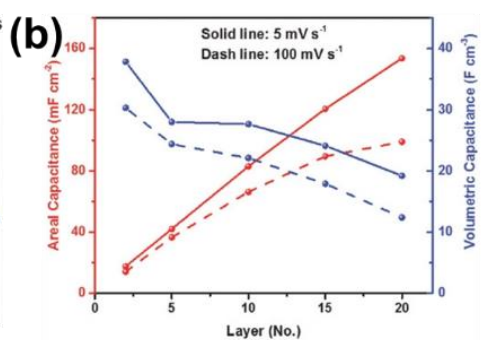

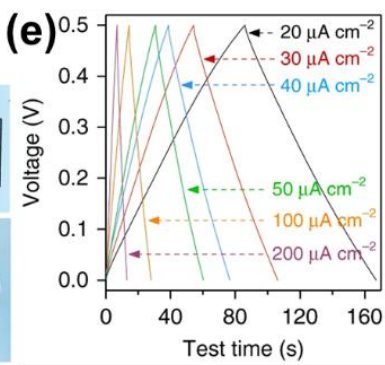

(c) Asymmetric Design

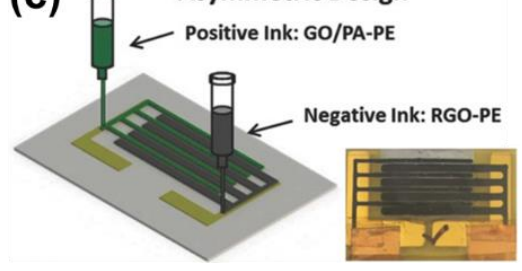

Fig. 13. FPMSCs with extrusion printing. (a) Schematic illustration of the fabrication process of FPMSCs on a PET substrate using extrusion printing technique. (b) Areal and volumetric capacitances of FPMSCs with different printing layers. (c) Schematic illustration and digital photograph of extrusion printed asymmetric FPMSC. Reproduced with permission from Ref. [275]. Copyright 2018, Wiley-VCH. (d) Photographs of MXene aqueous ink, showing its viscous nature; Extrusion-printed tandem devices (two FPMSCs in serial and two in parallel) on a paper substrate (left panel), showing a great flexibility (right panel). (e) GCD curves of a typical extrusion-printed FPMSC (line gap $\sim 89 \mu \mathrm{m},<\mathrm{N}>=3$ ). (f) Areal capacitances of inkjetand extrusion-printed FPMSCs with different $\langle\mathrm{N}\rangle$. Reproduced with permission from Ref. [276]. Copyright 2019, Nature Publishing Group.

Extrusion-based 3D printing has recently attracted wide interests in the fabrication of MSCs, owing to its capability of providing precise control of geometries, allowing up-scalable production, and offering a convenient strategy for the asymmetric electrode design [277-287]. The viscous inks were extruded through nozzle and directly printed on the substrate layer by layer in the vertical dimension [288-290]. It is critical to develop suitable inks with high 
viscosities and shear-thinning rheological properties. For example, highly concentrated GO aqueous inks show gel-like behavior with a high viscosity, making them suitable for printing fine filaments and complex 3D architectures. In 2015, a 3D-printed MSC was firstly realized by patterning concentrated GO ink $\left(\sim 20 \mathrm{mg} \mathrm{mL}^{-1}\right)$ on a temperature-controlled substrate holder $\left(100{ }^{\circ} \mathrm{C}\right)$ [278]. Afterwards, the electrodes were printed layer-by-layer to the desired thickness (one layer thickness: $\sim 1 \mu \mathrm{m}$ ). Finally, 3D interdigital electrodes were chemically reduced into rGO by using $\mathrm{HI}$, followed by the coating of PVA/ $\mathrm{H}_{2} \mathrm{SO}_{4}$ gel electrolyte (Fig. 14a). The CV curves with bending test of 3D MSC on a PET substrate shows no obvious change, highlighting the high mechanical robustness and flexibility, as well as electrochemical stability (Fig. 14b). However, as presented in Fig. 14c, the 3D MSC showed a large capacitance decay of about $50 \%$ after 10000 charge/discharge cycles, which may be due to the poor mass transfer in the thick dense electrodes. Later in 2017, Li et al. [282] optimized the production process of 3Dprinted graphene-based MSCs with freeze drying method. A honeycomb porous structure was formed (Fig. 14d-g). Fig. 14h presents a photo of $3 \times 3$ MSC arrays, implying the potential of this technique in a large area and scale-up production. Considering the possible clogging of the nozzles and structural integrity of the printed active materials, the optimization of the component and rheology of the inks is of great importance for extrusion-type 3D printing. To date, it remains at the initial stage for the $3 \mathrm{D}$ printed devices with high charge storage performance. 

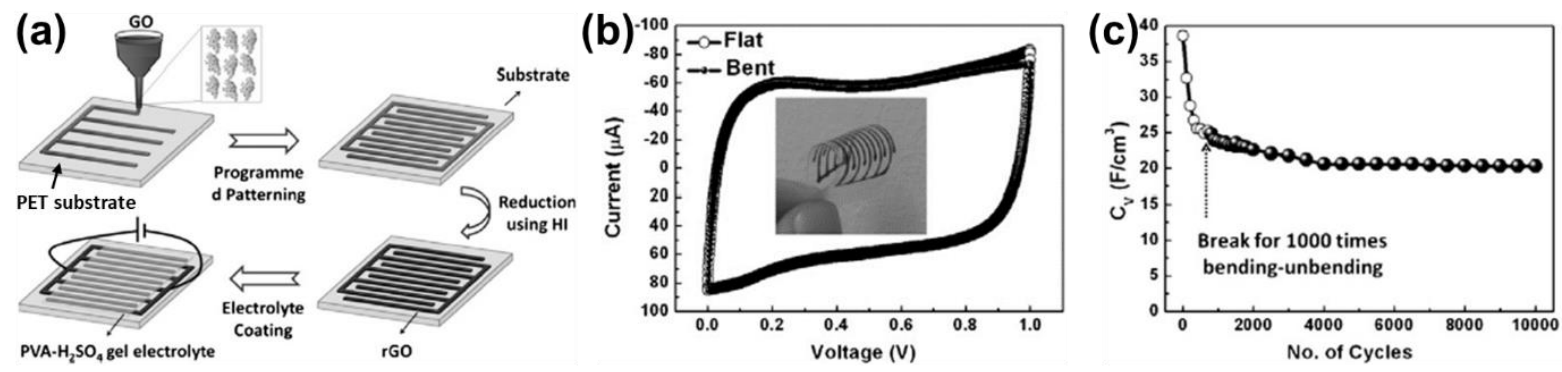

(d)

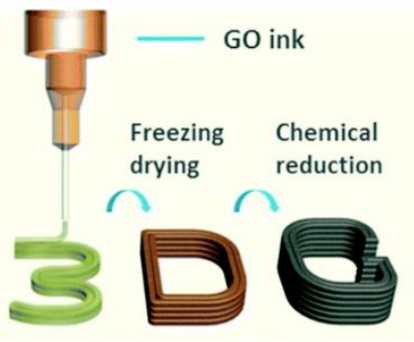

(g)

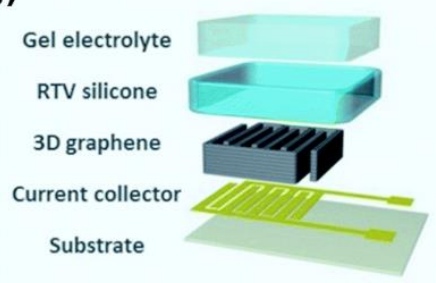

(e)

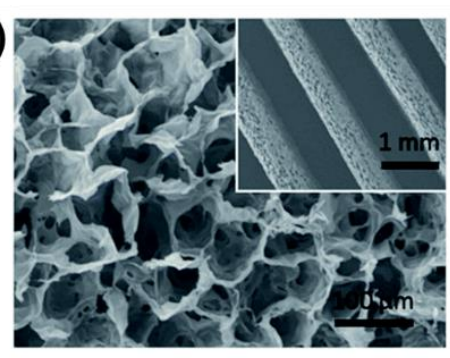

(f)

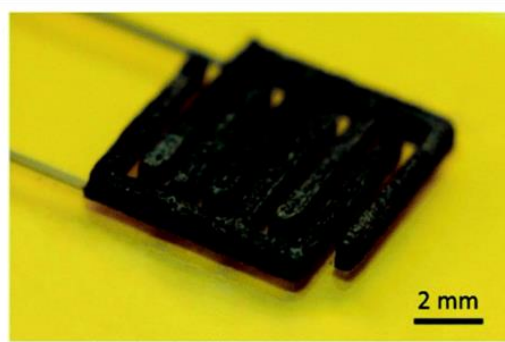

(h)
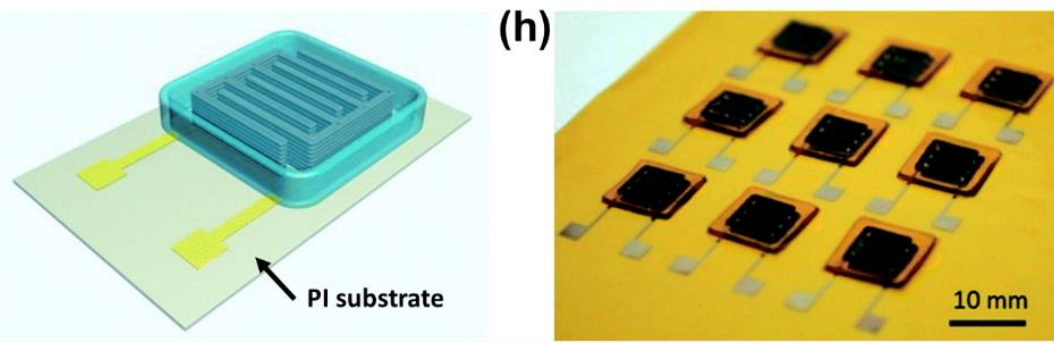

Fig. 14. 3D-printed MSCs. (a) Schematic illustration of device fabrication. (b) CV curves of PMSC at flat or bent states. The inset shows the photograph of a bent MSC device on a PET substrate. Each rGO finger is $1.5 \mathrm{~cm}$ long and $650 \mu \mathrm{m}$ wide. (c) Dependence of volumetric capacitance on GCD cycle numbers. The solid cycles represent the measurements after the device undertaking 1000 times of bending-unbending. Reproduced with permission from Ref. [278]. Copyright 2015, Elsevier Ltd. (d) Direct-ink writing of the 3D graphene architecture with GO ink. (e) SEM images of the macroporous structure. (f) Photograph of the 3D interdigitated architecture. (g) Construction of the quasi-solid-state MSCs. (h) Photograph of the large area MSCs in a $3 \times 3$ array. Reproduced with permission from Ref. [282]. Copyright 2017, Royal Society of Chemistry.

Overall, the fabrication of FPMSCs relies on single of or the combination of the abovementioned microfabrication technologies. Table 2 summarizes recent progresses in FPMSCs in recent years. Notably, in miniaturized electronics, volumetric energy and power densities 
seem to be less important than areal ones. However, thin-film MSCs have relatively low areal energy densities owing to the limited electrode thicknesses, which cannot meet the increasing energy demands of next-generation electronic devices. For further enhancing the areal performance of FPMSCs, 3D design of the MSC components in the out-of-plane dimension are highly desired.

Table 2. Comparison of electrochemical performances of typical FPMSCs reported in recent years.

\begin{tabular}{|c|c|c|c|c|c|c|c|c|c|c|c|}
\hline $\operatorname{MSC}(-) / /(+)$ & $\begin{array}{l}\text { Main } \\
\text { techniqu } \\
\text { es }\end{array}$ & $\begin{array}{l}\text { Electr } \\
\text { olyte }\end{array}$ & $\begin{array}{l}\text { Voltage } \\
\text { windo } \\
\text { w/V }\end{array}$ & $\begin{array}{l}\text { Areal } \\
\text { capaci } \\
\text { tance/ } \\
\mathbf{m F} \\
\mathrm{cm}^{-2}\end{array}$ & $\begin{array}{l}\text { Volum } \\
\text { etric } \\
\text { capaci } \\
\text { tance/ } \\
\text { F cm } \\
\end{array}$ & $\begin{array}{l}\text { Energy } \\
\text { density }\end{array}$ & $\begin{array}{l}\text { Power } \\
\text { density }\end{array}$ & $\begin{array}{l}\text { Substr } \\
\text { ate }\end{array}$ & $\begin{array}{l}\text { Flexibil } \\
\text { ity }\end{array}$ & $\begin{array}{l}\text { Cycling } \\
\text { stability }\end{array}$ & Ref. \\
\hline $\begin{array}{l}\text { LSG//LSG- } \\
\mathrm{MnO}_{2}\end{array}$ & $\begin{array}{l}\text { Laser } \\
\text { scribing }\end{array}$ & $\begin{array}{l}1 \quad \mathrm{M} \\
\mathrm{Na}_{2} \mathrm{~S} \\
\mathrm{O}_{4}\end{array}$ & $0-2.0$ & 400 & 76 & $42 \mathrm{mWh} \mathrm{cm}^{-3}$ & $10 \mathrm{~W} \mathrm{~cm}^{-3}$ & PI & $\begin{array}{l}1000 \\
(97.2 \%)\end{array}$ & $\begin{array}{l}10000 \\
(96 \%)\end{array}$ & [126] \\
\hline $\mathrm{PPy} / / \mathrm{MnO}_{2}$ & $\begin{array}{l}\text { Depositi } \\
\text { on }\end{array}$ & $\begin{array}{l}1 \quad \mathrm{M} \\
\mathrm{Na}_{2} \mathrm{~S} \\
\mathrm{O}_{4}\end{array}$ & $0-1.5$ & 25.8 & - & ${ }_{2}^{8.05} \mu \mathrm{Wh} \mathrm{cm}^{-}$ & $\begin{array}{l}7.32 \mathrm{~mW} \\
\mathrm{~cm}^{-2}\end{array}$ & $\begin{array}{l}\text { cellulos } \\
\text { e paper }\end{array}$ & $\begin{array}{l}10000 \\
(98.3 \%)\end{array}$ & $\begin{array}{l}60000 \\
(100 \%)\end{array}$ & [87] \\
\hline $\begin{array}{l}\mathrm{rGO} / / \mathrm{rGO}- \\
\mathrm{Mn}_{3} \mathrm{O}_{4}\end{array}$ & $\begin{array}{l}\text { LBL } \\
\text { assembly }\end{array}$ & $\begin{array}{l}\text { PVA/ } \\
\mathrm{LiCl}\end{array}$ & $0-1.6$ & $66 \mathrm{~F} \mathrm{~g}^{-1}$ & - & $23.5 \mathrm{Wh} \mathrm{kg}^{-1}$ & $\begin{array}{ll}21.3 & \mathrm{~kW} \\
\mathrm{~kg}^{-1} & \end{array}$ & PET & $\begin{array}{l}3000 \\
(100 \%)\end{array}$ & $\begin{array}{l}3000 \\
(94 \%)\end{array}$ & [212] \\
\hline 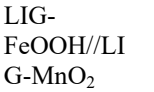 & $\begin{array}{l}\text { Laser } \\
\text { inductio } \\
\mathrm{n}\end{array}$ & $\begin{array}{l}\text { PVA/ } \\
\mathrm{LiCl}\end{array}$ & $0-1.8$ & 21.9 & 5.4 & $9.6 \mu \mathrm{Wh} \mathrm{cm}-2$ & $\begin{array}{l}11.85 \mathrm{~mW} \\
\mathrm{~cm}^{-2}\end{array}$ & PI & $\begin{array}{l}10000 \\
(90 \%)\end{array}$ & $\begin{array}{l}2000 \\
(84 \%)\end{array}$ & [239] \\
\hline $\mathrm{MnO}_{2} / / \mathrm{MnO}$ & $\begin{array}{l}\text { Depositi } \\
\text { on }\end{array}$ & $\begin{array}{l}\text { PVA/ } \\
\text { LiClO }\end{array}$ & $0-0.8$ & 11.9 & 75.5 & ${ }_{2}^{1.07 \mu \mathrm{Wh} \mathrm{cm}^{-}}$ & $\begin{array}{l}0.1 \mathrm{~mW} \\
\mathrm{~cm}^{-2}\end{array}$ & PET & $\begin{array}{l}4 \\
(100 \%)\end{array}$ & $\begin{array}{l}1000 \\
(67.9 \%)\end{array}$ & [152] \\
\hline $\begin{array}{l}\mathrm{PEDOT} / / \mathrm{PE} \\
\mathrm{DOT}\end{array}$ & $\begin{array}{l}\text { Depositi } \\
\text { on }\end{array}$ & $\begin{array}{l}4 \\
\mathrm{PVA} / \\
\mathrm{H}_{2} \mathrm{SO}_{4}\end{array}$ & $0-0.8$ & 9 & 37 & - & - & $\begin{array}{l}\text { polyeht } \\
\text { ylenena } \\
\text { phthalat } \\
\text { e }\end{array}$ & $\begin{array}{l}1000 \\
(99 \%)\end{array}$ & $\begin{array}{l}10000 \\
(80 \%)\end{array}$ & [155] \\
\hline $\begin{array}{l}\mathrm{CNF} / / \mathrm{NiCO}_{2} \\
\mathrm{~S}_{4}\end{array}$ & $\begin{array}{l}\text { Laser } \\
\text { engravin } \\
\mathrm{g}\end{array}$ & $\begin{array}{l}\mathrm{PVA} / \\
\mathrm{KOH}\end{array}$ & $0-1.6$ & $\begin{array}{l}240 \\
\mu \mathrm{Ah} \\
\mathrm{cm}^{-2}\end{array}$ & - & $200 \mu \mathrm{Wh} \mathrm{cm}{ }^{-2}$ & $\begin{array}{l}45 \\
\mathrm{~cm}^{-2}\end{array}$ & PDMS & - & $\begin{array}{l}10000 \\
(89 \%)\end{array}$ & [243] \\
\hline $\begin{array}{l}\text { MXene- } \\
\text { PEDOT//Mn } \\
\mathrm{O}_{2}\end{array}$ & $\begin{array}{l}\text { Depositi } \\
\text { on }\end{array}$ & $\begin{array}{l}\text { PVA/ } \\
\mathrm{LiCl}\end{array}$ & $0-1.6$ & 69.5 & 636.9 & $\begin{array}{l}250.1 \quad \mathrm{mWh} \\
\mathrm{cm}^{-3}\end{array}$ & $\begin{array}{l}32.9 \\
\mathrm{~cm}^{-3}\end{array}$ & - & $\begin{array}{l}4 \\
(100 \%)\end{array}$ & $\begin{array}{l}10000 \\
(92 \%)\end{array}$ & [291] \\
\hline $\begin{array}{l}\text { EG- } \\
\text { PANI//EG- } \\
\text { PANI }\end{array}$ & $\begin{array}{l}\text { Vacuum } \\
\text { filtration }\end{array}$ & $\begin{array}{l}\mathrm{PVA} / \\
\mathrm{H}_{2} \mathrm{SO}_{4}\end{array}$ & $0-1.0$ & 368 & 736 & $\begin{array}{l}21.1 \\
\mathrm{~cm}^{-3}\end{array}$ & $\begin{array}{l}10650 \\
\mathrm{~mW} \mathrm{~cm}\end{array}$ & PET & $\begin{array}{l}1000 \\
(92.6 \%)\end{array}$ & $\begin{array}{l}5000 \\
(86.6 \%)\end{array}$ & [190] \\
\hline $\mathrm{VN} / / \mathrm{MnO}_{2}$ & $\begin{array}{l}\text { Vacuum } \\
\text { filtration }\end{array}$ & $\begin{array}{l}\mathrm{SiO}_{2-} \\
\mathrm{LiTFS} \\
\mathrm{I}\end{array}$ & $0-2.0$ & 16.1 & 38.8 & $9.0 \mu \mathrm{Wh} \mathrm{cm}-2$ & $\begin{array}{l}21.6 \mathrm{mWh} \\
\mathrm{cm}^{-3}\end{array}$ & $\begin{array}{l}\text { nylon } \\
\text { membra } \\
\text { ne }\end{array}$ & $\begin{array}{l}4 \\
(100 \%)\end{array}$ & $\begin{array}{l}5000 \\
(90 \%)\end{array}$ & [192] \\
\hline $\begin{array}{l}\mathrm{Li}_{4} \mathrm{Ti}_{5} \mathrm{O}_{12} / / \mathrm{a} \\
\text { ctivated } \\
\text { graphene }\end{array}$ & $\begin{array}{l}\text { Vacuum } \\
\text { filtration }\end{array}$ & $\begin{array}{l}\text { LiTFS } \\
\text { I- } \\
\text { P }_{14} \mathrm{TF} \\
\text { SI- } \\
\text { PVDF } \\
\text {-HFP }\end{array}$ & $0-3.0$ & 27.8 & 42.8 & $\begin{array}{lll}53.5 & \mathrm{~mW} & \mathrm{~h} \\
\mathrm{~cm}^{-3} & & \end{array}$ & $\begin{array}{l}4.6 \mathrm{~W} \mathrm{~cm}^{-} \\
3\end{array}$ & $\begin{array}{l}\text { nylon } \\
\text { membra } \\
\text { ne }\end{array}$ & $\begin{array}{l}1000 \\
(100 \%)\end{array}$ & $\begin{array}{l}6000 \\
(98.9 \%)\end{array}$ & [194] \\
\hline $\begin{array}{l}\mathrm{rGO} / \mathrm{Fe}_{2} \mathrm{O}_{3} / / \\
\mathrm{rGO} / \mathrm{Fe}_{2} \mathrm{O}_{3}\end{array}$ & $\begin{array}{l}\text { Spin } \\
\text { coating }\end{array}$ & $\begin{array}{l}\text { PVA/ } \\
\text { KOH }\end{array}$ & $0-1.0$ & 0.347 & 11.57 & $\begin{array}{l}1.61 \\
\mathrm{~cm}^{-3}\end{array} \quad \mathrm{mWh}$ & $\begin{array}{l}9.82 \\
\mathrm{~cm}^{-3}\end{array}$ & PET & $\begin{array}{l}2000 \\
(96.6 \%)\end{array}$ & $\begin{array}{l}32000 \\
(92.08 \% \\
)\end{array}$ & {$[68]$} \\
\hline $\begin{array}{l}\mathrm{CH}_{4} \text {-reduced } \\
\text { graphene//C } \\
\mathrm{H}_{4} \text {-reduced } \\
\text { graphene }\end{array}$ & $\begin{array}{l}\text { Plasma } \\
\text { etching }\end{array}$ & $\begin{array}{l}\mathrm{PVA} / \\
\mathrm{H}_{2} \mathrm{SO}_{4}\end{array}$ & $0-1.0$ & 0.079 & 17.5 & $2.5 \mathrm{mWh} \mathrm{cm}^{-3}$ & $\begin{array}{l}495 \\
\mathrm{~cm}^{-3}\end{array}$ & PET & - & $\begin{array}{l}100000 \\
(99.1 \%)\end{array}$ & [123] \\
\hline $\begin{array}{l}\text { MXene//MX } \\
\text { ene }\end{array}$ & $\begin{array}{l}\text { Spray } \\
\text { coating }\end{array}$ & $\begin{array}{l}\mathrm{PVA} / \\
\mathrm{H}_{3} \mathrm{PO}_{4}\end{array}$ & $0-0.6$ & 23 & - & $2.8 \mathrm{mWh} \mathrm{cm}^{-3}$ & $\begin{array}{l}744 \mathrm{~mW} \\
\mathrm{~cm}^{-3}\end{array}$ & PET & $\begin{array}{l}4 \\
(100 \%)\end{array}$ & $\begin{array}{l}10000 \\
(76 \%)\end{array}$ & [104] \\
\hline $\begin{array}{l}\text { SWCNTs//S } \\
\text { WCNTs }\end{array}$ & $\begin{array}{l}\text { Spray } \\
\text { coating }\end{array}$ & $\begin{array}{l}\mathrm{PVA} / \\
\mathrm{H}_{3} \mathrm{PO}_{4}\end{array}$ & $0-1.0$ & 0.52 & 1.86 & $\begin{array}{l}0.17 \\
\mathrm{~cm}^{-3}\end{array} \quad \mathrm{mWh}$ & $40 \mathrm{~W} \mathrm{~cm}^{-3}$ & PI & $\begin{array}{l}4 \\
(100 \%)\end{array}$ & $\begin{array}{l}10000 \\
(90 \%)\end{array}$ & [163] \\
\hline $\begin{array}{l}\text { ZIF- } \\
\mathrm{C} / / \mathrm{NiCoP} @ \\
\mathrm{NiOOH}\end{array}$ & $\begin{array}{l}\text { Screen } \\
\text { printing }\end{array}$ & $\begin{array}{l}\mathrm{PVA} / \\
\mathrm{KOH}\end{array}$ & $0-1.4$ & 54.7 & - & ${ }_{2}^{13.9} \mu \mathrm{Wh} \mathrm{cm}^{-}$ & $\begin{array}{l}270.5 \mu \mathrm{W} \\
\mathrm{cm}^{-2}\end{array}$ & PET & $\begin{array}{l}500 \\
(100 \%)\end{array}$ & $\begin{array}{l}8000 \\
(86 \%)\end{array}$ & [292] \\
\hline $\begin{array}{l}\mathrm{V}_{2} \mathrm{O}_{5^{-}} \\
\mathrm{PANI} / \mathrm{MnO} \\
{ }_{2}-\mathrm{PPy}\end{array}$ & $\begin{array}{l}\text { Depositi } \\
\text { on }\end{array}$ & $\begin{array}{l}\text { PVA/ } \\
\mathrm{LiCl}\end{array}$ & $0-1.6$ & - & - & $\begin{array}{l}19.81 \\
\mathrm{~cm}^{-3}\end{array} \quad \mathrm{mWh}$ & $\begin{array}{l}2.57 \\
\mathrm{~cm}^{-3}\end{array}$ & PI & $\begin{array}{l}3000 \\
(95 \%)\end{array}$ & $\begin{array}{l}7000 \\
(92 \%)\end{array}$ & [264] \\
\hline
\end{tabular}




\begin{tabular}{|c|c|c|c|c|c|c|c|c|c|c|c|}
\hline $\begin{array}{l}\mathrm{Ti}_{3} \mathrm{C}_{2} \mathrm{~T}_{\mathrm{x}} / / \mathrm{Ti}_{3} \\
\mathrm{C}_{2} \mathrm{~T}_{\mathrm{x}}\end{array}$ & $\begin{array}{l}\text { Gravure } \\
\text { printing }\end{array}$ & $\begin{array}{l}\mathrm{PVA} / \\
\mathrm{H}_{2} \mathrm{SO}_{4}\end{array}$ & $0-0.6$ & 56.8 & - & ${ }_{2}^{0.76 \mu \mathrm{Wh} \mathrm{cm}^{-}}$ & $\begin{array}{l}0.33 \mathrm{~mW} \\
\mathrm{~cm}^{-2}\end{array}$ & PET & $\begin{array}{l}1600 \\
(85 \%)\end{array}$ & $\begin{array}{l}10000 \\
(93.7 \%)\end{array}$ & [273] \\
\hline $\begin{array}{l}\mathrm{Ti}_{3} \mathrm{C}_{2} \mathrm{~T}_{\mathrm{x}} / / \mathrm{Co}- \\
\mathrm{Al}-\mathrm{LDH}\end{array}$ & $\begin{array}{l}\text { Screen } \\
\text { printing }\end{array}$ & $\begin{array}{l}\mathrm{PVA} / \\
\mathrm{KOH}\end{array}$ & $\begin{array}{l}0.4- \\
1.45\end{array}$ & 40 & - & ${ }_{2}^{8.84} \mu \mathrm{Wh} \mathrm{cm}^{-}$ & $\begin{array}{l}0.23 \mathrm{~mW} \\
\mathrm{~cm}^{-2}\end{array}$ & PET & $\begin{array}{l}4 \\
(100 \%)\end{array}$ & $\begin{array}{l}10000 \\
(92 \%)\end{array}$ & [270] \\
\hline $\begin{array}{l}\text { rGO- } \\
\text { PEDOT:PSS } \\
\text { //GO-PANI- } \\
\text { PEDOT:PSS }\end{array}$ & $\begin{array}{l}\text { Extrusio } \\
\mathrm{n} \\
\text { printing }\end{array}$ & $\begin{array}{l}\mathrm{PVA} / \\
\mathrm{H}_{3} \mathrm{PO}_{4}\end{array}$ & $0-1.2$ & - & 25 & $\begin{array}{l}4.83 \\
\mathrm{~cm}^{-3}\end{array} \quad \mathrm{mWh}$ & $\begin{array}{l}25.3 \\
\mathrm{~cm}^{-3}\end{array}$ & PET & - & $\begin{array}{l}5000 \\
(100 \%)\end{array}$ & [275] \\
\hline $\begin{array}{l}\text { Graphene//G } \\
\text { raphene }\end{array}$ & $\begin{array}{l}\text { Screen } \\
\text { printing }\end{array}$ & $\begin{array}{l}\mathrm{PVA} / \\
\mathrm{H}_{3} \mathrm{PO}_{4}\end{array}$ & $0-0.8$ & 1 & 2.2 & $\begin{array}{l}1.81 \\
\mathrm{~cm}^{-3}\end{array} \quad \mathrm{mWh}$ & $\begin{array}{l}297 \\
\mathrm{~cm}^{-3}\end{array} \mathrm{~mW}$ & PET & $\begin{array}{l}4 \\
(100 \%)\end{array}$ & $\begin{array}{l}10000 \\
(91.8)\end{array}$ & [271] \\
\hline $\begin{array}{l}\text { Graphene//G } \\
\text { raphene }\end{array}$ & $\begin{array}{l}\text { Inkjet } \\
\text { printing }\end{array}$ & $\begin{array}{l}\mathrm{PVA} / \\
\mathrm{H}_{3} \mathrm{PO}_{4}\end{array}$ & $0-1.0$ & - & 9.3 & $\begin{array}{l}1.29 \\
\mathrm{~cm}^{-3}\end{array} \quad \mathrm{mWh}$ & $\begin{array}{l}278 \\
\mathrm{~cm}^{-3}\end{array}$ & PI & $\begin{array}{l}5000 \\
(100 \%)\end{array}$ & $\begin{array}{l}10000 \\
(100 \%)\end{array}$ & [257] \\
\hline $\mathrm{EG} / / \mathrm{EG}$ & $\begin{array}{l}\text { Inkjet } \\
\text { printing }\end{array}$ & $\begin{array}{l}\text { poly(4 } \\
- \\
\text { styren } \\
\text { esulfo } \\
\text { nic } \\
\text { acid) }\end{array}$ & $0-1.0$ & 0.7 & - & $1 \mathrm{mWh} \mathrm{cm}^{-3}$ & ${ }_{3}^{0.1 \mathrm{~W} \mathrm{~cm}^{-}}$ & PI & - & $\begin{array}{l}11000 \\
(77 \%)\end{array}$ & [262] \\
\hline $\begin{array}{l}\text { MXene//MX } \\
\text { ene }\end{array}$ & $\begin{array}{l}\text { Extrusio } \\
\mathrm{n} \\
\text { printing }\end{array}$ & $\begin{array}{l}\mathrm{PVA} / \\
\mathrm{H}_{2} \mathrm{SO}_{4}\end{array}$ & $0-0.5$ & 43 & - & ${ }_{2}^{0.32} \mu \mathrm{Wh} \mathrm{cm}^{-}$ & $\begin{array}{l}11.4 \\
\mathrm{~cm}^{-2}\end{array} \mu \mathrm{W}$ & paper & $\begin{array}{l}1000 \\
(97 \%)\end{array}$ & $\begin{array}{l}14000 \\
(97 \%)\end{array}$ & [276] \\
\hline $\mathrm{CDC} / / \mathrm{CDC}$ & $\begin{array}{l}\text { Gas } \\
\text { etching }\end{array}$ & $\begin{array}{l}1 \mathrm{M} \\
\mathrm{H}_{2} \mathrm{SO}_{4}\end{array}$ & $0-0.9$ & 240 & 300 & - & - & PET & - & $\begin{array}{l}10000 \\
(100 \%)\end{array}$ & [53] \\
\hline $\mathrm{rGO} / / \mathrm{rGO}$ & $\begin{array}{l}3 \mathrm{D} \\
\text { printing }\end{array}$ & $\begin{array}{l}\mathrm{PVA} / \\
\mathrm{H}_{2} \mathrm{SO}_{4}\end{array}$ & $0-1.0$ & 74.31 & 0.45 & - & - & PI & $\begin{array}{l}200 \\
(97 \%)\end{array}$ & $\begin{array}{l}10000 \\
(100 \%)\end{array}$ & [282] \\
\hline
\end{tabular}

\section{Smart responsive FPMSCs}

The rapid development of science and technology triggers high consumption demands on electronics towards miniaturization, individualization, lightweight, and intelligentization [27, 293-298]. To fulfil the growing demands for smart flexible microelectronics, FPMSCs as the great potential energy power sources are expected not only to provide high performance based on aforementioned microfabrication technologies, but also own the smart functions as functional components. Smart functions, such as self-healing, electrochromism, stretchability, and thermal response, are desirable and promising in FPMSCs. Such smart or stimuliresponsive FPMSCs can response to the changes from either the external environment or devices themselves. Up to now, developing functional electrolyte, functional substrate, and functional electrode are three main approaches to endow FPMSCs with smart functions.

\subsection{Electrochromic FPMSCs}

The electrochromic phenomenon represents reversible color change in the electrochromic materials during electrochemical reduction/oxidation processes. Integrating electrochromism into MSCs can realize the real-time display of charging-discharging status, which enhances the 
user experience and avoids the unexpected overuse or overcharge [27, 28, 299, 300]. In 2017, our group [128] reported the first electrochromic FPMSC with a reversible electrochromic window within $0-1 \mathrm{~V}$. The methyl viologen mixed with $\mathrm{PVA} / \mathrm{LiCl}$ gel was used as the electrolyte for the EG/V $\mathrm{V}_{2} \mathrm{O}_{5}$-based FPMSCs (Fig. 15a). The reversible electrochromic function of the FPMSCs results from the redox reaction between the colorless viologen and the purple radical ion derivative of viologen in the $\mathrm{PVA} / \mathrm{LiCl}$ gel electrolyte (Fig. 15b). The electrochromic FPMSCs exhibited a high volumetric capacitance of $130.7 \mathrm{~F} \mathrm{~cm}^{-3}$ at $10 \mathrm{mV} \mathrm{s}^{-1}$ and a high volumetric energy density of $20 \mathrm{mWh} \mathrm{cm}^{-3}$ at a power density of $235 \mathrm{~W} \mathrm{~cm}^{-3}$, as well as long lifetime up to 6000 cycles. During the charging process, the color of the fabricated FPMSC gradually became deeper, and the deepest purple color was observed when the voltage reached $1 \mathrm{~V}$. During discharge process, the color of FPMSC gradually fade until colorless at 0 $\mathrm{V}$ (Fig. 15c). Accordingly, the EG/ $\mathrm{V}_{2} \mathrm{O}_{5}$-based FPMSC showed in-situ electrochromic phenomenon evidenced by varying UV-vis absorbance at different voltages (Fig. 15d). After 200 cycles, the absorbance of the $\mathrm{EG} / \mathrm{V}_{2} \mathrm{O}_{5}$-based FPMSC remained no obvious change according to the in-situ monitored UV-Vis spectra, suggesting good cycling stability of the electrochromic FPMSCs. Importantly, the electrochromic time of the EG/V ${ }_{2} \mathrm{O}_{5}$-based FPMSC could be adjusted from several minutes to only a few seconds by increasing the charge/discharge current densities from 0.01 to $0.4 \mathrm{~mA} \mathrm{~cm}^{-2}$. The developed electrochromism in the above FPMSC not only provides direct visualization of the energy storage state without the aid of extra techniques, but also enhances the human-device interaction experience. 

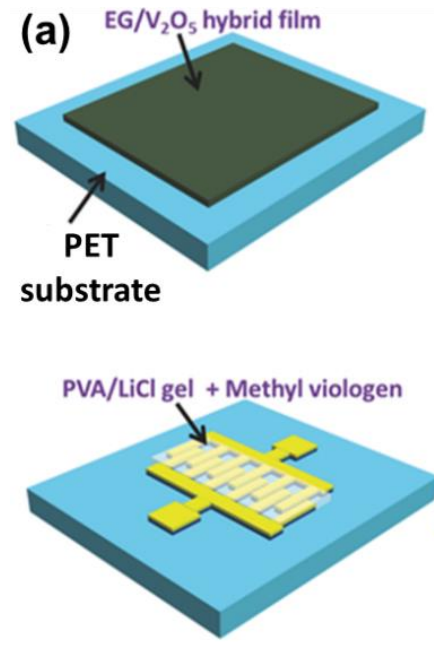

(i) Masking and depositing Au

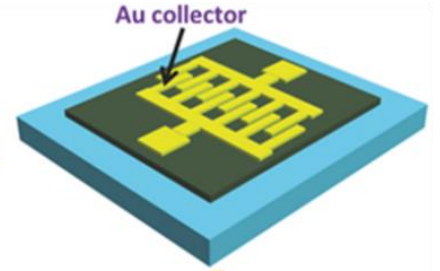

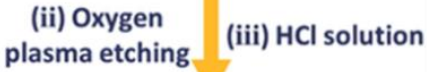

(iv) Electrolyte, methyl viologen

(v) Solidification

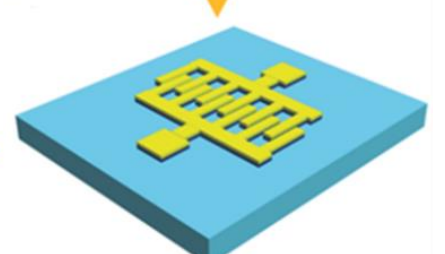

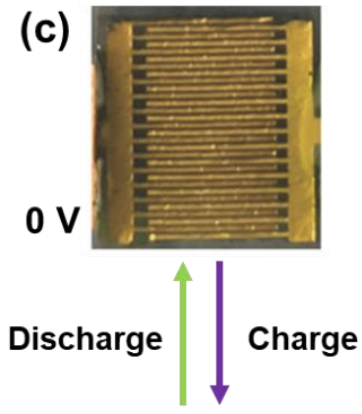

(b)<smiles></smiles>

colorless

(d)<smiles>Cn1ccc(-c2ccncc2)c1</smiles>
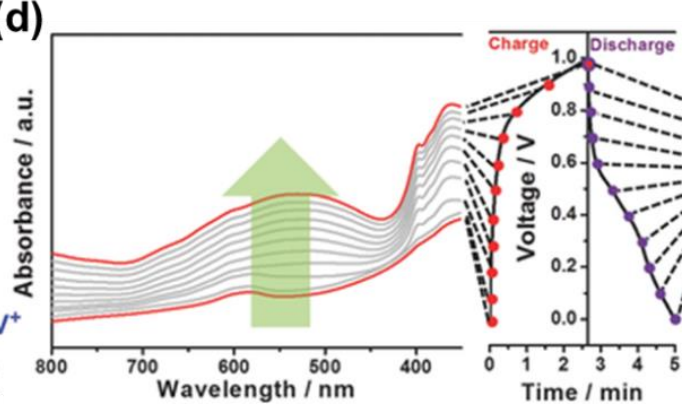

$1 \mathrm{~V}$

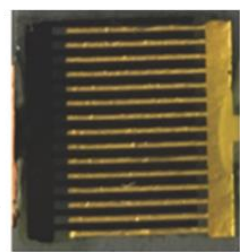

Fig. 15. Electrochromic FPMSCs. (a) Schematic fabrication of the electrochromic FPMSCs.

(b) Electrochromic mechanism of methyl viologen. (c) Photographs of reversible electrochromic effect of the electrochromic FPMSCs during GCD cycles. (d) UV-vis spectra of the electrochromic FPMSCs at different voltages at a current density of $0.015 \mathrm{~mA} \mathrm{~cm}{ }^{-2}$ between 0-1 V during one charge-discharge cycle. Reproduced with permission from Ref. [128]. Copyright 2017, Wiley-VCH.

\subsection{Thermoswitchable FPMSCs}

MSCs are generally operated at around room temperature $\left(20-30{ }^{\circ} \mathrm{C}\right)$. However, abusive conditions such as internal short circuits or overheating, can cause the increase of internal temperature, pressure, package cracking, and even explosion [301, 302]. To control the possible thermal runaway, a thermoswitchable FPMSC with thermal self-protection ability was developed by our group in 2018 [303]. The thermal-switching function originates from the thermodynamic behavior of the used smart electrolyte, a lithium salt-dissolved polymer sol with 
poly-(N-isopropylacrylamide)-g-methylcellulose (PNIPAAm/MC). At a high temperature, the breaking of hydrogen bonds between $\mathrm{N}$-isopropyl groups and water molecules would cause the transformation of PNIPAAm/MC from the initial hydrophilic state to a hydrophobic state, which can thus inhibit the $\mathrm{Li}^{+}$diffusion between the positive and negative microelectrodes (Fig. 16a). The resulted thermoswitchable FPMSC would be switched off when the temperature increased to $80{ }^{\circ} \mathrm{C}$ (Fig. 16b). The areal capacitance of the thermoswitchable FPMSC decreased from $1.83 \mathrm{mF} \mathrm{cm}^{-2}$ at $30{ }^{\circ} \mathrm{C}$ to $0 \mathrm{mF} \mathrm{cm}^{-2}$ at $80^{\circ} \mathrm{C}$ (Fig. 16c), demonstrating a totally switch-off behavior. More importantly, the PNIPAAm electrolyte could recover its original ionic conductivity when the temperature decreased below the glass-transition temperature of the PNIPAAm/MC. Thus, this thermoswitchable FPMSC could restore its original electrochemical properties in a few seconds. To mimic the realistic working conditions, the thermoswitchable FPMSC connected in series (Fig. 16d and e) and in parallel (Fig. 16f and g) were attached on a central processing unit of a computer, also exhibiting excellent switch on/off behaviors. This work paves the way for the development of self-protection FPMSCs with inherent intelligent thermal management to ensure high safety. 

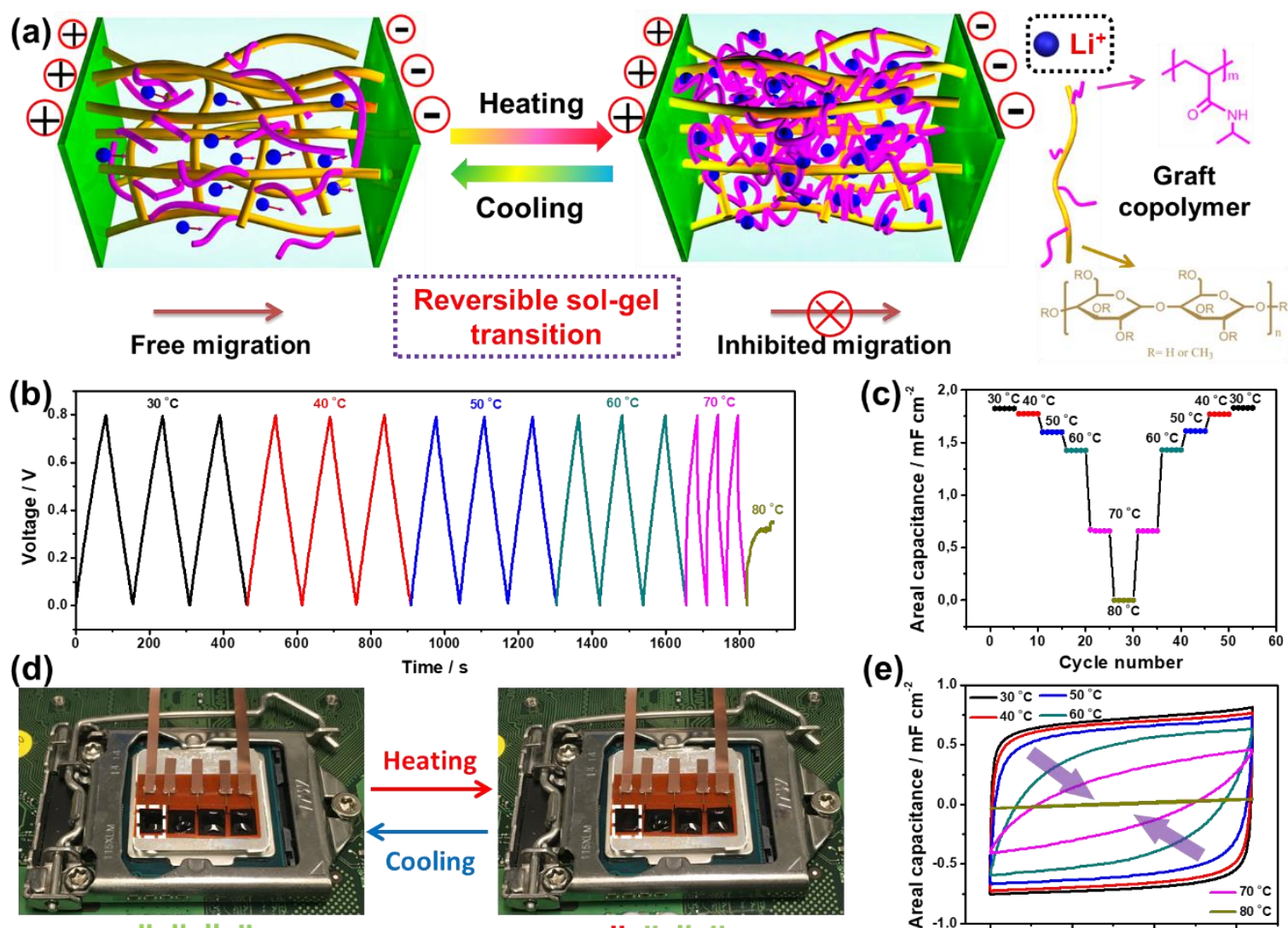
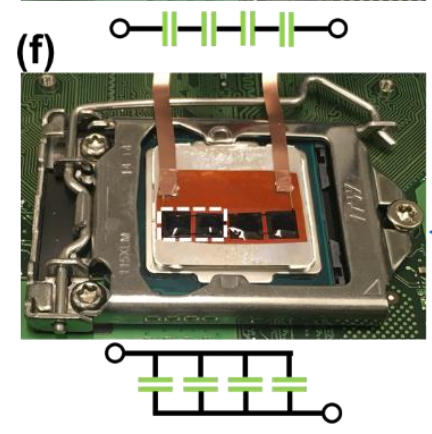
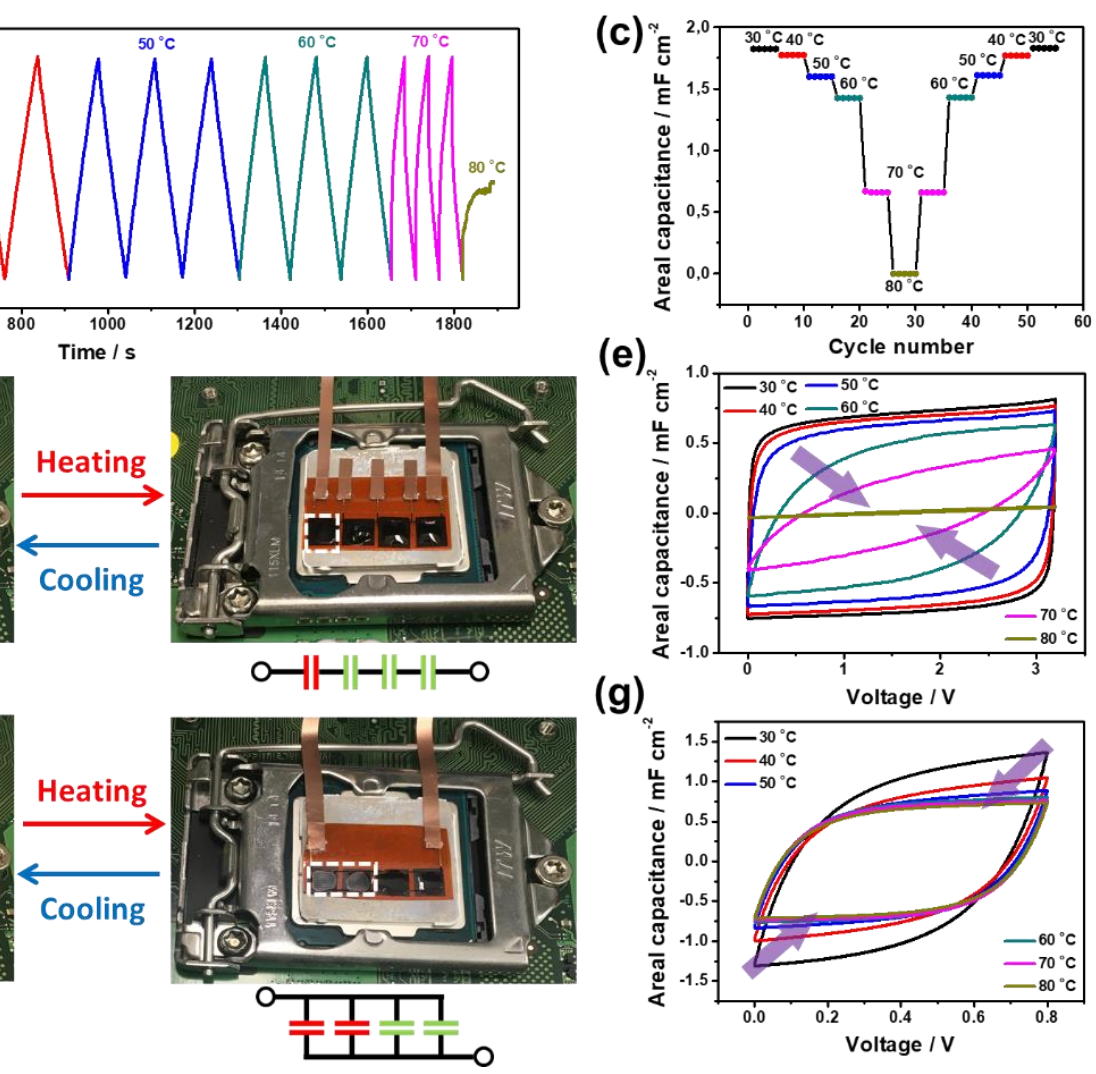

(g)

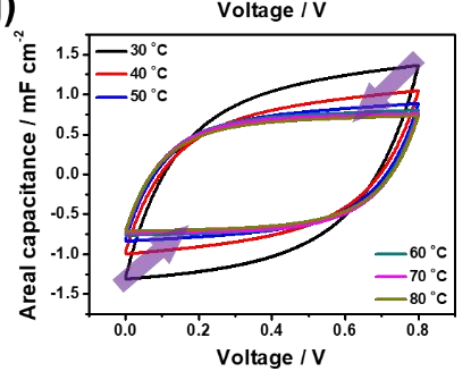

Fig. 16. Thermoswitchable FPMSCs. (a) Illustration of the reversible sol-gel transition for the thermoresponsive electrolyte and ion transport between interdigital electrodes under heating and cooling. (b) GCD curves at different temperatures from 30 to $80{ }^{\circ} \mathrm{C}$. (c) Areal capacitance as a function of temperature from 30 to $80{ }^{\circ} \mathrm{C}$ at a current density of $20 \mathrm{~mA} \mathrm{~cm}^{-2}$. (d) Digital photographs and circuit diagrams of four thermoswitchable FPMSCs connected in series. The white-dotted box represents the thermoswitchable FPMSC unit and the other units in the FPMSC array are the conventional MSCs with PVA/LiCl gel electrolyte. The red and green symbolic capacitors represent the capacitors with switch-on and switch-off states, respectively. (e) CV curves at a scan rate of $500 \mathrm{mV} \mathrm{s}^{-1}$ for four thermoswitchable FPMSCs connected in series in the $30-80{ }^{\circ} \mathrm{C}$ temperature range. (f) Photographs and circuit diagrams of four 
thermoswitchable FPMSCs connected in parallel. (g) CV curves at a scan rate of $500 \mathrm{mV} \mathrm{s}^{-1}$ for four thermoswitchable FPMSCs connected in parallel in the $30-80{ }^{\circ} \mathrm{C}$ temperature range. Reproduced with permission from Ref. [303]. Copyright 2018, Royal Society of Chemistry.

\subsection{Self-healing FPMSCs}

In practical applications, mechanical bending or other deformations would cause the structural damage of electrodes in MSCs and the breakdown of the whole device. The integration of selfhealing functions into MSCs can repair the structural fracture and realize the restoration of the electrochemical properties after being damaged or destroyed, extending the lifetime of MSCs. The realization of self-healing function with MSCs relies on the smart substrates. Recently, self-healing MSCs based on MXene/graphene aerogels were fabricated by using a simple laser cutting method (Fig. 17a) [101]. The MXene/graphene aerogels were wrapped by a self-healing carboxylated PU shell. The carboxylated PU is an industrially compatible self-healing material, which has a rich interfacial hydrogen bond in the supramolecular network (Fig. 17b). In the voltage range of $0-0.6 \mathrm{~V}$, the areal capacitance of the fabricated MSC based on MXene/graphene aerogels reached up to $34.6 \mathrm{mF} \mathrm{cm}^{-2}$ at a low scan rate of $1 \mathrm{mV} \mathrm{s}^{-1}$, and 9.2 $\mathrm{mF} \mathrm{cm}{ }^{-2}$ at a high scan rate of $100 \mathrm{mV} \mathrm{s}^{-1}$. Meanwhile, the MSC presented the maximum energy density of $2.18 \mu \mathrm{Wh} \mathrm{cm}^{-2}$ and the maximum power density of $180 \mu \mathrm{W} \mathrm{cm}{ }^{-2}$. More importantly, an outstanding cycling stability was verified by the assembled MSC with a high capacitance retention of $91 \%$ after 15000 cycles. Fig. 17c exhibits the cutting-healing process of the fabricated MSC. Owning to the reversible noncovalent hydrogen bond interactions in the supramolecular network, the MSCs exhibited distinctive self-healing ability. The CV curves of the fabricated self-healing MSCs were well maintained during repeated deformation/healing processes (Fig. 17d). Specifically, the self-healing MSC exhibited a high capacitance retention of $81.7 \%$ after the fifth healing process, demonstrating an excellent self-healing property. Moreover, the equivalent series resistances of the device before cutting and after the fifth 
cutting-healing cycle were 99.5 and $139 \Omega$, respectively (Fig. 17e). In spite of this progress in self-healing MSCs, since the self-healing polymers are electrochemically inactive, the use of self-healing PU shell sacrificed the volumetric/mass capacitance.

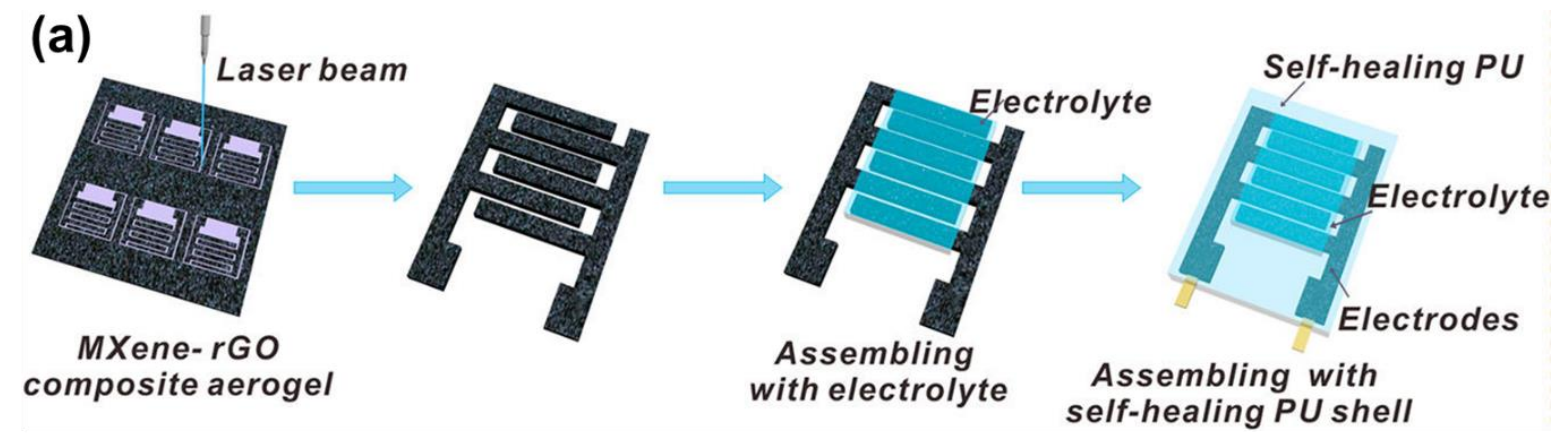

(b)

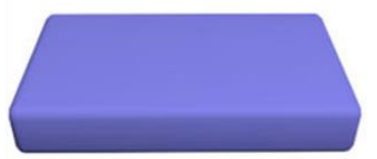

Self-healing PU

(c)
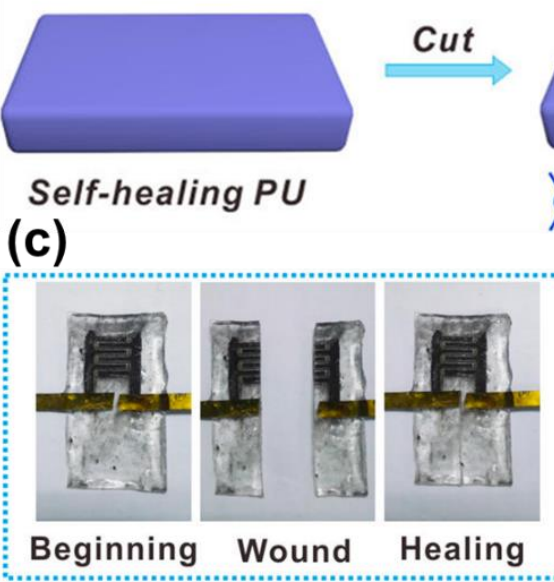

Hydrogen bonds broken

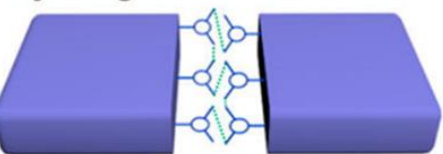

C-Carboxyl - H bond

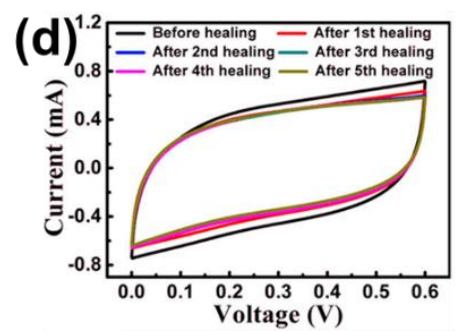

Hydrogen bonds re-establish

Healing

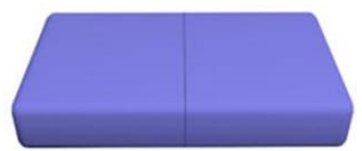

After self-healing

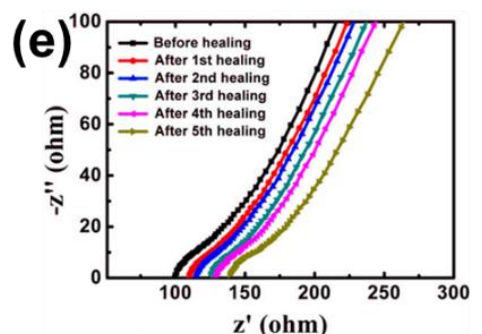

Fig. 17. Self-healing FPMSCs. (a) Schematic of the fabrication process of MXene-rGO selfhealing MSCs. (b) Schematic illustration of the self-healable mechanism from the interface hydrogen bond. (c) Photographs of the 3D self-healing MSC (left: original MSC, middle: MSC after cutting, right: MSC after self-healing). (d) CV curves at a scan rate of $50 \mathrm{mV} \mathrm{s}^{-1}$, and (e) Nyquist curves of the original and after several cutting-healing of MSC. Reproduced with permission from Ref. [101]. Copyright 2018, American Chemical Society.

\subsection{Stretchable FPMSCs}

Electronic devices applied in wearable electronics, power dressing, electronic skins, and paperlike smart phones require their components including their power sources to be flexible, bendable, foldable and stretchable [10, 304]. The appearance of stretchable MSCs paves the 
way to future applications in wearable and implantable integrated systems $[84,85,105,163$, 177, 180, 198, 305-308]. The incorporation of stretchability can enable MSCs the ability to not only get back to their initial shape, but also retain their electrochemical performance. In the beginning of 2013, the stretchable MSC array was first realized through using narrow and long serpentine metallic interconnections in a mechanical neutral plane by Kim et al. [96]. Individual MSC was fabricated by patterning spray-coated SWCNTs on thick PI film, then transferring to an elastomeric PDMS substrate via tape transfer method, and finally drop-casting ionogel electrolyte (Fig. 18a). Since the joints between the SWCNT electrode and the interconnection suffer the largest strain upon stretching the entire device, the rounding of the interconnection at the joints was designed. Fig. 18b shows the digital photos of the obtained stretchable MSC array. As displayed in Fig. 18c and d, the entire device was stretched up to 30\%. No noticeable cracking or change was observed, indicating the good stretchability of the entire array. This work opens up the rational designs of stretchable MSC array. Afterwards, a series of stretchable MSC arrays were designed and fabricated [92, 180, 203, 309, 310]. Another approach to design stretchable MSCs is to pattern microelectrodes on the prestrained substrate [92, 305, 308]. For example, in 2019, a microporous, deformable silicon rubber film was fabricated by using a rough sandpaper as a mold [92]. Then, the gold interdigital current collectors were deposited onto the prestrained silicon rubber film with $50 \%$ strain. After that, MWCNTs were spraycoated onto the current collectors, followed by the deposition of Mn/Mo mixed oxide to enhance the electrochemical performance (Fig. 18e). As the demonstration, a LED attached to a balloon was powered by two serially connected stretchable MSCs. When a strain of $50 \%$ was applied to the attached stretchable MSC array by the inflation of the balloon, the brightness and operation time of the LED remained constant (Fig. 18f). 


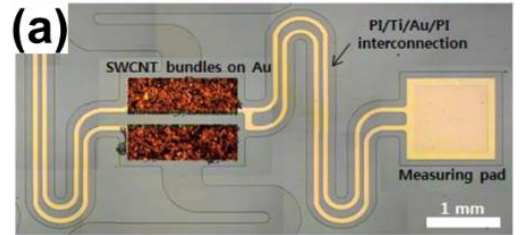

(c)

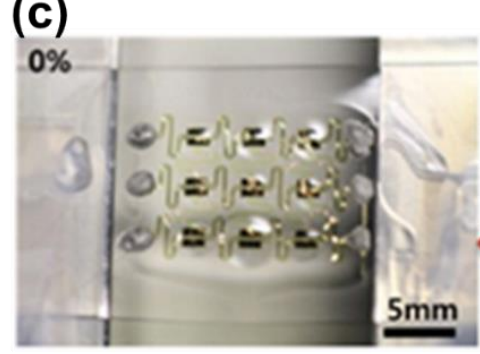

(e) Prestrained

Cr/Au

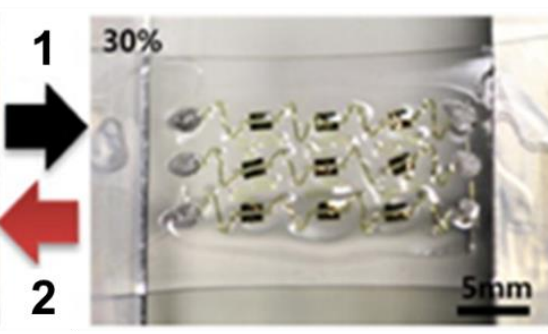

(b)

\begin{abstract}
MWCNT
\end{abstract}
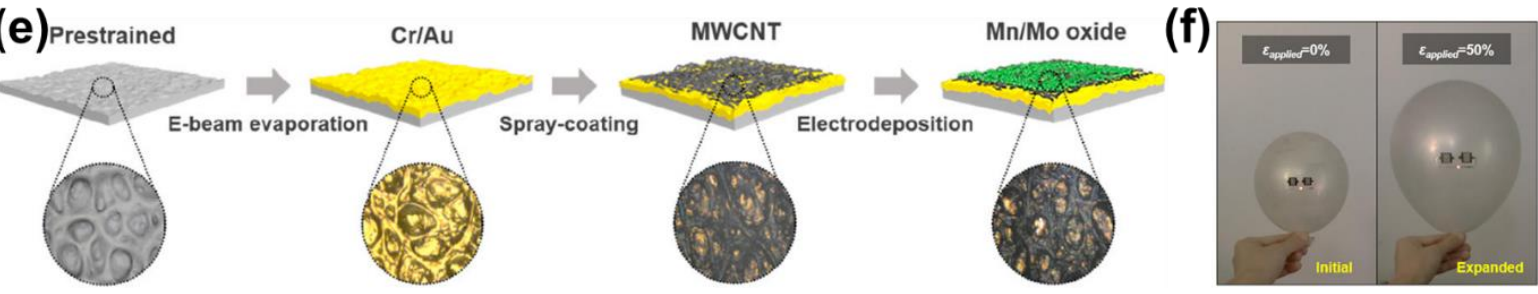

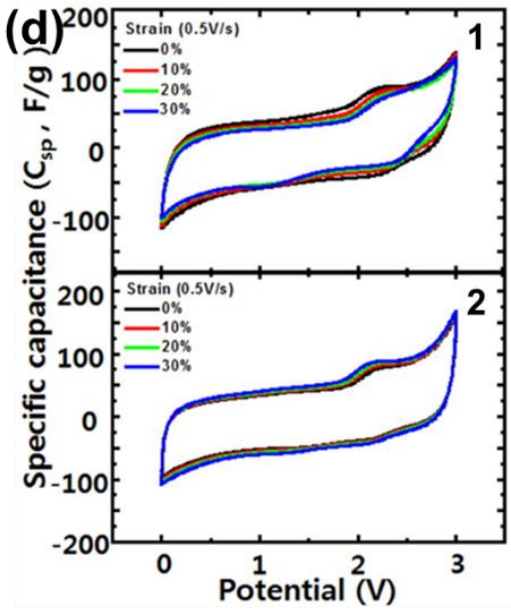

(f)

Fig. 18. Stretchable FPMSCs. (a) Magnified optical microscope image of an individual MSC with serpentine interconnections. (b) Photograph of the 2D planar stretchable MSCs with iongel electrolyte. (c) Photographs of the entire device of the $3 \times 3$ MSC array before (left) and after straining of $30 \%$ (right). (d) CV curves of 1 were obtained while increasing the strain from 0 to $30 \%$, and those of 2 were obtained while decreasing the strain from $30 \%$ to 0 . Reproduced with permission from Ref. [96]. Copyright 2013, American Chemical Society. (e) Schematic of the fabrication process of a biaxially stretchable MSC. (f) Photographs of two serially connected stretchable MSCs and an LED lit by them on a balloon without and with shear deformation. Reproduced with permission from Ref. [92]. Copyright 2019, American Chemical Society.

\subsection{Other smart FPMSCs}

Apart from the above-mentioned smart functions, the abilities to response other stimuli such as light, pressure, and magnetic field are also desired for practical applications [311-314]. For instance, Liu et al. [315] demonstrated a kind of photoswitchable MSCs based on the diarylethene-functionalized graphene (DAE-G) composite. Photoswitching of the capacitance was enabled by the reversible control of interfacial charge injection into DAE molecular orbitals, 
owing to the charge transfer at the DAE-G interface upon light modulation. Besides, some new concepts such as photo-charging, thermo-charging, magnetic capacitance enhancement, shapememory, and compression have been demonstrated in conventional SCs [316-319]. These concepts are also meaningful and significant for FPMSCs due to the great potential applications in smart microelectronics. However, these responsive FPMSCs have not yet been reported so far due to the poor compatibility among those stimuli active materials, and processing technologies.

\section{Applications of FPMSCs}

Beyond pursuing high electrochemical performance of FPMSCs, the practical application of FPMSCs should always be taken into consideration. The extensive popularity of wearable and flexible electronics urgently demands innovation in the flexibility of energy storage devices. They are fabricated to be directly worn on the human bodies or attached to the soft clothes. Particular mechanical features are necessary for adapting to this environment. The mechanical properties of the electronic components, power sources, external circuits, and substrates play an important role on the overall flexibility of the integrated systems. As the power sources, FPMSCs should be able to exhibit remarkable mechanical flexibility without noticeable structural destruction and performance degradation. Fig. 19a illustrates the typical electronics with operating power ranging from $10 \mathrm{nW}$ to $10 \mathrm{~W}$. Note that state-of-the-art FPMSCs can deliver areal power densities in the range of $10^{-1}-10^{3} \mathrm{~mW} \mathrm{~cm}^{-2}$. According to the required power, working time, current, and voltage of electronic device, the required number of FPMSCs connect in series or parallel can be calculated. Notably, to extend the usage time of the electronic device, multiple FPMSCs should be integrated to increase the overall energy storage capacity, which would inevitably increase the volume and surface area of FPMSCs. Thus, the reported FPMSCs are suitable for powering electronics with relatively low energy consumption. 
On the other hand, frequent charging or replacement of external power sources for electronic devices causes great inconvenience and high maintenance cost under certain conditions. Designing flexible self-powered systems integrating energy-harvesting and energy storage devices offers a feasible approach to simultaneously scavenge and store environmental energy, in which FPMSCs can serve as sustainable power supply for microelectronics (Fig. 19b). Certainly, there is a need of transmission module to manage the dynamic voltage and current variations between energy-harvesting and energy storage devices. As the demonstration of the flexible self-powered system, FPMSCs can be assembled with microsized energy harvesters to deliver high rate capability, large output power, and long lifetime for powering flexible microelectronics.

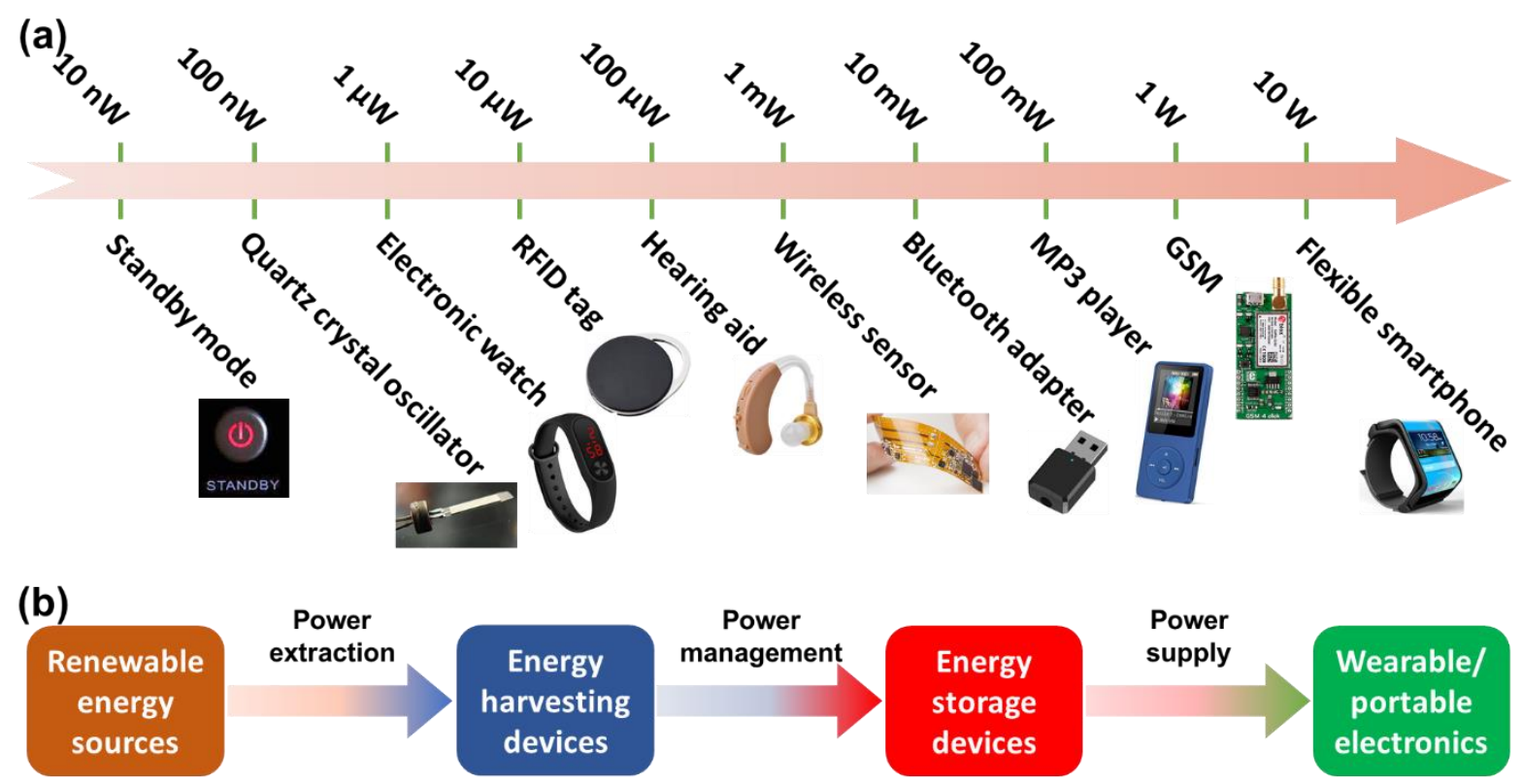

Fig. 19. (a) Power consumption of typical electronics in the range of $10 \mathrm{nW}-10 \mathrm{~W}$. (b) Illustration of smart self-powered integrated systems with energy harvesting, power management and stable energy storing for flexible, wearable and portable electronics.

\subsection{Self-powered integrated systems}

The work mechanism of self-powered integrated systems is first harvesting energy from natural sources (e.g., heat, solar, wave, and wind) or human movements (via piezoelectric and 
triboelectric generators) and converting the energy into electricity, and then storing electricity in a electrochemical energy storage device as backup power for powering energy-consumption electronics [28, 105, 154, 227, 320-322]. Such intelligent integration is also applied to construct miniaturized self-powered integrated systems. Basically, there are three kinds of integrated systems: energy harvesting/storage, energy storage/consumption, and energy harvesting/storage/consumption. The first two systems are semi-integrated products. For instance, in 2017, Zhu et al. [154] reported a miniaturized self-powered integrated system by combining the piezoelectric energy generator (PEG) and durable FPMSC. Mechanical energy can be harvested and converted to electricity by the PEG. Through the rectifier, the alternating current was converted to direct current, and finally stored in a polypyrrole nanowire (PPyNW)based FPMSC. Fig. 20a and b show the circuit and digital photographs of the integrated system. In a typical operation, after the FPMSC was charged for $400 \mathrm{~s}$ by typing the PEG, the voltage can reach around $0.1 \mathrm{~V}$. The stored electricity was discharged at $0.2 \mu \mathrm{A} \mathrm{cm} \mathrm{cm}^{-2}$ with quite small voltage drop, demonstrating the energy storage capability of the PPyNW-based FPMSC in the integrated system (Fig. 20c).

In addition, the stored energy in MSCs is aimed at driving microelectronics sustainably and robustly. Among diverse microelectronics, photodetectors/sensors (e.g., strain, pressure, gas, light, and temperature sensors) require operation power on the order of microwatts or milliwatts, matching well with the output power of MSCs [66, 68, 97, 99, 132, 162, 305, 323-325]. Thus, photodetectors/sensors are good end users for the self-powered systems, which are expected to continuously monitor personal healthcare or external environment. In 2017, a self-powered UV photodetection system was fabricated by combining FPMSCs with UV detectors. As illustrated in Fig. 20d and e, UV photodetection was achieved through the change of leakage current [305]. When the integrated device was irradiated by UV light with an intensity of $5 \mathrm{~mW} \mathrm{~cm} \mathrm{~cm}^{-2}$, an anodic photocurrent of $0.32 \mathrm{~mA}$ was detected without decay (Fig. 20f). The corresponding photodetection switch on/off ratio of the integrated system was 6.2. Additionally, the integrated 
device exhibited stable electrochemical performance without any capacitance degradation at different stretching states and stretching times, indicating its excellent stability and durability as a stretchable photodetector (Fig. 20g-i).

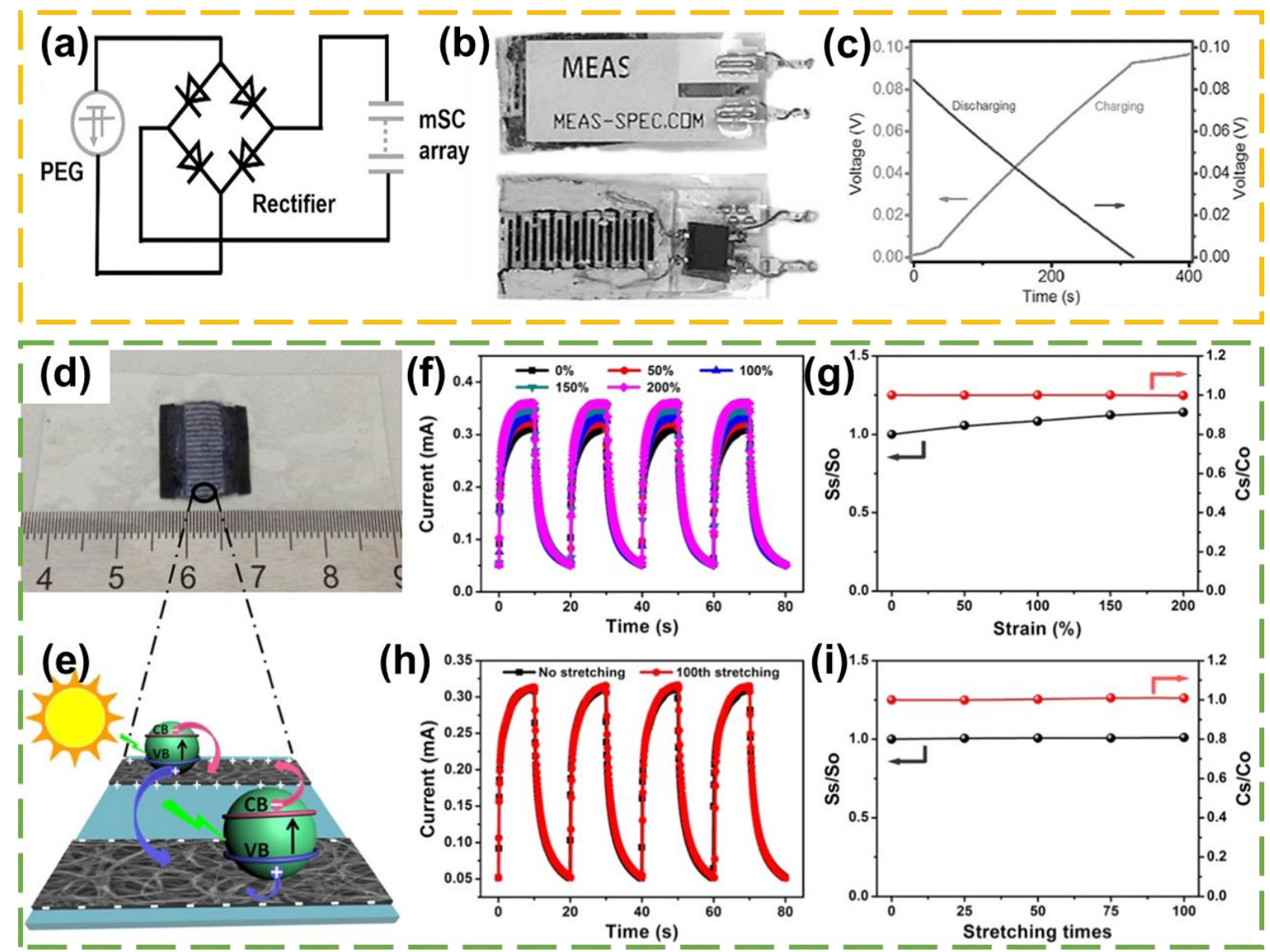

Fig. 20. (a) Schematic circuit of the mechanical harvesting and storing system by integrating the PEG with PPyNW FPMSC. (b) Photographs of front side (upper one) and back side (below one) of the integrated system. (c) Charging curve of the PPyNW FPMSC by tapping the PEG and discharging curve of PPyNW FPMSC with the current density of $0.2 \mu \mathrm{A} \mathrm{cm}^{-2}$. Reproduced with permission from Ref. [154]. Copyright 2017, Wiley-VCH. (d) Photograph of a stretchable integrated device. (e) Schematic of integrated device as a photodetector. (f) Photocurrent response of integrated device as a photodetector under different strain states with UV light intensity of $5 \mathrm{~mW} \mathrm{~cm}^{-2}$. (g) Sensitivity and specific capacitance of integrated device under different strain levels. The sensitivity and specific capacitance in the original state is normalized to 1. (h) Photocurrent response of integrated device as a photodetector before and after 100 
stretching cycles. (i) Sensitivity and specific capacitance of integrated device for different stretching times. The sensitivity and specific capacitance in the original state is normalized to 1. Reproduced with permission from Ref. [305]. Copyright 2017, Elsevier Ltd.

A complete self-powered integrated system (also named all-in-one device) should contain energy harvesting device, energy storage device, and energy consumption electronic. Recently, several examples of self-powered energy harvesting/storage/consumption systems have been demonstrated [83, 87, 88, 104, 218, 264, 274, 292, 306, 326-332]. By harvesting and converting solar energy and then converting it into electrical energy to power gas sensors, self-powered photovoltaic systems with high conversion efficiency provide a feasible approach to build energy-autonomous integrated systems. Guo et al. [87] reported an integrated device on a piece of flexible paper in 2017. As shown in Fig. 21a, a commercially available Si-based solar cell was connected to a tandem AMSC and a PANI-based gas sensor. When S1 was switched on and S2 was switched off, tandem AMSCs were charged by solar cells. After being charged for $78 \mathrm{~s}$, AMSCs achieved an open-circuit potential of $2.82 \mathrm{~V}$. The corresponding charging (S1 switched on) curve of the tandem AMSC by the solar cell and discharging (S1 switched off) curve at a current density of $0.1 \mathrm{~mA} \mathrm{~cm}^{-2}$ were recorded as shown in Fig. 21b. When S1 (switch 1) was switched off and S2 (switch 2) was switched on, the PANI-based gas sensor could work well driven by the tandem AMSC. Fig. 21c displays the current curve of the PANI-based gas sensor when gaseous $\mathrm{NH}_{3}$ and $\mathrm{HCl}$ were alternately supplied. The curves indicate that the current alternately decreased and increased with the alternative introduction of $\mathrm{NH}_{3}$ and $\mathrm{HCl}$, reflecting the good sensitivity of this sustainably self-powered integrated device.

Similarly, another fully self-powered sensor system was constructed by integrating an amorphous silicon solar cell as the energy harvester, an inkjet-printed $\mathrm{MnO}_{2}$-based FPMSC as the energy storage unit, and also a fully printed $\mathrm{SnO}_{2}$-based gas sensor as the end user of the produced energy (Fig. 21d) [331]. As one demonstration in Fig. 21e, the integrated system with 
a size of $15 \mathrm{~cm} \times 4 \mathrm{~cm}$ was built on a single PET substrate and packaged into a flexible and wearable wristband with PDMS. Under the illuminance of a table lamp ( $8 \mathrm{~W}$ white light), the $4 \times 5$ array of commercial amorphous silicon solar cells can provide an output voltage of $2.8 \mathrm{~V}$. When photo-charging was switched on, the large-scale FPMSCs (single device area of $5.9 \mathrm{~cm}^{2}$ ) connected in series can be quickly charged to more than $1.6 \mathrm{~V}$ for more than 1 min as a single power supply unit. The voltage applied on the $\mathrm{SnO}_{2}$ gas sensor and mounted LED was stabilized by a voltage regulator with an upper limit of $2.75 \mathrm{~V}$. As shown in Fig. 21 and g, when the system is exposed to ethanol or acetone, the resistance decrease of $\mathrm{SnO}_{2}$ sensor lead in the voltage applied on LED to increase from 1.56 to $1.96 \mathrm{~V}$. Therefore, the LED can be turned on as a warning signal, as shown in the inset of Fig. 21e. Such a concept demonstration highlights the high scalability and versatility of the printable fabrication approach.

In addition, the mechanical energy can be also converted and stored in MSCs for powering the gas sensor. In 2018, an integrated device was fabricated by direct laser writing on PI substrate (Fig. 21h and i). It contains PEG energy harvester, diode bridge rectifier, multilayered graphene (MG)-based FPMSC line filter, MG-PANI FPMSC array, and graphene/polymer hybrid film-based gas sensors. The obtained MG-PANI FPMSCs with $\mathrm{PVA} / \mathrm{H}_{2} \mathrm{SO}_{4}$ gel electrolyte show outstanding specific capacitances of $3.8 \mathrm{mF} \mathrm{cm}^{-2}$ and $155 \mathrm{~F} \mathrm{~cm}^{-3}$ at $1 \mathrm{mV} \mathrm{s}^{-1}$ [329]. Powered by the integrated FPMSC array, PANI gas sensors respond quickly to toxic gas (such as $\mathrm{NO}_{2}$ and $\mathrm{NH}_{3}$ ) with high sensitivity (200 ppm) and fast response at room temperature powered by the integrated FPMSC array (Fig. 21j). The distinct response to $\mathrm{NO}_{2}$ or $\mathrm{NH}_{3}$ gas can be explained by the transfer of electrons/protons between PANI and gas molecules (inset of Fig. 21j). This flexible device shows great potential for the application in the wearable selfpowered integrated system. 

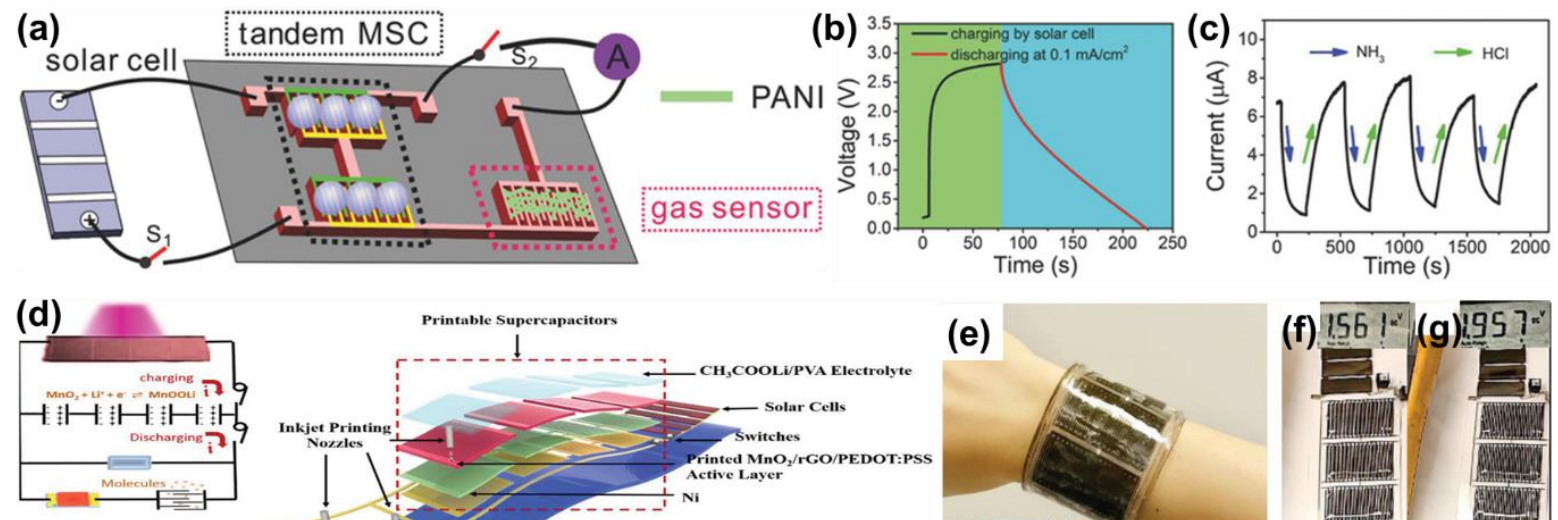

(e)
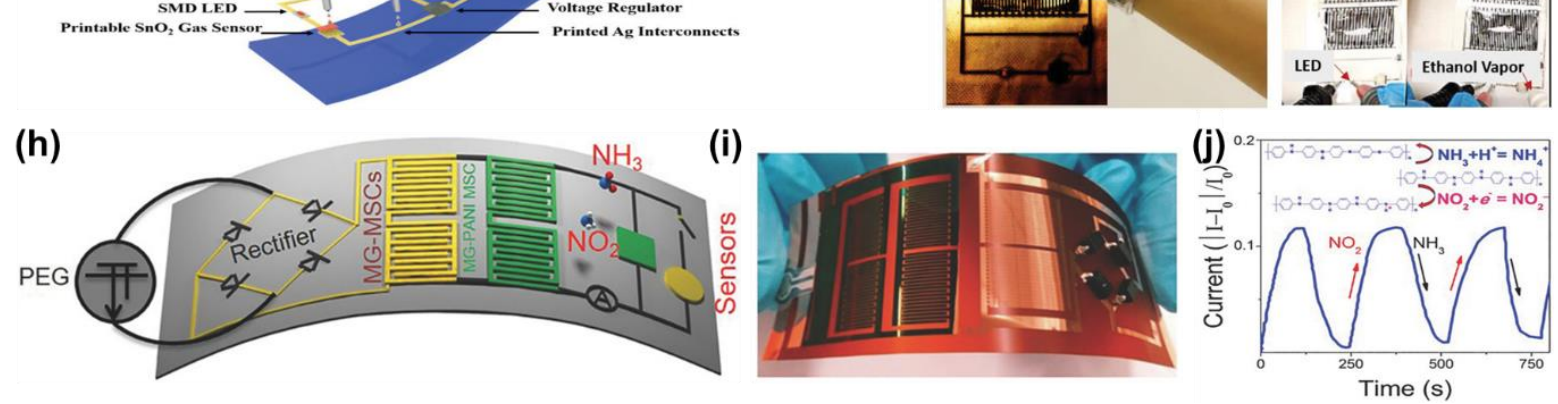

Fig. 21. Design of flexible self-powered integrated systems. (a) Schematic of tandem AMSC bridging a solar cell for energy supply and a gas sensor. (b) Charging curve of tandem AMSC when charged by a commercial solar cell and discharging curve of the tandem AMSC at 0.1 $\mathrm{mA} \mathrm{cm}^{-2}$. (c) Response and recovery curves of PANI-based gas sensor driven by tandem AMSC when alternately inputting gaseous $\mathrm{NH}_{3}$ and $\mathrm{HCl}$. Reproduced with permission from Ref. [87]. Copyright 2017, Wiley-VCH. (d) Schematic of printable fabrication procedures and system operational mechanism (inset) of the flexible and wearable monolithically integrated selfpowered sensor system on a plastic substrate. (e) Photographs of wearable wristband. Inset: LED as the indicator of gas detection. Voltage drop on LED (f) without and (g) with detection of ethanol in ambient. Inset: Voltage values read on multimeter. Reproduced with permission from Ref. [331]. Copyright 2019, Wiley-VCH. (h) Schematic and electrical circuit diagram of an integrated sensor device on a PI substrate. (i) Photograph of the integrated energy harvesting/storage/gas sensors device. (j) Response of current exposure to $\mathrm{NO}_{2}$ and $\mathrm{NH}_{3}$. Reproduced with permission from Ref. [329]. Copyright 2018, Wiley-VCH. 
Besides, other energy conversion devices have been also employed in constructing selfpowered integrated systems [237, 333-336]. For example, a biocompatible self-charging power unit was constructed and sealed compactly by silicone rubber (Fig. 22a) [104]. It combines a triboelectric nanogenerator (TENG), an MXene-based FPMSC, and a rectifier to harvest and store energy from human activities. Yue et al. [264] demonstrated a flexible integrated system including a $\mathrm{MnO}_{2}-\mathrm{PPy} / / \mathrm{V}_{2} \mathrm{O}_{5}-\mathrm{PANI}$ AMSC, a photodetector made of perovskite $\mathrm{CH}_{3} \mathrm{NH}_{3} \mathrm{PbI}_{3}$ NWs, and a wireless charging coil (Fig. 22b). With alternating the on/off illumination, the photocurrent on/off ratio of the integrated system was comparable to that with external power driven system. Wind energy is regarded as one of the cleanest energy sources in nature. Interestingly, Gao et al. [274] fabricated polypyrrole/graphene-based MSC (PPyG-MSC) array on printed paper. Then, PPyG-MSC array was patterned onto the leaves of windmill and integrated with wind generator to make a self-powered device. Fig. 22c shows the illustration of the assembled integrated system. The PPyG-MSC array was charged by a wind driven generator during the rotation of the windmill and used to light an LED. However, the integrated systems have a big size, which hinders the possible practical applications in microelectronics. The miniaturization, lightweight, and high-speed operation of micropower sources are the developing trends to satisfy the demands of electronic devices. Yun et al. [306] reported the fabrication of a stretchable MSC array charged by solar cells, which could function as power sources for an integrated strain sensor (Fig. 22d). When the whole integrated system was attached to the wrist, the integrated strain sensor powered by the energy stored in MSCs could detect the externally applied strain (such as arterial pulse). Recently, Shen et al. [330, 332] developed ready-to-use wearable gas and sweat sensing systems with a short response time and high sensitivity (Fig. 22e and f). Importantly, a mobile phone could display the concentrations of $\mathrm{C}_{2} \mathrm{H}_{5} \mathrm{OH}$ and sweat with the assistance of a microcontroller central processing unit. The result demonstrated their potential application in personal healthcare. 


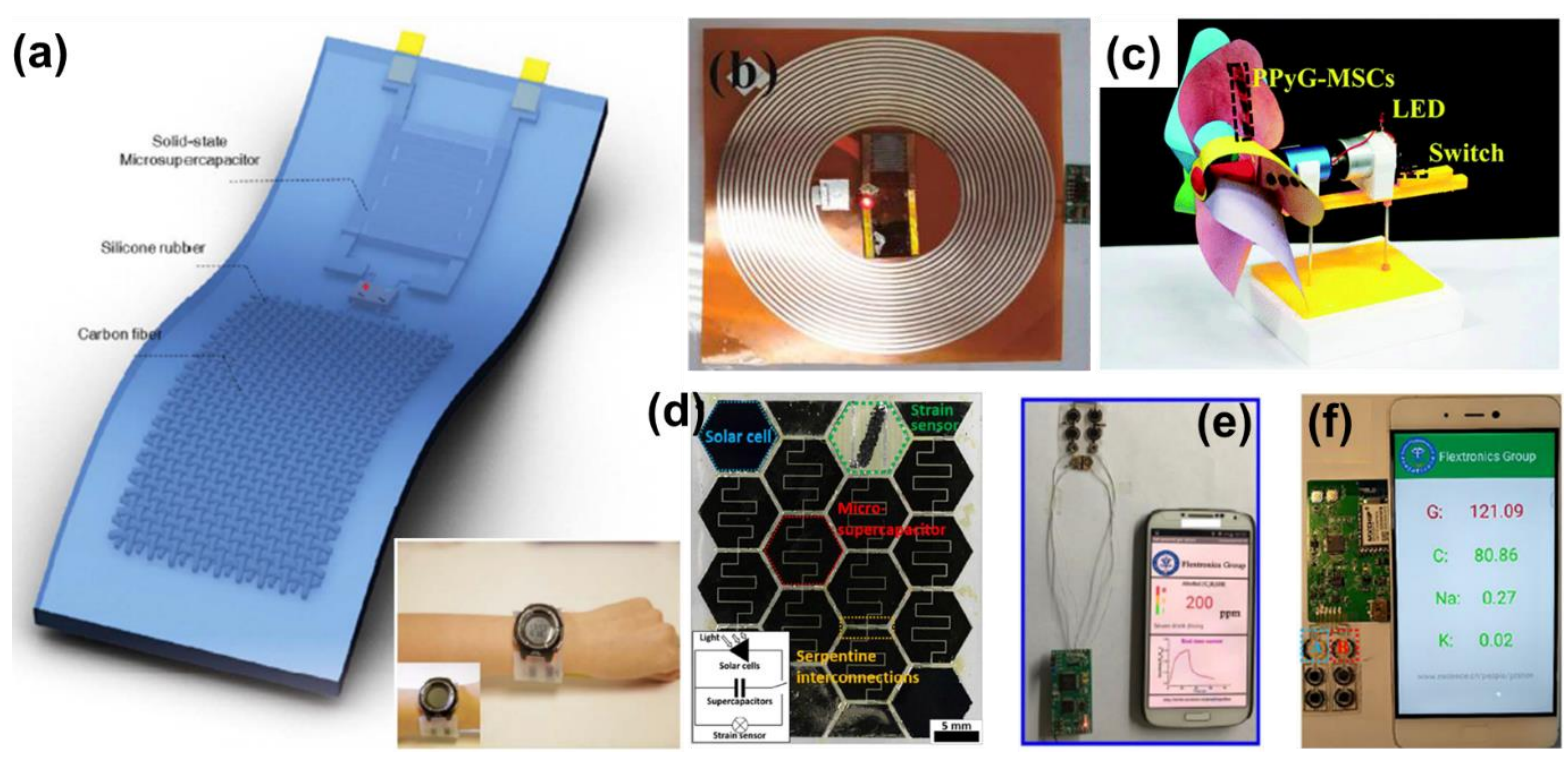

Fig. 22. Self-powered integrated systems. (a) Schematic diagram of the whole device, inset photograph demonstrates that the integrated system worn on the forearm. Reproduced with permission from Ref. [104]. Copyright 2018, Elsevier Ltd. (b) Photograph of the integrated system consisting of a coil as power receiver, a FPMSC, and a photoconductive-type photodetectors of perovskite NWs. Reproduced with permission from Ref. [264]. Copyright 2016, American Chemical Society. (c) Photograph of the self-powered system with the PPyGMSCs on the windmill. Reproduced with permission from Ref. [274]. Copyright 2018, Royal Society of Chemistry. (d) Optical image of the biaxially stretchable MSC array with integrated strain sensors and solar cells. Inset shows the circuit diagram. Reproduced with permission from Ref. [306]. Copyright 2018, Elsevier Ltd. (e) Real-time $\mathrm{C}_{2} \mathrm{H}_{5} \mathrm{OH}$ concentration analysis/display in the case of a high concentration. Reproduced with permission from Ref. [330]. Copyright 2017, Elsevier Ltd. (f) Flow chart of the integrated system for energy supply and concentration analysis. The real time analysis/display in the case of high concentration sweat after movement, and the $\mathrm{G}, \mathrm{C}, \mathrm{Na}$ and $\mathrm{K}$ represented glucose sensor, compensation electrode, $\left[\mathrm{Na}^{+}\right]$sensor and $\left[\mathrm{K}^{+}\right]$sensors in the screen, respectively. Reproduced with permission from Ref. [332]. Copyright 2019, Elsevier Ltd.

\subsection{Smart responsive integrated systems}


Rapid development towards intelligent electronic devices, such as implantable biosensors, thermo switches, foldable displays, and smart garments, have stimulated the growing demand for smart responsive integration [337-340]. Devices with planar configurations can be easily integrated with other on-chip components. The smart combination not only provides additional functions, but also saves materials and areas in modern electronics. For instance, in 2018, Qin et al. [130] demonstrated a compact smart self-charging power package by integrating hybrid tribo/piezoelectric nanogenerators (NGs) and electrochromic FPMSC array, as illustrated in Fig. 23a. This power package is capable of indicating the charging state of FPMSC array with color change. The electrochromic FPMSC based on $\mathrm{AgNW} / \mathrm{NiO}$ nanocomposites depicted an areal capacitance of $3.47 \mathrm{mF} \mathrm{cm}^{-2}$ at $2 \mu \mathrm{A} \mathrm{cm} \mathrm{cm}^{-2}$ (Fig. 23b and c). Simultaneously, along with the charging of the FPMSC, the positive electrodes of the FPMSC gradually turn to gray color and finally the darkest, which can be assigned to the oxidation reaction from $\mathrm{NiO}$ to $\mathrm{NiOOH}$ (Fig. 23d). The hybrid NG combined the high output current of piezoelectric NG and high output voltage of triboelectric NG. As presented in Fig. 23e, the power density of the hybrid NG is determined by the external loading resistance, reaching the maximum value of $0.8 \mathrm{~W} \mathrm{~m}^{-2}$ at a loading resistance of $10^{7} \Omega$. Fig. 23f shows the equivalent circuit of the self-charging power package. The electrochromic FPMSCs can be charged by the continuous palm impact, with the voltage of FPMSCs increased from 0.05 to $1 \mathrm{~V}$ (charged by $0.95 \mathrm{~V}$ ) in $260 \mathrm{~s}$ (Fig. 23g). Top panels of Fig. 23g present the corresponding color variation of the interdigitated electrodes at different charging states. The electrode turned to a darker color at higher charging state. As a demonstration, nine electrochromic FPMSCs were assembled in parallel and series to drive a LED (Fig. 23h). Fig. 23i displays the potential of the assembled device during the self-charging process in real-time. Hence, smart responsive devices/materials with multiple roles are imperative for the development of future smart self-powered integrated devices. 

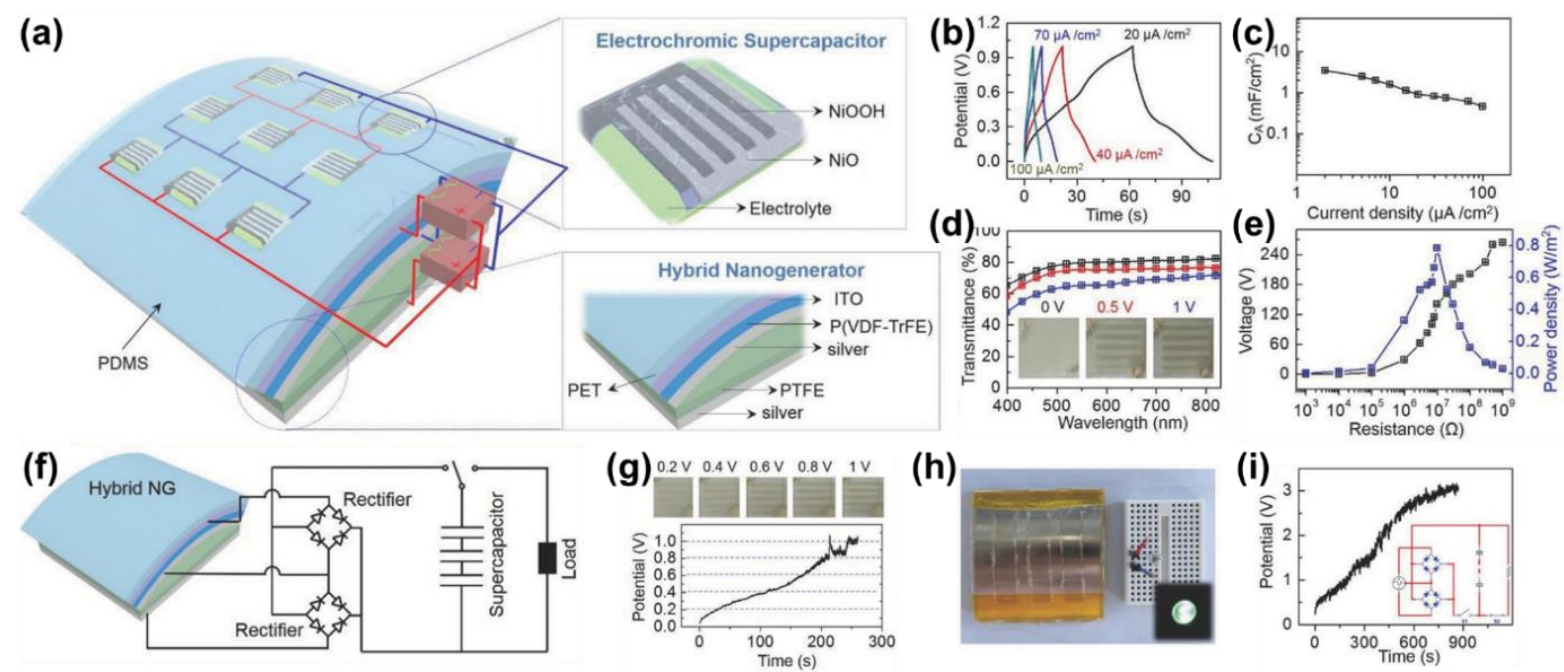

Fig. 23. Hybrid piezo/triboelectric-driven self-charging electrochromic FPMSC power package. (a) Schematic illustration of the self-charging power package. Top inset shows the structure of electrochromic FPMSC; bottom inset shows the structure of hybrid NG. (b) GCD curves of the electrochromic FPMSC at different current densities. (c) Areal capacitances calculated from GCD curves. (d) Transmittance spectra of the electrochromic FPMSC under different charging states $(0,0.5$, and $1 \mathrm{~V})$. Insets are the corresponding photographs. (e) The dependence of the output voltage and power density of the hybrid NG on the resistance of external load. (f) The equivalent circuit of the smart self-charging power package. (g) The real-time charged voltage of the electrochromic FPMSC by the hybrid NG under palm impact. Top panels show the corresponding chromatic transitions of a FPMSC at different voltages. (h) The self-charging electrochromic power package as the power source to light a LED. (i) Self-charged voltage of the assembled nine electrochromic FPMSCs by the hybrid NG. Reproduced with permission from Ref. [130]. Copyright 2018, Wiley-VCH.

\section{Summary and outlook}

Over the past two decades, the fabrication and applications of FPMSCs have gained extensive attention and achieved significant progresses. This review article outlines the criteria associated with device design principles and performance evaluation of FPMSCs. Recent advances in 
microfabrication technologies, including deposition techniques, coating strategies, etching methods, and printing technologies, are thoroughly discussed in terms of the simplicity, cost, efficiency, scalability, safety, and environmental friendliness. Meanwhile, the electrochemical performances of FPMSCs based on different electrode materials are analyzed in detail, and briefly summarized in Table 1. Beyond the pursuit of high electrochemical performance, the introduction of smart functions, such as electrochromism, thermal response, self-healing, and stretchability, into FPMSCs is a crucial developing trend of FPMSCs. Therefore, we put the focus also on the recent progresses in smart responsive FPMSCs. Finally, special emphasis is given to the smart self-powered integrated systems for making ready-to-use products/demonstrators. Although considerable achievements have been made in the fabrication and application of FPMSCs, future efforts are needed to address the following challenges with the aspects to flexibility, performance improvement, smart response, and micro-device integration.

(1) Ideal FPMSCs should have the merits, including bendable, foldable, and twistable properties, as well as superior and stable electrochemical performance. However, the weak affinity between current collectors and flexible plastic substrates, as well as electrode materials often leads to the detachment/cracking of current collectors or electrode materials during the continuous bending tests, which greatly limits the work durability of FPMSCs. Therefore, the mechanical properties of the substrates, current collectors, and electrode materials, as well as the interfacial adhesion strengths between them are of critical importance. To realize an efficient connection and adhesion, thin flat metal current collectors can be replaced by a 3D conductive scaffold. At the same time, 3D electrical conducting pathways enable rapid electron and ion transport and afford mechanically/chemically stable interfaces. Moreover, chemical modification or functionalization of current collectors also represents a good approach for forming robust interaction forces with substrates and electrode materials. On the other hand, 
standard evaluation method for flexibility has not been established so far, proper benchmarking for flexibility test is highly desirable.

(2) There is still large room to further improve the electrochemical performance of FPMSCs, particularly their areal metrics (capacitance, power density, energy density, and cycling performance). The electrode, electrolyte, and device fabrication are three vital factors determining the electrochemical performance of FPMSCs. a) From the perspective of electrode, a series of successful strategies have been demonstrated to enhance the overall electrochemical performance of FPMSCs, such as constructing nanostructured morphology, designing hybrid structure, heteroatom doping of carbon materials, and surface/interface modification. In addition, most of reported FPMSCs have the same electrode geometries with interdigital configuration. It remains highly desirable to design new electrode geometries, which would lead to great improvements in electrochemical performance of FPMSCs. For instance, large footprint areas, narrow distances between electrode fingers, and increased finger lengths are required for side-by-side electrodes to improve the access and transport of electrolyte ions. Another efficient strategy to improve areal performance is to employ a thick electrode with large mass loading of active materials. In other words, one future direction is to fabricate FPMSCs based on 3D architectures with high specific area, high mass loading and robust 3D scaffolds. b) From the viewpoint of electrolytes, the development of gel/solid-state electrolytes becomes the general trend, since the liquid electrolytes have the risk of leakage and complicated packaging procedures. Currently reported gel electrolytes are made of a polymeric material as matrix and an electrolyte salt to provide mobile ions. Non-aqueous gel electrolytes, such as block-copolymer- and silica-based gel electrolytes dissolved in ionic liquid, exhibit good thermal stability and mechanical strength, excellent safety, and wide potential window (3-5 V), realizing the high energy density of FPMSCs. Aqueous gel electrolytes based on PVA matrix, are eco-friendly, safe, sustainable, and inexpensive. However, their potential window is limited owing to the electrolysis of water. In addition, the aforementioned gel electrolytes suffer from 
low ionic conductivity and ion migration rate. The novel polymer matrix such as charged polymer with robust water retention ability shows the great potential. c) As for the device fabrication, the development of simple, eco-friendly, energy-saving, cost-effective, and scalable microfabrication technologies for FPMSCs is urgently needed for large-scale applications in the field of microelectronics. The emerging printing approaches such as inkjet printing, extrusion printing, screen printing, and 3D printing offer great opportunity for the upscalable production of FPMSCs, since these techniques allow the printing of all the components of FPMSCs (i.e. current collector, electrode, and electrolyte).

(3) In order to meet the demand for intelligent electronic devices, smart responsive FPMSCs have emerged as functional power sources. Good switchability, short response time, and excellent cycling stability are highly desirable for smart responsive FPMSCs. Developing smart electrolytes with novel or integrated functions may increase the adaptability of the whole device to various working environment or external stimuli, such as light, heat, force, etc. For example, thermochromic hydrogel can reflect thermal distribution by color change. Biocompatible or biodegradable hydrogel electrolytes are beneficial to the environment and sustainable development of the society. In addition, realizing the multifunction of FPMSCs is still challenging. In this respect, the exploration of novel functional polymers is needed. A variety of multi-responsive polymers (including photo-, $\mathrm{pH}-$, thermo-, electric-, and magneticresponsive abilities) can be the excellent candidates. Apart from smart electrolytes, there is still a huge space for the development of smart electrodes that are flexible, stretchable, transparent, electrochromic, and compressible. Because the introduction of smart functions into electrodes would cause the sacrifice of electrochemical performance, the smart electrodes have been rarely reported so far. Surface functionalization of electrode materials sheds a light on the smart electrodes due to the physically/chemically tunable properties such as electric conductivity, surface area, and the accessibility of ion transport. For example, if the superhydrophobicity/superhydrophilicity of active materials in FPMSCs is reversible under 
UV/visible light irradiation. Then, the ion transport between aqueous electrolyte and microelectrodes can be controlled, resulting in switch on/off behavior of FPMSCs. In addition, the emerging researches in $3 \mathrm{D}$, editable, programmable, and shapeless SCs provide important inspirations for the future design of smart FPMSCs [341-344].

(4) Ultimately, as micro-power sources, FPMSCs aim at powering ready-to-use microelectronics. Fully self-powered integrated systems containing energy harvesting units, energy storage units, and energy consumption units represent a highly attractive research topic. Additionally, to satisfy the requirements of the future smart electronics, the design of smart self-powered integrated system with multifunctional integration such as foldable, washable, and biodegradable features is desirable. The perspective all-in-one self-powered microelectronics can be attached on cloth with color change at different room temperatures, can work all the day without charging, and can be stretched/bended/washed for long-term operation. In spite of the huge challenges, the development of these fully self-powered integrated systems with FPMSCs will open up new doors for the next-generation smart electronics.

\section{Acknowledgements}

The authors thank the financial support from the Initiative and Networking Fund of the German Helmholtz Association, Helmholtz International Research School for Nanoelectronic Networks NanoNet (VH-KO-606), the European Union's Horizon 2020 research and innovation programme (Graphene Flagship Core 2) under grant agreement No. 785219, and German Research Foundation (DFG) within the Cluster of Excellence. We gratefully acknowledge the Center of Advancing Electronics Dresden (cfaed) and Dresden Center for Nanoanalysis (DCN) at TU Dresden.

\section{References}

[1] Y. Yang, W. Gao, Chem. Soc. Rev. 48 (2019) 1465-1491. 
[2] N. A. Kyeremateng, T. Brousse, D. Pech, Nat. Nanotechnol. 12 (2017) 7-15.

[3] C. W. Shen, S. X. Xu, Y. X. Xie, M. Sanghadasa, X. H. Wang, L. W. Lin, J.

Microelectromech. Syst. 26 (2017) 949-965.

[4] Z. Lou, Li, L. Wang, G. Shen, Small 13 (2017) 1701791.

[5] E. Pomerantseva, F. Bonaccorso, X. Feng, Y. Cui, Y. Gogotsi, Science 366 (2019) eaan8285.

[6] F. Yi, H. Ren, J. Shan, X. Sun, D. Wei, Z. Liu, Chem. Soc. Rev. 47 (2018) 3152-3188.

[7] D. P. Dubal, N. R. Chodankar, D. H. Kim, P. Gomez-Romero, Chem. Soc. Rev. 47 (2018) 2065-2129.

[8] A. Tyagi, K. M. Tripathi, R. K. Gupta, J. Mater. Chem. A 3 (2015) 22507-22541.

[9] P. Zhang, F. Wang, M. Yu, X. Zhuang, X. Feng, Chem. Soc. Rev. 47 (2018) 74267451.

[10] Y. R. Jeong, G. Lee, H. Park, J. S. Ha, Acc. Chem. Res. 52 (2019) 91-99.

[11] Z. S. Lv, W. L. Li, L. Yang, X. J. Loh, X. D. Chen, ACS Energy Lett. 4 (2019) 606614.

[12] G. Xiong, C. Meng, R. G. Reifenberger, P. P. Irazoqui, T. S. Fisher, Electroanalysis 26 (2014) 30-51.

[13] S. Zheng, X. Shi, P. Das, Z. S. Wu, X. Bao, Adv. Mater. 31 (2019) 1900583.

[14] J. F. M. Oudenhoven, L. Baggetto, P. H. L. Notten, Adv. Energy Mater. 1 (2011) 1033.

[15] S. Ferrari, M. Loveridge, S. D. Beattie, M. Jahn, R. J. Dashwood, R. Bhagat, J. Power Sources 286 (2015) 25-46.

[16] L. Liu, H. Zhao, Y. Lei, InfoMat 1 (2019) 74-84.

[17] J. Wang, F. Li, F. Zhu, O. G. Schmidt, Small Methods 3 (2019) 1800367.

[18] M. Beidaghi, Y. Gogotsi, Energy Environ. Sci. 7 (2014) 867-884.

[19] N. Liu, Y. Gao, Small 13 (2017) 1701989. 
[20] L. Liu, Z. Niu, J. Chen, Nano Res. 10 (2017) 1524-1544.

[21] D. Qi, Y. Liu, Z. Liu, L. Zhang, X. Chen, Adv. Mater. 29 (2017) 1602802.

[22] R. Hou, G. S. Gund, K. Qi, P. Nakhanivej, H. Liu, F. Li, B. Y. Xia, H. S. Park, Energy Storage Mater. 19 (2019) 212-241.

[23] Y. Da, J. Liu, L. Zhou, X. Zhu, X. Chen, L. Fu, Adv. Mater. 31 (2019) 1802793.

[24] T. Sang Tran, N. K. Dutta, N. Roy Choudhury, Materials 12 (2019) 978.

[25] C. Lethien, J. Le Bideau, T. Brousse, Energy Environ. Sci. 12 (2019) 96-115.

[26] W. Shi, Y. Guo, Y. Liu, Adv. Mater. 31 (2019) 1901493.

[27] F. Wang, X. Wu, X. Yuan, Z. Liu, Y. Zhang, L. Fu, Y. Zhu, Q. Zhou, Y. Wu, W. Huang, Chem. Soc. Rev. 46 (2017) 6816-6854.

[28] Y. Zhong, X. Xia, W. Mai, J. Tu, H. J. Fan, Adv. Mater. Technol. 2 (2017) 1700182.

[29] H. Zhang, Y. Cao, M. O. L. Chee, P. Dong, M. Ye, J. Shen, Nanoscale 11 (2019) $5807-5821$

[30] C. Zhao, Y. Q. Liu, S. Beirne, J. Razal, J. Chen, Adv. Mater. Technol. 3 (2018) 1800028.

[31] J. Liang, A. K. Mondal, D.-W. Wang, F. Iacopi, Adv. Mater. Technol. 4 (2019) 1800200.

[32] H. Li, J. Liang, Adv. Mater. 32 (2020) 1805864.

[33] G. F. Zhang, Y. Y. Han, C. X. Shao, N. Chen, G. Q. Sun, X. T. Jin, J. Gao, B. X. Ji, H. S. Yang, L. T. Qu, Mater. Chem. Front. 2 (2018) 1750-1764.

[34] H. Hu, Z. Pei, C. Ye, Energy Storage Mater. 1 (2015) 82-102.

[35] Z.-S. Wu, X. Feng, H.-M. Cheng, Natl. Sci. Rev. 1 (2014) 277-292.

[36] L. Li, Z. Wu, S. Yuan, X.-B. Zhang, Energy Environ. Sci. 7 (2014) 2101-2122.

[37] M. Yu, Y. Lu, H. Zheng, X. Lu, Chem. Eur. J. 24 (2018) 3639-3649.

[38] Y. Han, Z. Lai, Z. Wang, M. Yu, Y. Tong, X. Lu, Chem. Eur. J. 24 (2018) 7312-7329.

[39] G. Yu, X. Xie, L. Pan, Z. Bao, Y. Cui, Nano Energy 2 (2013) 213-234. 
[40] D. P. Dubal, O. Ayyad, V. Ruiz, P. Gomez-Romero, Chem. Soc. Rev. 44 (2015) 1777-

1790.

[41] G. Wang, L. Zhang, J. Zhang, Chem. Soc. Rev. 41 (2012) 797-828.

[42] P. Simon, Y. Gogotsi, Nat. Mater. 7 (2008) 845-854.

[43] Y. Gogotsi, P. Simon, Science 334 (2011) 917-918.

[44] X. Wang, Y. Chen, O. G. Schmidt, C. Yan, Chem. Soc. Rev. 45 (2016) 1308-1330.

[45] A. S. Arico, P. Bruce, B. Scrosati, J.-M. Tarascon, W. van Schalkwijk, Nat. Mater. 4 (2005) 366-377.

[46] Y.-Z. Zhang, Y. Wang, T. Cheng, W.-Y. Lai, H. Pang, W. Huang, Chem. Soc. Rev. 44 (2015) 5181-5199.

[47] X. Lu, M. Yu, G. Wang, Y. Tong, Y. Li, Energy Environ. Sci. 7 (2014) 2160-2181.

[48] C. Shen, X. Wang, W. Zhang, F. Kang, J. Power Sources 196 (2011) 10465-10471.

[49] M. Beidaghi, W. Chen, C. Wang, J. Power Sources 196 (2011) 2403-2409.

[50] M. Beidaghi, C. Wang, Electrochim. Acta 56 (2011) 9508-9514.

[51] J. Chmiola, C. Largeot, P.-L. Taberna, P. Simon, Y. Gogotsi, Science 328 (2010) 480483.

[52] P. Huang, M. Heon, D. Pech, M. Brunet, P.-L. Taberna, Y. Gogotsi, S. Lofland, J. D. Hettinger, P. Simon, J. Power Sources 225 (2013) 240-244.

[53] P. Huang, C. Lethien, S. Pinaud, K. Brousse, R. Laloo, V. Turq, M. Respaud, A.

Demortière, B. Daffos, P. L. Taberna, B. Chaudret, Y. Gogotsi, P. Simon, Science 351 (2016) 691-695.

[54] M. Heon, S. Lofland, J. Applegate, R. Nolte, E. Cortes, J. D. Hettinger, P.-L. Taberna, P. Simon, P. Huang, M. Brunet, Y. Gogotsi, Energy Environ. Sci. 4 (2011) 135-138.

[55] M. Létiche, K. Brousse, A. Demortière, P. Huang, B. Daffos, S. Pinaud, M. Respaud, B. Chaudret, P. Roussel, L. Buchaillot, P. L. Taberna, P. Simon, C. Lethien, Adv. Funct. Mater. 27 (2017) 1606813. 
[56] D. Pech, M. Brunet, H. Durou, P. Huang, V. Mochalin, Y. Gogotsi, P.-L. Taberna, P. Simon, Nat. Nanotechnol. 5 (2010) 651-654.

[57] P. Huang, D. Pech, R. Lin, J. K. McDonough, M. Brunet, P.-L. Taberna, Y. Gogotsi, P. Simon, Electrochem. Commun. 36 (2013) 53-56.

[58] C.-C. Liu, D.-S. Tsai, W.-H. Chung, K.-W. Li, K.-Y. Lee, Y.-S. Huang, J. Power Sources 196 (2011) 5761-5768.

[59] B. Hsia, J. Marschewski, S. Wang, J. B. In, C. Carraro, D. Poulikakos, C. P. Grigoropoulos, R. Maboudian, Nanotechnology 25 (2014) 055401.

[60] M. Yu, Z. Wang, H. Zhang, P. Zhang, T. Zhang, X. Lu, X. Feng, Nano Energy 65 (2019) 103987.

[61] M. Yu, D. Lin, H. Feng, Y. Zeng, Y. Tong, X. Lu, Angew. Chem. Int. Ed. 56 (2017) 5454-5459.

[62] X. Zhao, B. M. Sanchez, P. J. Dobson, P. S. Grant, Nanoscale 3 (2011) 839-855.

[63] W. Si, C. Yan, Y. Chen, S. Oswald, L. Han, O. G. Schmidt, Energy Environ. Sci. 6 (2013) 3218-3223.

[64] S. Li, X. Wang, C. Shen, J. g. Wang, F. Kang, Micro \& Nano Lett. 7 (2012) 744-748.

[65] H. Xu, X. Hu, H. Yang, Y. Sun, C. Hu, Y. Huang, Adv. Energy Mater. 5 (2015) 1401882.

[66] D. Kim, J. Yun, G. Lee, J. S. Ha, Nanoscale 6 (2014) 12034-12041.

[67] Z. Liu, X. Tian, X. Xu, L. He, M. Yan, C. Han, Y. Li, W. Yang, L. Mai, Nano Res. 10 (2017) 2471-2481.

[68] S. Gu, Z. Lou, L. Li, Z. Chen, X. Ma, G. Shen, Nano Res. 9 (2015) 424-434.

[69] F. Yu, T. Huang, P. Zhang, Y. Tao, F.-Z. Cui, Q. Xie, S. Yao, F. Wang, Energy Storage Mater. 22 (2019) 235-255.

[70] S. Ouendi, C. Arico, F. Blanchard, J.-L. Codron, X. Wallart, P. L. Taberna, P. Roussel, L. Clavier, P. Simon, C. Lethien, Energy Storage Mater. 16 (2019) 581-588. 
[71] F. Béguin, V. Presser, A. Balducci, E. Frackowiak, Adv. Mater. 26 (2014) 2219-2251.

[72] C. Schütter, T. Husch, M. Korth, A. Balducci, J. Phys. Chem. C 119 (2015) 1341313424.

[73] J. Le Bideau, L. Viau, A. Vioux, Chem. Soc. Rev. 40 (2011) 907-925.

[74] X. L. Cheng, J. Pan, Y. Zhao, M. Liao, H. S. Peng, Adv. Energy Mater. 8 (2018) 1702184.

[75] N. S. Mohamed, A. K. Arof, J. Power Sources 132 (2004) 229-234.

[76] Y.-G. Cho, C. Hwang, D. S. Cheong, Y.-S. Kim, H.-K. Song, Adv. Mater. 31 (2019) 1804909.

[77] V. Vijayakumar, B. Anothumakkool, A. T. A. Torris, S. B. Nair, M. V. Badiger, S. Kurungot, J. Mater. Chem. A 5 (2017) 8461-8476.

[78] A. Balducci, J. Power Sources 326 (2016) 534-540.

[79] Z. Liu, G. Liang, Y. Zhan, H. Li, Z. Wang, L. Ma, Y. Wang, X. Niu, C. Zhi, Nano Energy 58 (2019) 732-742.

[80] Z. F. Wang, H. F. Li, Z. J. Tang, Z. X. Liu, Z. H. Ruan, L. T. Ma, Q. Yang, D. H. Wang, C. Y. Zhi, Adv. Funct. Mater. 28 (2018) 1804560.

[81] K. Jiang, I. A. Baburin, P. Han, C. Yang, X. Fu, Y. Yao, J. Li, E. Cánovas, G. Seifert, J. Chen, M. Bonn, X. Feng, X. Zhuang, Adv. Funct. Mater. 30 (2020) 1908243.

[82] H. Tian, J. Qin, D. Hou, Q. Li, C. Li, Z. S. Wu, Y. Mai, Angew. Chem. Int. Ed. 58 (2019) 10173-10178.

[83] S. L. Zhang, Q. Jiang, Z. Wu, W. Ding, L. Zhang, H. N. Alshareef, Z. L. Wang, Adv. Energy Mater. 9 (2019) 1900152.

[84] H. Kim, J. Yoon, G. Lee, S.-h. Paik, G. Choi, D. Kim, B.-M. Kim, G. Zi, J. S. Ha, ACS Appl. Mater. Interfaces 8 (2016) 16016-16025.

[85] Y. Lim, J. Yoon, J. Yun, D. Kim, S. Y. Hong, S.-J. Lee, G. Zi, J. S. Ha, ACS Nano 8 (2014) 11639-11650. 
[86] Y. Chen, X. Li, Z. Bi, G. Li, X. He, X. Gao, Chem. Eng. J. 353 (2018) 499-506.

[87] R. S. Guo, J. T. Chen, B. J. Yang, L. Y. Liu, L. J. Su, B. S. Shen, X. B. Yan, Adv. Funct. Mater. 27 (2017) 1702394.

[88] G. Lee, S. K. Kang, S. M. Won, P. Gutruf, Y. R. Jeong, J. Koo, S. S. Lee, J. A.

Rogers, J. S. Ha, Adv. Energy Mater. 7 (2017) 1700157.

[89] X. Chen, S. Wang, J. Shi, X. Du, Q. Cheng, R. Xue, Q. Wang, M. Wang, L. Ruan, W. Zeng, Adv. Mater. Interfaces 6 (2019) 1901160.

[90] J.-H. Sung, S.-J. Kim, K.-H. Lee, J. Power Sources 133 (2004) 312-319.

[91] J. Yun, H. Lee, C. Song, Y. R. Jeong, J. W. Park, J. H. Lee, D. S. Kim, K. Keum, M. S. Kim, S. W. Jin, Y. H. Lee, J. W. Kim, G. Zi, J. S. Ha, Chem. Eng. J. 387 (2020) 124076.

[92] G. Lee, J. W. Kim, H. Park, J. Y. Lee, H. Lee, C. Song, S. W. Jin, K. Keum, C. H. Lee, J. S. Ha, ACS Nano 13 (2019) 855-866.

[93] X. Shi, F. Zhou, J. Peng, R. a. Wu, Z. S. Wu, X. Bao, Adv. Funct. Mater. 29 (2019) 1902860.

[94] Q. Jiang, N. Kurra, H. N. Alshareef, Adv. Funct. Mater. 25 (2015) 4976-4984.

[95] D. Song, E. B. Secor, Y. Wang, M. C. Hersam, C. D. Frisbie, ACS Appl. Mater. Interfaces 10 (2018) 22303-22310.

[96] D. Kim, G. Shin, Y. J. Kang, W. Kim, J. S. Ha, ACS Nano 7 (2013) 7975-7982.

[97] J. Yun, Y. Lim, H. Lee, G. Lee, H. Park, S. Y. Hong, S. W. Jin, Y. H. Lee, S. S. Lee, J. S. Ha, Adv. Funct. Mater. 27 (2017) 1700135.

[98] D. W. Zhao, C. J. Chen, Q. Zhang, W. S. Chen, S. X. Liu, Q. W. Wang, Y. X. Liu, J. Li, H. P. Yu, Adv. Energy Mater. 7 (2017) 1700739.

[99] S. Xu, W. Liu, B. Hu, X. Wang, Nano Energy 58 (2019) 803-810.

[100] B. Xie, Y. Wang, W. Lai, W. Lin, Z. Lin, Z. Zhang, P. Zou, Y. Xu, S. Zhou, C. Yang, F. Kang, C.-P. Wong, Nano Energy 26 (2016) 276-285. 
[101] Y. Yue, N. Liu, Y. Ma, S. Wang, W. Liu, C. Luo, H. Zhang, F. Cheng, J. Rao, X. Hu, J. Su, Y. Gao, ACS Nano 12 (2018) 4224-4232.

[102] X. Zhang, W. Zhao, L. Wei, Y. Jin, J. Hou, X. Wang, X. Guo, Energy 170 (2019) 338348.

[103] H. Xiao, Z.-S. Wu, L. Chen, F. Zhou, S. Zheng, W. Ren, H.-M. Cheng, X. Bao, ACS Nano 11 (2017) 7284-7292.

[104] Q. Jiang, C. S. Wu, Z. J. Wang, A. C. Wang, J. H. He, Z. L. Wang, H. N. Alshareef, Nano Energy 45 (2018) 266-272.

[105] X. Wang, Y. Yin, F. Yi, K. Dai, S. Niu, Y. Han, Y. Zhang, Z. You, Nano Energy 39 (2017) 429-436.

[106] J. Wen, B. Xu, J. Zhou, J. Xu, Y. Chen, Small 15 (2019) 1901313.

[107] X. Zhuang, X. Feng, Angew. Chem. Int. Ed. 55 (2016) 6136-6138.

[108] A. Ferris, D. Bourrier, S. Garbarino, D. Guay, D. Pech, Small 15 (2019) 1901224.

[109] D. P. Dubal, J. G. Kim, Y. Kim, R. Holze, C. D. Lokhande, W. B. Kim, Energy

Technol. 2 (2014) 325-341.

[110] H. U. Lee, S. W. Kim, J. Mater. Chem. A 5 (2017) 13581-13590.

[111] Z. Tian, X. Tong, G. Sheng, Y. Shao, L. Yu, V. Tung, J. Sun, R. B. Kaner, Z. Liu, Nat. Commun. 10 (2019) 4913.

[112] E. Quain, T. S. Mathis, N. Kurra, K. Maleski, K. L. Van Aken, M. Alhabeb, H. N. Alshareef, Y. Gogotsi, Adv. Mater. Technol. 4 (2019) 1800256.

[113] P. Sundriyal, S. Bhattacharya, ACS Appl. Energy Mater. 2 (2019) 1876-1890.

[114] S. S. Lee, K. H. Choi, S. H. Kim, S. Y. Lee, Adv. Funct. Mater. 28 (2018) 1705571.

[115] S. Zhu, Y. T. Li, H. Y. Zhu, J. F. Ni, Y. Li, Small 15 (2019) 1804037.

[116] K. Jiang, Q. Weng, ChemSusChem (2019).

[117] H. F. Li, Z. J. Tang, Z. X. Liu, C. Y. Zhi, Joule 3 (2019) 613-619.

[118] J.-H. Sung, S.-J. Kim, K.-H. Lee, J. Power Sources 124 (2003) 343-350. 
[119] J.-H. Sung, S.-J. Kim, S.-H. Jeong, E.-H. Kim, K.-H. Lee, J. Power Sources 162 (2006) 1467-1470.

[120] W. Sun, X. Chen, J. Power Sources 193 (2009) 924-929.

[121] W. Gao, N. Singh, L. Song, Z. Liu, A. L. M. Reddy, L. Ci, R. Vajtai, Q. Zhang, B. Wei, P. M. Ajayan, Nat. Nanotechnol. 6 (2011) 496-500.

[122] H. Durou, D. Pech, D. Colin, P. Simon, P.-L. Taberna, M. Brunet, Microsyst. Technol. 18 (2012) 467-473.

[123] Z. S. Wu, K. Parvez, X. Feng, K. Müllen, Nat. Commun. 4 (2013) 2487.

[124] C. Shen, X. Wang, S. Li, J. g. Wang, W. Zhang, F. Kang, J. Power Sources 234 (2013) 302-309.

[125] J. Lin, Z. Peng, Y. Liu, F. Ruiz-Zepeda, R. Ye, E. L. Samuel, M. J. Yacaman, B. I. Yakobson, J. M. Tour, Nat. Commun. 5 (2014) 5714.

[126] M. F. El-Kady, M. Ihns, M. Li, J. Y. Hwang, M. F. Mousavi, L. Chaney, A. T. Lech, R. B. Kaner, Proc. Natl. Acad. Sci. USA 112 (2015) 4233-4238.

[127] Y.-Y. Peng, B. Akuzum, N. Kurra, M.-Q. Zhao, M. Alhabeb, B. Anasori, E. C.

Kumbur, H. N. Alshareef, M.-D. Ger, Y. Gogotsi, Energy Environ. Sci. 9 (2016) 2847-2854.

[128] P. Zhang, F. Zhu, F. Wang, J. Wang, R. Dong, X. Zhuang, O. G. Schmidt, X. Feng, Adv. Mater. 29 (2017) 1604491.

[129] C. Yang, K. S. Schellhammer, F. Ortmann, S. Sun, R. Dong, M. Karakus, Z. Mics, M. Löffler, F. Zhang, X. Zhuang, E. Cánovas, G. Cuniberti, M. Bonn, X. Feng, Angew. Chem. Int. Ed. 56 (2017) 3920-3924.

[130] S. Qin, Q. Zhang, X. Yang, M. Liu, Q. Sun, Z. L. Wang, Adv. Energy Mater. 8 (2018) 1800069.

[131] P. Zhang, Y. Li, G. Wang, F. Wang, S. Yang, F. Zhu, X. Zhuang, O. G. Schmidt, X. Feng, Adv. Mater. 31 (2019) 1806005. 
[132] Y. S. Moon, D. Kim, G. Lee, S. Y. Hong, K. K. Kim, S. M. Park, J. S. Ha, Carbon 81 (2015) 29-37.

[133] G. Xiong, C. Meng, R. G. Reifenberger, P. P. Irazoqui, T. S. Fisher, Energy Technol. 2 (2014) 897-905.

[134] J. Li, M. Zhu, Z. An, Z. Wang, M. Toda, T. Ono, J. Power Sources 401 (2018) 204212.

[135] A. Achour, J. B. Ducros, R. L. Porto, M. Boujtita, E. Gautron, L. Le Brizoual, M. A. Djouadi, T. Brousse, Nano Energy 7 (2014) 104-113.

[136] K. Grigoras, J. Keskinen, L. Grönberg, E. Yli-Rantala, S. Laakso, H. Välimäki, P. Kauranen, J. Ahopelto, M. Prunnila, Nano Energy 26 (2016) 340-345.

[137] K. Robert, C. Douard, A. Demortière, F. Blanchard, P. Roussel, T. Brousse, C. Lethien, Adv. Mater. Technol. 3 (2018) 1800036.

[138] J. P. Alper, M. S. Kim, M. Vincent, B. Hsia, V. Radmilovic, C. Carraro, R. Maboudian, J. Power Sources 230 (2013) 298-302.

[139] S. M. Mirvakili, I. W. Hunter, Adv. Mater. 29 (2017) 1700671.

[140] J. P. Alper, S. Wang, F. Rossi, G. Salviati, N. Yiu, C. Carraro, R. Maboudian, Nano Lett. 14 (2014) 1843-1847.

[141] J. Lin, C. Zhang, Z. Yan, Y. Zhu, Z. Peng, R. H. Hauge, D. Natelson, J. M. Tour, Nano Lett. 13 (2013) 72-78.

[142] T. M. Dinh, F. Mesnilgrente, V. Conédéra, N. A. Kyeremateng, D. Pech, J. Electrochem. Soc. 162 (2015) A2016-A2020.

[143] Z. Niu, L. Zhang, L. Liu, B. Zhu, H. Dong, X. Chen, Adv. Mater. 25 (2013) 40354042.

[144] M. Beidaghi, C. Wang, Adv. Funct. Mater. 22 (2012) 4501-4510.

[145] W.-W. Liu, Y.-Q. Feng, X.-B. Yan, J.-T. Chen, Q.-J. Xue, Adv. Funct. Mater. 23 (2013) 4111-4122. 
[146] B. Shen, J. Lang, R. Guo, X. Zhang, X. Yan, ACS Appl. Mater. Interfaces 7 (2015) 25378-25389.

[147] C. Du, N. Pan, Nanotechnology 17 (2006) 5314-5318.

[148] L. Sun, X. Wang, K. Zhang, J. Zou, Q. Zhang, Nano Energy 22 (2016) 11-18.

[149] N. Kurra, Q. Jiang, H. N. Alshareef, Nano Energy 16 (2015) 1-9.

[150] T. M. Dinh, A. Achour, S. Vizireanu, G. Dinescu, L. Nistor, K. Armstrong, D. Guay, D. Pech, Nano Energy 10 (2014) 288-294.

[151] Y. Lin, Y. Gao, Z. Fan, Adv. Mater. 29 (2017) 1701736.

[152] H. Hu, Z. Pei, H. Fan, C. Ye, Small 12 (2016) 3059-3069.

[153] K. Wang, W. Zou, B. Quan, A. Yu, H. Wu, P. Jiang, Z. Wei, Adv. Energy Mater. 1 (2011) 1068-1072.

[154] M. Zhu, Y. Huang, Y. Huang, H. Li, Z. Wang, Z. Pei, Q. Xue, H. Geng, C. Zhi, Adv. Mater. 29 (2017) 1605137.

[155] N. Kurra, M. K. Hota, H. N. Alshareef, Nano Energy 13 (2015) 500-508.

[156] M. Xue, F. Li, J. Zhu, H. Song, M. Zhang, T. Cao, Adv. Funct. Mater. 22 (2012) 12841290.

[157] C. Z. Meng, J. Maeng, S. W. M. John, P. P. Irazoqui, Adv. Energy Mater. 4 (2014) 1301269.

[158] X. Chu, H. Huang, H. Zhang, H. Zhang, B. Gu, H. Su, F. Liu, Y. Han, Z. Wang, N. Chen, C. Yan, W. Deng, W. Deng, W. Yang, Electrochim. Acta 301 (2019) 136-144.

[159] C. Zhang, J. Xiao, L. Qian, S. Yuan, S. Wang, P. Lei, J. Mater. Chem. A 4 (2016) 9502-9510.

[160] B. Song, L. Li, Z. Lin, Z.-K. Wu, K.-s. Moon, C.-P. Wong, Nano Energy 16 (2015) 470-478.

[161] D. Kim, G. Lee, D. Kim, J. S. Ha, ACS Appl. Mater. Interfaces 7 (2015) 4608-4615. [162] J. Xu, G. Shen, Nano Energy 13 (2015) 131-139. 
[163] J. Pu, X. Wang, R. Xu, K. Komvopoulos, ACS Nano 10 (2016) 9306-9315.

[164] Z. Liu, Z.-S. Wu, S. Yang, R. Dong, X. Feng, K. Müllen, Adv. Mater. 28 (2016) 2217 2222.

[165] J. Yun, D. Kim, G. Lee, J. S. Ha, Carbon 79 (2014) 156-164.

[166] S. Wang, Z.-S. Wu, S. Zheng, F. Zhou, C. Sun, H.-M. Cheng, X. Bao, ACS Nano 11 (2017) 4283-4291.

[167] X. Shi, Z. S. Wu, J. Qin, S. Zheng, S. Wang, F. Zhou, C. Sun, X. Bao, Adv. Mater. 29 (2017) 1703034.

[168] H. Li, Y. Hou, F. Wang, M. R. Lohe, X. Zhuang, L. Niu, X. Feng, Adv. Energy Mater. 7 (2017) 1601847.

[169] H. Wu, K. Jiang, S. Gu, H. Yang, Z. Lou, D. Chen, G. Shen, Nano Res. 8 (2015) $3544-3552$.

[170] S.-W. Kim, K.-N. Kang, J.-W. Min, J.-H. Jang, Nano Energy 50 (2018) 410-416.

[171] J. Pu, X. Wang, R. Xu, S. Xu, K. Komvopoulos, Microsystems \& Nanoengineering 4 (2018) 16.

[172] B. D. Boruah, S. Nandi, A. Misra, ACS Appl. Energy Mater. 1 (2018) 1567-1574.

[173] C. Couly, M. Alhabeb, K. L. Van Aken, N. Kurra, L. Gomes, A. M. Navarro-Suárez, B. Anasori, H. N. Alshareef, Y. Gogotsi, Adv. Electron. Mater. 4 (2018) 1700339.

[174] Q. Jiang, N. Kurra, K. Maleski, Y. Lei, H. Liang, Y. Zhang, Y. Gogotsi, H. N. Alshareef, Adv. Energy Mater. 9 (2019) 1901061.

[175] Z. Xiong, X. Yun, L. Qiu, Y. Sun, B. Tang, Z. He, J. Xiao, D. Chung, T. W. Ng, H. Yan, R. Zhang, X. Wang, D. Li, Adv. Mater. 31 (2019) 1804434.

[176] G. Lee, D. Kim, J. Yun, Y. Ko, J. Cho, J. S. Ha, Nanoscale 6 (2014) 9655-9664.

[177] G. Lee, D. Kim, D. Kim, S. Oh, J. Yun, J. Kim, S.-S. Lee, J. S. Ha, Energy Environ. Sci. 8 (2015) 1764-1774. 
[178] Z.-S. Wu, K. Parvez, A. Winter, H. Vieker, X. Liu, S. Han, A. Turchanin, X. Feng, K. Müllen, Adv. Mater. 26 (2014) 4552-4558.

[179] Z.-K. Wu, Z. Lin, L. Li, B. Song, K.-s. Moon, S.-L. Bai, C.-P. Wong, Nano Energy 10 (2014) 222-228.

[180] S. Y. Hong, J. Yoon, S. W. Jin, Y. Lim, S.-J. Lee, G. Zi, J. S. Ha, ACS Nano 8 (2014) 8844-8855.

[181] Y. Yu, J. Zhang, X. Wu, Z. Zhu, J. Mater. Chem. A 3 (2015) 21009-21015.

[182] D. Qi, Z. Liu, Y. Liu, W. R. Leow, B. Zhu, H. Yang, J. Yu, W. Wang, H. Wang, S. Yin, X. Chen, Adv. Mater. 27 (2015) 5559-5566.

[183] Y. He, P. Zhang, F. Wang, L. Wang, Y. Su, F. Zhang, X. Zhuang, X. Feng, Nano Energy 60 (2019) 8-16.

[184] J. Y. Cheng, S. M. Chen, D. Chen, L. B. Dong, J. J. Wang, T. L. Zhang, T. P. Jiao, B. Liu, H. Wang, J. J. Kai, D. Q. Zhang, G. P. Zheng, L. J. Zhi, F. Y. Kang, W. J. Zhang, J. Mater. Chem. A 6 (2018) 20254-20266.

[185] Z. Liu, S. Liu, R. Dong, S. Yang, H. Lu, A. Narita, X. Feng, K. Müllen, Small 13 (2017) 1603388.

[186] W. Liu, C. Lu, X. Wang, R. Y. Tay, B. K. Tay, ACS Nano 9 (2015) 1528-1542.

[187] S. Liu, P. Gordiichuk, Z. S. Wu, Z. Liu, W. Wei, M. Wagner, N. Mohamed-Noriega, D. Wu, Y. Mai, A. Herrmann, K. Müllen, X. Feng, Nat. Commun. 6 (2015) 8817.

[188] J. Chang, S. Adhikari, T. H. Lee, B. Li, F. Yao, D. T. Pham, V. T. Le, Y. H. Lee, Adv. Energy Mater. 5 (2015) 1500003.

[189] S. Byun, J. Yu, J. Power Sources 307 (2016) 849-855.

[190] Z. S. Wu, K. Parvez, S. Li, S. Yang, Z. Liu, S. Liu, X. Feng, K. Müllen, Adv. Mater. 27 (2015) 4054-4061.

[191] J. Qin, F. Zhou, H. Xiao, R. Ren, Z.-S. Wu, Sci. China Mater. 26 (2017) 949-965. 
[192] J. Qin, S. Wang, F. Zhou, P. Das, S. Zheng, C. Sun, X. Bao, Z.-S. Wu, Energy Storage Mater. 18 (2019) 397-404.

[193] B.-S. Shen, H. Wang, L.-J. Wu, R.-S. Guo, Q. Huang, X.-B. Yan, Chin. Chem. Lett. 27 (2016) 1586-1591.

[194] S. Zheng, J. Ma, Z.-S. Wu, F. Zhou, Y.-B. He, F. Kang, H.-M. Cheng, X. Bao, Energy Environ. Sci. 11 (2018) 2001-2009.

[195] S. Wang, Z.-S. Wu, F. Zhou, X. Shi, S. Zheng, J. Qin, H. Xiao, C. Sun, X. Bao, npj 2D Materials and Applications 2 (2018) 7.

[196] F. Zhou, H. Huang, C. Xiao, S. Zheng, X. Shi, J. Qin, Q. Fu, X. Bao, X. Feng, K. Müllen, Z. S. Wu, J. Am. Chem. Soc. 140 (2018) 8198-8205.

[197] S. Zheng, C. Zhang, F. Zhou, Y. Dong, X. Shi, V. Nicolosi, Z.-S. Wu, X. Bao, J. Mater. Chem. A 7 (2019) 9478-9485.

[198] S. Jiao, A. Zhou, M. Wu, H. Hu, Adv. Sci. 6 (2019) 1900529.

[199] Y. He, P. Zhang, M. Wang, F. Wang, D. Tan, Y. Li, X. Zhuang, F. Zhang, X. Feng, Mater. Horiz. 6 (2019) 1041-1049.

[200] Y. Dong, L. Wang, L. Ban, W. Du, X. Feng, P. Chen, F. Xiao, S. Wang, B.-F. Liu, J. Power Sources 396 (2018) 632-638.

[201] J. Qin, Z.-S. Wu, F. Zhou, Y. Dong, H. Xiao, S. Zheng, S. Wang, X. Shi, H. Huang, C. Sun, X. Bao, Chin. Chem. Lett. 29 (2018) 582-586.

[202] Z.-S. Wu, Y. Zheng, S. Zheng, S. Wang, C. Sun, K. Parvez, T. Ikeda, X. Bao, K. Müllen, X. Feng, Adv. Mater. 29 (2017) 1602960.

[203] H. Xiao, Z.-S. Wu, F. Zhou, S. Zheng, D. Sui, Y. Chen, X. Bao, Energy Storage Mater. 13 (2018) 233-240.

[204] L. Peng, X. Peng, B. Liu, C. Wu, Y. Xie, G. Yu, Nano Lett. 13 (2013) 2151-2157.

[205] J. Xu, Y. He, S. Bi, M. Wang, P. Yang, D. Wu, J. Wang, F. Zhang, Angew. Chem. Int. Ed. 58 (2019) 12065-12069. 
[206] W. Tian, A. VahidMohammadi, M. S. Reid, Z. Wang, L. Ouyang, J. Erlandsson, T. Pettersson, L. Wagberg, M. Beidaghi, M. M. Hamedi, Adv. Mater. 31 (2019) 1902977.

[207] N. Wang, J. Liu, Y. Zhao, M. Hu, G. Shan, Nanotechnology 30 (2019) 235403.

[208] L. Zhang, Z. Chen, S. Zheng, S. Qin, J. Wang, C. Chen, D. Liu, L. Wang, G. Yang, Y. Su, Z.-S. Wu, X. Bao, J. Razal, W. Lei, J. Mater. Chem. A 7 (2019) 14328-14336.

[209] Q. C. Zhang, J. Zhang, Z. Y. Zhou, L. Wei, Y. G. Yao, J. Mater. Chem. A 6 (2018) 20145-20151.

[210] H. Pang, Y. Zhang, W.-Y. Lai, Z. Hu, W. Huang, Nano Energy 15 (2015) 303-312.

[211] S. C. Lee, U. M. Patil, S. J. Kim, S. Ahn, S.-W. Kang, S. C. Jun, RSC Adv. 6 (2016) 43844-43854.

[212] X. Wang, F. Wan, L. Zhang, Z. Zhao, Z. Niu, J. Chen, Adv. Funct. Mater. 28 (2018) 1707247.

[213] J. Gao, C. Shao, S. Shao, F. Wan, C. Gao, Y. Zhao, L. Jiang, L. Qu, Small 14 (2018) 1801809.

[214] Y. Shao, M. F. El-Kady, J. Sun, Y. Li, Q. Zhang, M. Zhu, H. Wang, B. Dunn, R. B. Kaner, Chem. Rev. 118 (2018) 9233-9280.

[215] X. Yun, Z. Xiong, L. Tu, L. Bai, X. Wang, Carbon 125 (2017) 308-317.

[216] R. P. R.-Z. Li, K. D. Kihm, S. Bai, D. Bridges, U. Tumuluri, Z. Wu,, G. C. T. Zhang, Z. Feng, A. Hu, Energy Environ. Sci. 9 (2016) 1458-1467.

[217] D. Zhao, W. Chang, C. Lu, C. Yang, K. Jiang, X. Chang, H. Lin, F. Zhang, S. Han, Z. Hou, X. Zhuang, Small 15 (2019) 1901494.

[218] J. Cai, C. Lv, A. Watanabe, Nano Energy 30 (2016) 790-800.

[219] J. Cai, C. Lv, A. Watanabe, J. Mater. Chem. A 4 (2016) 1671-1679.

[220] H.-C. Huang, C.-J. Chung, C.-T. Hsieh, P.-L. Kuo, H. Teng, Nano Energy 21 (2016) 90-105. 
[221] J. B. In, B. Hsia, J.-H. Yoo, S. Hyun, C. Carraro, R. Maboudian, C. P. Grigoropoulos, Carbon 83 (2015) 144-151.

[222] F. Wen, C. Hao, J. Xiang, L. Wang, H. Hou, Z. Su, W. Hu, Z. Liu, Carbon 75 (2014) 236-243.

[223] L. Zhang, D. DeArmond, N. T. Alvarez, R. Malik, N. Oslin, C. McConnell, P. K. Adusei, Y.-Y. Hsieh, V. Shanov, Small 13 (2017) 1603114.

[224] M. F. El-Kady, R. B. Kaner, Nat. Commun. 4 (2013) 1475.

[225] Z. Peng, R. Ye, J. A. Mann, D. Zakhidov, Y. Li, P. R. Smalley, J. Lin, J. M. Tour, ACS Nano 9 (2015) 5868-5875.

[226] P. Yadav, A. Basu, A. Suryawanshi, O. Game, S. Ogale, Adv. Mater. Interfaces 3 (2016) 1600057.

[227] L. V. Thekkekara, B. Jia, Y. Zhang, L. Qiu, D. Li, M. Gu, Appl. Phys. Lett. 107 (2015) 031105.

[228] L. Cao, S. Yang, W. Gao, Z. Liu, Y. Gong, L. Ma, G. Shi, S. Lei, Y. Zhang, S. Zhang, R. Vajtai, P. M. Ajayan, Small 9 (2013) 2905-2910.

[229] M. F. El-Kady, V. Strong, S. Dubin, R. B. Kaner, Science 335 (2012) 1326-1330.

[230] Y. Shao, J. Li, Y. Li, H. Wang, Q. Zhang, R. B. Kaner, Mater. Horiz. 4 (2017) 11451150.

[231] J. Y. Hwang, M. F. El-Kady, Y. Wang, L. Wang, Y. Shao, K. Marsh, J. M. Ko, R. B. Kaner, Nano Energy 18 (2015) 57-70.

[232] V. Strong, S. Dubin, M. F. El-Kady, A. Lech, Y. Wang, B. H. Weiller, R. B. Kaner, ACS Nano 6 (2012) 1395-1403.

[233] J. Luo, F. R. Fan, T. Jiang, Z. Wang, W. Tang, C. Zhang, M. Liu, G. Cao, Z. L. Wang, Nano Res. 8 (2015) 3934-3943.

[234] A. Basu, K. Roy, N. Sharma, S. Nandi, R. Vaidhyanathan, S. Rane, C. Rode, S. Ogale, ACS Appl. Mater. Interfaces 8 (2016) 31841-31848. 
[235] J. Lee, J. Y. Seok, S. Son, M. Yang, B. Kang, J. Mater. Chem. A 5 (2017) 2458524593.

[236] N. Kamboj, T. Purkait, M. Das, S. Sarkar, K. S. Hazra, R. S. Dey, Energy Environ. Sci. 12 (2019) 2507-2517.

[237] B. D. Boruah, Energy Storage Mater. 21 (2019) 219-239.

[238] N. Kurra, Q. Jiang, P. Nayak, H. N. Alshareef, Nano Today 24 (2019) 81-102.

[239] L. Li, J. Zhang, Z. Peng, Y. Li, C. Gao, Y. Ji, R. Ye, N. D. Kim, Q. Zhong, Y. Yang, H. Fei, G. Ruan, J. M. Tour, Adv. Mater. 28 (2016) 838-845.

[240] H. Wu, W. Zhang, S. Kandambeth, O. Shekhah, M. Eddaoudi, H. N. Alshareef, Adv. Energy Mater. 9 (2019) 1900482.

[241] N. Choudhary, C. Li, J. Moore, N. Nagaiah, L. Zhai, Y. Jung, J. Thomas, Adv. Mater. 29 (2017) 1605336.

[242] S. E. Moosavifard, J. Shamsi, M. K. Altafi, Z. S. Moosavifard, Chem. Commun. 52 (2016) 13140-13143.

[243] Q. Jiang, N. Kurra, C. Xia, H. N. Alshareef, Adv. Energy Mater. 7 (2017) 1601257.

[244] P. Zhang, L. Wang, F. Wang, D. Tan, G. Wang, S. Yang, M. Yu, J. Zhang, X. Feng, Batteries \& Supercaps 2 (2019) 918-923.

[245] H. F. Liang, F. W. Ming, H. N. Alshareef, Adv. Energy Mater. 8 (2018) 1801804.

[246] L. Liu, D. Ye, Y. Yu, L. Liu, Y. Wu, Carbon 111 (2017) 121-127.

[247] Y. Z. Zhang, Y. Wang, T. Cheng, L. Q. Yao, X. Li, W. Y. Lai, W. Huang, Chem. Soc. Rev. 48 (2019) 3229-3264.

[248] Y. Lin, Y. Gao, F. Fang, Z. Fan, Nano Res. 11 (2018) 3065-3087.

[249] C.-W. Wu, B. Unnikrishnan, I. W. P. Chen, S. G. Harroun, H.-T. Chang, C.-C. Huang, Energy Storage Mater. 25 (2019) 563-571.

[250] L. Yu, Z. Fan, Y. Shao, Z. Tian, J. Sun, Z. Liu, Adv. Energy Mater. 9 (2019) 1901839. 
[251] J. Li, F. Ye, S. Vaziri, M. Muhammed, M. C. Lemme, M. Östling, Adv. Mater. 25

(2013) 3985-3992.

[252] K.-H. Choi, J. Yoo, C. K. Lee, S.-Y. Lee, Energy Environ. Sci. 9 (2016) 2812-2821.

[253] W. Liu, C. Lu, H. Li, R. Y. Tay, L. Sun, X. Wang, W. L. Chow, X. Wang, B. K. Tay, Z. Chen, J. Yan, K. Feng, G. Lui, R. Tjandra, L. Rasenthiram, G. Chiu, A. Yu, J. Mater. Chem. A 4 (2016) 3754-3764.

[254] S. Wang, N. Liu, J. Tao, C. Yang, W. Liu, Y. Shi, Y. Wang, J. Su, L. Li, Y. Gao, J. Mater. Chem. A 3 (2015) 2407-2413.

[255] Y. Xiao, L. Huang, Q. Zhang, S. Xu, Q. Chen, W. Shi, Appl. Phys. Lett. 107 (2015) 013906.

[256] W. J. Hyun, E. B. Secor, C.-H. Kim, M. C. Hersam, L. F. Francis, C. D. Frisbie, Adv. Energy Mater. 7 (2017) 1700285.

[257] L. Li, E. B. Secor, K.-S. Chen, J. Zhu, X. Liu, T. Z. Gao, J.-W. T. Seo, Y. Zhao, M. C. Hersam, Adv. Energy Mater. 6 (2016) 1600909.

[258] D. Pech, M. Brunet, P.-L. Taberna, P. Simon, N. Fabre, F. Mesnilgrente, V. Conédéra, H. Durou, J. Power Sources 195 (2010) 1266-1269.

[259] H. Su, P. Zhu, L. Zhang, F. Zhou, X. liang, T. Li, Q. Wang, R. Sun, C. Wong, Sustainable Energy Fuels 1 (2017) 1601-1610.

[260] Y. Wang, Y. Shi, C. X. Zhao, J. I. Wong, X. W. Sun, H. Y. Yang, Nanotechnology 25 (2014) 094010.

[261] Y. Wang, Y.-Z. Zhang, D. Dubbink, J. E. ten Elshof, Nano Energy 49 (2018) 481-488.

[262] J. Li, S. Sollami Delekta, P. Zhang, S. Yang, M. R. Lohe, X. Zhuang, X. Feng, M. Östling, ACS Nano 11 (2017) 8249-8256.

[263] J. Li, M. M. Naiini, S. Vaziri, M. C. Lemme, M. Östling, Adv. Funct. Mater. 24 (2014) 6524-6531. 
[264] Y. Yue, Z. Yang, N. Liu, W. Liu, H. Zhang, Y. Ma, C. Yang, J. Su, L. Li, F. Long, Z. Zou, Y. Gao, ACS Nano 10 (2016) 11249-11257.

[265] J. Li, V. Mishukova, M. Östling, Appl. Phys. Lett. 109 (2016) 123901.

[266] L. Liu, Q. Lu, S. Yang, J. Guo, Q. Tian, W. Yao, Z. Guo, V. A. L. Roy, W. Wu, Adv. Mater. Technol. 3 (2018) 1700206.

[267] J.-K. Chih, A. Jamaluddin, F. Chen, J.-K. Chang, C.-Y. Su, J. Mater. Chem. A 7 (2019) 12779-12789.

[268] H. Li, X. Li, J. Liang, Y. Chen, Adv. Energy Mater. 9 (2019) 1803987.

[269] S. Bellani, E. Petroni, A. E. Del Rio Castillo, N. Curreli, B. Martín - García, R. Oropesa - Nuñez, M. Prato, F. Bonaccorso, Adv. Funct. Mater. 29 (2019) 1807659.

[270] S. Xu, Y. Dall'Agnese, G. Wei, C. Zhang, Y. Gogotsi, W. Han, Nano Energy 50 (2018) 479-488.

[271] X. Shi, S. Pei, F. Zhou, W. Ren, H.-M. Cheng, Z.-S. Wu, X. Bao, Energy Environ. Sci. 12 (2019) 1534-1541.

[272] Q. Zhang, L. Huang, Q. Chang, W. Shi, L. Shen, Q. Chen, Nanotechnology 27 (2016) 105401.

[273] C. F. Zhang, M. P. Kremer, A. Seral-Ascaso, S. H. Park, N. McEvoy, B. Anasori, Y. Gogotsi, V. Nicolosi, Adv. Funct. Mater. 28 (2018) 1705506.

[274] C. Gao, J. Gao, C. X. Shao, Y. K. Xiao, Y. Zhao, L. T. Qu, J. Mater. Chem. A 6 (2018) 19750-19756.

[275] Y. Liu, B. Zhang, Q. Xu, Y. Hou, S. Seyedin, S. Qin, G. G. Wallace, S. Beirne, J. M. Razal, J. Chen, Adv. Funct. Mater. 28 (2018) 1706592.

[276] C. Zhang, L. McKeon, M. P. Kremer, S.-H. Park, O. Ronan, A. Seral - Ascaso, S.

Barwich, C. Ó. Coileáin, N. McEvoy, H. C. Nerl, B. Anasori, J. N. Coleman, Y. Gogotsi, V. Nicolosi, Nat. Commun. 10 (2019) 1795.

[277] K. Shen, J. Ding, S. Yang, Adv. Energy Mater. 8 (2018) 1800408. 
[278] G. Sun, J. An, C. K. Chua, H. Pang, J. Zhang, P. Chen, Electrochem. Commun. 51 (2015) 33-36.

[279] W. Yu, H. Zhou, B. Q. Li, S. Ding, ACS Appl. Mater. Interfaces 9 (2017) 4597-4604.

[280] X. Tang, H. Zhou, Z. Cai, D. Cheng, P. He, P. Xie, D. Zhang, T. Fan, ACS Nano 12 (2018) 3502-3511.

[281] Y. Wei, Q. L. Ben, D. Shujiang, L. Hongzhong, J. Micromech. Microeng. 28 (2018) 105014.

[282] W. B. Li, Y. H. Li, M. Su, B. X. An, J. Liu, D. Su, L. H. Li, F. Y. Li, Y. L. Song, J. Mater. Chem. A 5 (2017) 16281-16288.

[283] P. Chang, H. Mei, S. Zhou, K. G. Dassios, L. Cheng, J. Mater. Chem. A 7 (2019) 4230-4258.

[284] X. Tian, J. Jin, S. Yuan, C. K. Chua, S. B. Tor, K. Zhou, Adv. Energy Mater. 7 (2017) 1700127.

[285] C. Zhu, T. Liu, F. Qian, W. Chen, S. Chandrasekaran, B. Yao, Y. Song, E. B. Duoss, J. D. Kuntz, C. M. Spadaccini, M. A. Worsley, Y. Li, Nano Today 15 (2017) 107-120. [286] F. Zhang, M. Wei, V. V. Viswanathan, B. Swart, Y. Shao, G. Wu, C. Zhou, Nano Energy 40 (2017) 418-431.

[287] W. Yang, J. Yang, J. J. Byun, F. P. Moissinac, J. Xu, S. J. Haigh, M. Domingos, M. A. Bissett, R. A. W. Dryfe, S. Barg, Adv. Mater. 31 (2019) 1902725.

[288] Y. Jiang, H. Shao, C. Li, T. Xu, Y. Zhao, G. Shi, L. Jiang, L. Qu, Adv. Mater. 28 (2016) 10287-10292.

[289] Y. Zhang, T. Ji, S. Hou, L. Zhang, Y. Shi, J. Zhao, X. Xu, J. Power Sources 403 (2018) 109-117.

[290] Z. Wang, Q. e. Zhang, S. Long, Y. Luo, P. Yu, Z. Tan, J. Bai, B. Qu, Y. Yang, J. Shi, H. Zhou, Z.-Y. Xiao, W. Hong, H. Bai, ACS Appl. Mater. Interfaces 10 (2018) 10437-10444. 
[291] L. Qin, Q. Tao, X. Liu, M. Fahlman, J. Halim, P. O. Å. Persson, J. Rosen, F. Zhang, Nano Energy 60 (2019) 734-742.

[292] M. Qiu, P. Sun, G. Cui, Y. Tong, W. Mai, ACS Nano 13 (2019) 8246-8255.

[293] L. Li, Z. Lou, D. Chen, K. Jiang, W. Han, G. Shen, Small 14 (2018) 1702829.

[294] T. C. An, W. L. Cheng, J. Mater. Chem. A 6 (2018) 15478-15494.

[295] V. Kumar, S. Park, K. Parida, V. Bhavanasi, P. S. Lee, Mater. Today Energy 4 (2017) $41-57$.

[296] L. Zhang, M. Liao, L. Bao, X. Sun, H. Peng, Small Methods 1 (2017) 1700211.

[297] Y. Huang, M. Zhu, Y. Huang, Z. Pei, H. Li, Z. Wang, Q. Xue, C. Zhi, Adv. Mater. 28 (2016) 8344-8364.

[298] M. Sygletou, C. Petridis, E. Kymakis, E. Stratakis, Adv. Mater. 29 (2017) 1700335.

[299] H. Peng, X. Sun, F. Cai, X. Chen, Y. Zhu, G. Liao, D. Chen, Q. Li, Y. Lu, Y. Zhu, Q. Jia, Nat. Nanotechnol. 4 (2009) 738.

[300] J. Li, A. Levitt, N. Kurra, K. Juan, N. Noriega, X. Xiao, X. Wang, H. Wang, H. N. Alshareef, Y. Gogotsi, Energy Storage Mater. 20 (2019) 455-461.

[301] H. Yang, W. R. Leow, X. Chen, Adv. Mater. 30 (2018) 1704347.

[302] Y. Yang, D. Yu, H. Wang, L. Guo, Adv. Mater. 29 (2017) 1703040.

[303] P. Zhang, J. Wang, W. Sheng, F. Wang, J. Zhang, F. Zhu, X. Zhuang, R. Jordan, O. G. Schmidt, X. Feng, Energy Environ. Sci. 11 (2018) 1717-1722.

[304] Y. Zheng, Y. Yang, S. Chen, Q. Yuan, CrystEngComm 18 (2016) 4218-4235.

[305] C. Chen, J. Cao, X. Wang, Q. Lu, M. Han, Q. Wang, H. Dai, Z. Niu, J. Chen, S. Xie, Nano Energy 42 (2017) 187-194.

[306] J. Yun, C. Song, H. Lee, H. Park, Y. R. Jeong, J. W. Kim, S. W. Jin, S. Y. Oh, L. Sun, G. Zi, J. S. Ha, Nano Energy 49 (2018) 644-654.

[307] W. Song, J. Zhu, B. Gan, S. Zhao, H. Wang, C. Li, J. Wang, Small 14 (2018) 1702249. 
[308] S. Park, H. Lee, Y.-J. Kim, P. S. Lee, NPG Asia Mater. 10 (2018) 959-969.

[309] L. Li, Z. Lou, W. Han, D. Chen, K. Jiang, G. Shen, Adv. Mater. Technol. 2 (2017) 1600282.

[310] J. Yun, Y. Lim, G. N. Jang, D. Kim, S.-J. Lee, H. Park, S. Y. Hong, G. Lee, G. Zi, J. S. Ha, Nano Energy 19 (2016) 401-414.

[311] I. Tomatsu, K. Peng, A. Kros, Adv. Drug. Deliv. Rev. 63 (2011) 1257-1266.

[312] J. Thévenot, H. Oliveira, O. Sandre, S. Lecommandoux, Chem. Soc. Rev. 42 (2013) 7099-7116.

[313] F. D. Jochum, P. Theato, Chem. Soc. Rev. 42 (2013) 7468-7483.

[314] O. Bertrand, J. F. Gohy, Polym. Chem. 8 (2017) 52-73.

[315] Z. Liu, H. I. Wang, A. Narita, Q. Chen, Z. Mics, D. Turchinovich, M. Klaui, M. Bonn, K. Müllen, J. Am. Chem. Soc. 139 (2017) 9443-9446.

[316] V. Sharma, S. Biswas, A. Chandra, Adv. Energy Mater. 8 (2018) 1800573.

[317] Y. Huang, M. Zhong, F. Shi, X. Liu, Z. Tang, Y. Wang, Y. Huang, H. Hou, X. Xie, C. Zhi, Angew. Chem. Int. Ed. 56 (2017) 9141-9145.

[318] F. Yi, H. Y. Ren, K. R. Dai, X. F. Wang, Y. Z. Han, K. X. Wang, K. Li, B. L. Guan, J. Wang, M. Tang, J. Y. Shan, H. Yang, M. S. Zheng, Z. You, D. Wei, Z. F. Liu, Energy Environ. Sci. 11 (2018) 2016-2024.

[319] J. Wang, V. K. Bandari, D. Karnaushenko, Y. Li, F. Li, P. Zhang, S. Baunack, D. D. Karnaushenko, C. Becker, M. Faghih, T. Kang, S. Duan, M. Zhu, X. Zhuang, F. Zhu, X. Feng, O. G. Schmidt, ACS Nano 13 (2019) 8067-8075.

[320] K. Yang, K. Cho, S. Yang, Y. Park, S. Kim, Nano Energy 60 (2019) 667-672.

[321] J. Luo, Z. L. Wang, Energy Storage Mater. 23 (2019) 617-628.

[322] J. Maeng, C. Meng, P. P. Irazoqui, Biomed. Microdevices 17 (2015) 7.

[323] Y. Song, H. T. Chen, X. X. Chen, H. X. Wu, H. Guo, X. L. Cheng, B. Meng, H. X. Zhang, Nano Energy 53 (2018) 189-197. 
[324] J. X. Zhao, Y. Zhang, Y. A. Huang, X. X. Zhao, Y. H. Shi, J. Y. Qu, C. F. Yang, J. X. Xie, J. J. Wang, L. Li, Q. H. Yan, S. H. Hou, C. H. Lu, X. H. Xu, Y. G. Yao, J. Mater. Chem. A 7 (2019) 972-978.

[325] L. Zong, X. K. Li, L. T. Zhu, J. You, Z. H. Li, H. W. Gao, M. J. Li, C. X. Li, J. Mater. Chem. A 7 (2019) 7736-7744.

[326] M. K. Hota, Q. Jiang, Z. Wang, Z. L. Wang, K. N. Salama, H. N. Alshareef, Adv. Mater. 31 (2019) 1807450.

[327] B. Luca Giacomo, B. Andrea, P. Paolo, M. Paolo, Flex. Print. Electron. 2 (2017) 025002.

[328] Y. Song, H. Wang, X. Cheng, G. Li, X. Chen, H. Chen, L. Miao, X. Zhang, H. Zhang, Nano Energy 55 (2019) 29-36.

[329] J. Ye, H. Tan, S. Wu, K. Ni, F. Pan, J. Liu, Z. Tao, Y. Qu, H. Ji, P. Simon, Y. Zhu, Adv. Mater. 30 (2018) 1801384.

[330] L. Li, C. W. Fu, Z. Lou, S. Chen, W. Han, K. Jiang, D. Chen, G. Z. Shen, Nano Energy 41 (2017) 261-268.

[331] Y. Lin, J. Chen, M. M. Tavakoli, Y. Gao, Y. Zhu, D. Zhang, M. Kam, Z. He, Z. Fan, Adv. Mater. 31 (2019) 1804285.

[332] Y. Lu, K. Jiang, D. Chen, G. Shen, Nano Energy 58 (2019) 624-632.

[333] J. Qin, P. Das, S. Zheng, Z.-S. Wu, APL Mater. 7 (2019) 090902.

[334] Y. Lu, Z. Lou, j. Kai, D. Chen, G. Shen, Mater. Today Nano 8 (2019) 100050.

[335] M. H. Yu, X. L. Feng, Joule 3 (2019) 338-360.

[336] X.-S. Zhang, M. Han, B. Kim, J.-F. Bao, J. Brugger, H. Zhang, Nano Energy 47 (2018) 410-426.

[337] Z. L. Wang, Nano Today 5 (2010) 512-514.

[338] Z. L. Wang, W. Wu, Angew. Chem. Int. Ed. 51 (2012) 11700-11721.

[339] X. Yu, H. Cheng, M. Zhang, Y. Zhao, L. Qu, G. Shi, Nat. Rev. Mater. 2 (2017) 17046. 
[340] M. Ye, Z. Zhang, Y. Zhao, L. Qu, Joule 2 (2018) 245-268.

[341] Z. Lv, Y. Luo, Y. Tang, J. Wei, Z. Zhu, X. Zhou, W. Li, Y. Zeng, W. Zhang, Y.

Zhang, D. Qi, S. Pan, X. J. Loh, X. Chen, Adv. Mater. 30 (2018) 1704531.

[342] B. Lu, F. Liu, G. Sun, J. Gao, T. Xu, Y. Xiao, C. Shao, X. Jin, H. Yang, Y. Zhao, Z.

Zhang, L. Jiang, L. Qu, Adv. Mater. 32 (2020) 1907005.

[343] P. Das, X. Y. Shi, Q. Fu, Z. S. Wu, Adv. Funct. Mater. 30 (2020) 1908758.

[344] Z. Lv, Y. Tang, Z. Zhu, J. Wei, W. Li, H. Xia, Y. Jiang, Z. Liu, Y. Luo, X. Ge, Y.

Zhang, R. Wang, W. Zhang, X. J. Loh, X. Chen, Adv. Mater. 30 (2018) 1805468. 